\title{
RE-HEALABLE COATING BASED UPON THERMALLY RESPONSIVE LINKAGES
}

\author{
A Thesis \\ presented to \\ the Faculty of California Polytechnic State University, \\ San Luis Obispo
}

\author{
In Partial Fulfillment \\ of the Requirements for the Degree \\ Master of Science in Polymers and Coatings (Chemistry Department) \\ by \\ Dahlia Ningrum Amato \\ June, 2013
}


(C) 2013

Dahlia Ningrum Amato

ALL RIGHTS RESERVED 
COMMITTEE MEMBERSHIP

TITLE:

AUTHOR:

DATE SUBMITTED:

COMMITTEE CHAIR:

COMMITTEE MEMBER:

COMMITTEE MEMBER:
Re-healable Coating Based Upon Thermally

Responsive Linkages

Dahlia Ningrum Amato

May 31, 2013

Dr. Philip J. Costanzo, Professor

Chemistry and Biochemistry Department

Dr. Ray Fernando, Professor

Chemistry and Biochemistry Department

Dr. Dane Jones, Professor

Chemistry and Biochemistry Department 


\author{
ABSTRACT \\ Re-healable Coating Based Upon Thermally Responsive Linkages \\ Dahlia Ningrum Amato
}

The goal of this thesis was to design thermally responsive polyol resins that would be compatible with isocyanates. Two approaches were made to reach this goal, the first involved functionalizing soybean oil and the second involved post-polymerization modification of a methacrylate based resin.

A soybean based coating with thermally responsive Diels-Alder linkages has been prepared following an automotive two-component formulation. The resulting coatings displayed the capability to be healed following physical deformation by a thermal stimulus, and such a material has significant potential for end users. Various curing agents were employed, and resulted in variation of scratch resistance and re-healablity. Different thermally responsive soybean resins were synthesized to have varying amounts of reversible and nonreversible linkages when incorporated into the coating.

Additionally, different isocyanates were added at differing ratios of $\mathrm{NCO}: \mathrm{OH}$ in search of the optimum coating. It was found through the analysis of re-healabilty, hardness, gloss, and adhesion that the optimal combination was an acetylated resin (no irreversible crosslinks) with 54\% reversible Diels Alder linkages at an $\mathrm{NCO}: \mathrm{OH}$ ratio of 5:1 using isophorone diiscocyanate. Materials were evaluated via differential scanning calorimetry (DSC), scratch resistance, Koenig hardness, gloss measurements, and topographical analysis. 
In the second project, copolymerization of methyl methacrylate and 2isocyanatoethyl methacrylate via free radical polymerization was done to synthesize a polymer with pendant isocyanates. The isocyanate was used as a chemical handle to incorporate Diels-Alder linkages into the PMMA resin. The PMMA resin with DielsAlder linkages was successfully synthesized and incorporated into a polyurethane gel as proven via ${ }^{1} \mathrm{H}$ NMR and IR. The gel showed thermal reversibility at $120^{\circ} \mathrm{C}$ due to retroDA reaction via DSC as well as thermally reversible bulk properties. 


\section{ACKNOWLEDGMENTS}

Apart from my own effort, the success of my work is heavily dependent on the encouragement and help of many others. I would like to acknowledge Dr. Phil Costanzo for the support and guidance that encouraged me to be a better scientist and to thank him for always having faith in me. I thank my thesis committee, Dr. Dane Jones and Dr. Ray Fernando, for their tremendous support of my graduate education. I would also like to acknowledge Dr. Costanzo's research group for stimulating discussions and assistance in the lab. Next, I thank my husband, Douglas Amato, for helping me with all types of problems - at all times. I am grateful to my family, especially my mother, Mary Ellen Lewis, and my dog, Lucy, for being my most loyal and supportive fans. 
TABLE OF CONTENTS

LIST OF TABLES ...................................................................................................ii

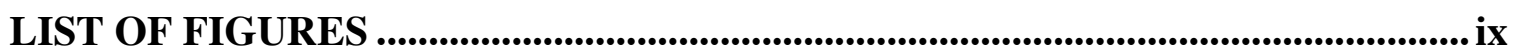

LIST OF SCHEMES ......................................................................................................................

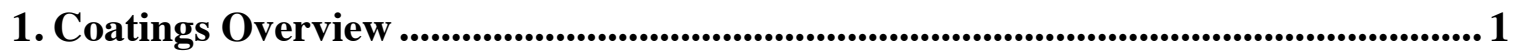

1.1 Introduction ................................................................................................... 1

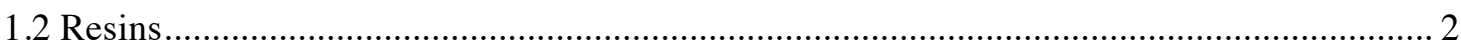

1.3 Pigments and Fillers ………………………………………………………….. 5

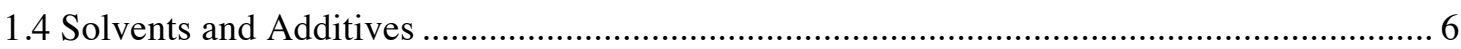

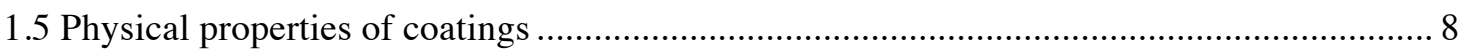

1.6 Self-healing materials ……………………………………………………………... 10

1.7 Polyurethanes................................................................................................... 13

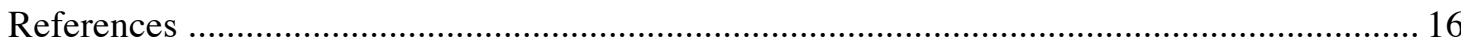

2. Thermally Responsive Soybean Oil Resin and Coatings.............................................. 19

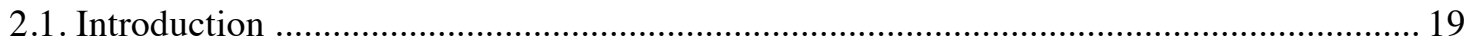

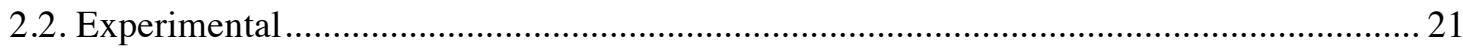

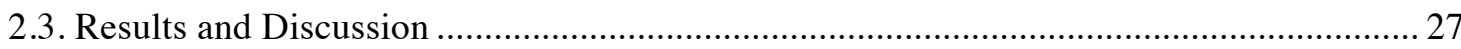

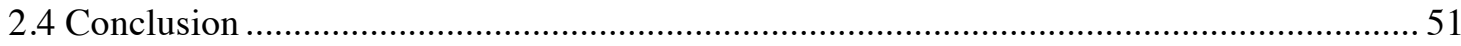

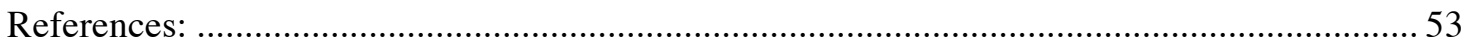

3. Preparation of Polymeric Resin via Post Polymerization Modification .................. 55

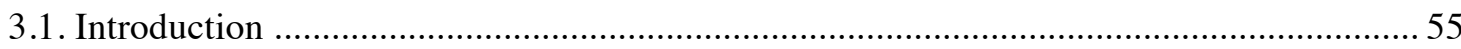

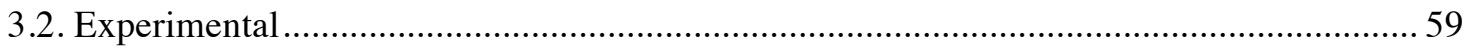

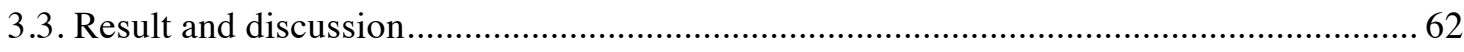

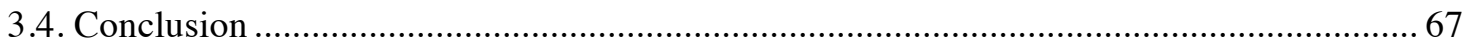

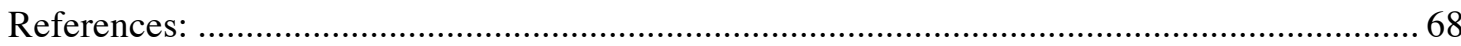

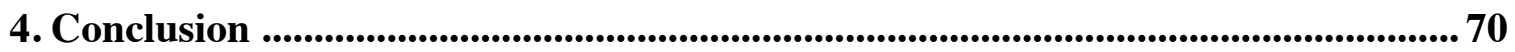




\section{LIST OF TABLES}

Tables

Page

1.2.1 List of thermoset and thermoplastic resins with applications.

1.3.1 Enhanced properties due to modified fillers. $\quad 6$

1.7.1 Composition and Reactivity of IPDI, HMDI and Desmodur N3300. 15

2.1.1 The composition of soybean oil. 20

2.2.1 Acetylated resin coating preparation. 24

2.2.2 Unacetylated resin coating preparation. 24

2.2.3 Typical polyurethane formulation. 25

2.3.1 Calculated crosslink sites for coatings. $\quad 30$

2.3.2 Calculated crosslink sites both permanent and reversible for IPDI coatings. 33

3.1.1 Reactivity ratios at $60^{\circ} \mathrm{C}$ for free radical copolymerization. 57 


\section{LIST OF FIGURES}

Figure

1.2.1 Thermoset (left) and a thermoplastic (right)

1.3.1 Plate particles create a better barrier by providing a more complex path for the water to reach the substrate.

1.5.1 Cross cut adhesion test.

1.5.2 Gloss measurement for a rough surface (left) and a smooth surface (right). 9

1.6.1 Categories and subcategories of self-healing materials.

1.6.2 Three main branches of autonomic self-healing.

1.6.3 Non-autonomic self-healing materials need stimuli in order to regain the properties

1.6.4 Retro Diels-Alder (rDA) reaction of a furan with a maleimide.

1.6.5 Polymeric system comprised entirely out of reversible crosslinks.

1.7.1 Intermolecular hydrogen bonding in polyurethanes.

1.7.2 Reaction of an isocyanate (red) with an alcohol (blue) to form a urethane/carbamate (right).

2.1.1 Example of a typical epoxidation.

2.3.1 DSC data of polyol with various percentages of Diels-Alder $(100,54,30)$ acetylated TR-SBO.

2.3.2 Hardness data of coating using IPDI as an isocyanate in various ratios $(1,3,5)$ with percentages of Diels-Alder $(100,54,30)$ acetylated TR-SBO. 31

2.3.3 Hardness data of coating using Desmodur N3300, HMDI, and IPDI as isocyanate in various ratios with $100 \%$ DA TR-SBO (acetylated).

2.3.4 Three different isocyanates (from the left to right) (IPDI, HMDI and Desmodur N3300).

2.3.5 Hardness data of coating using IPDI as isocyanate using both acetylated (left) and unacetylated (right) with 100\% DA TR-SBO.

2.3.6 Crosscut of coating using three different isocyanates (Desmodur N3300, IPDI and HMDI) with various percentage Diels-Alder of TR-SBO. 
Figure

Page

2.3.7 Crosscut of coating using IPDI as isocyanates with various percentages

Diels-Alder of unacetylated TR-SBO.

2.3.8 Rehealability of the coating employing three different isocyanates

(Desmodur N3300, IPDI and HMDI) with 100\% Diels-Alder of TR-SBO. 37

2.3.9 Gloss of the coating using three different isocyanates

(Desmodur N3300, IPDI and HMDI) 1:1 ratio isocyanate to alcohol.

2.3.10 Improvement in gloss for three different isocyanates at three different ratios including the control (FSBO). $\quad 40$

2.3.11 Mechanism for decreased gloss values for different treatments of panels. $\quad 40$

2.3.12 Gloss of the coating using three different isocyanates (Desmodur N3300, IPDI and HMDI) in various ratio $(1,3,5)$ with $100 \%$ Diels-Alder of acetylated TR-SBO.

2.3.13 Gloss measurements of IPDI under various ratios $(1,3,5)$ using a $54 \%$ Diels-Alder acetylated TR-SBO.

2.3.14 Gloss of the coating using IPDI in various ratios $(1,3,5)$ with $30 \%$ Diels-Alder acetylated TR-SBO.

2.3.15 Comparison between acetylated (left) and unacetylated (right) coatings with different percentages of Diels Alder.

2.3.16 Gloss of the coating using IPDI 1:1 ratio with $30 \%, 54 \%$, and $100 \%$ Diels-Alder unacetylated TR-SBO.

2.3.17 NCO:OH ratio effect on acetylated TR-SBO with varying amounts of DA. 46

2.3.18 The effect of excess furans on rehealabilty of TR-SBO. 47

2.3.19 TGA analysis of IPDI 5:1 ratio with 54\% DA unacetylated TR-SBO. $\quad 48$

2.3.20 DSC analysis of IPDI 5:1 ratio with 54\% DA unacetylated TR-SBO. 49

2.3.21 ImageJ analysis of control coating (IPDI 1:1 FSBO) and IPDI 5:1 ratio with 54\% DA unacetylated TR-SBO (Day 12).

2.3.22 Left: IPDI 5:1 ratio with $54 \%$ Diels-Alder of TR-SBO

Right: gloss of control coating (IPDI 1:1 FSBO) for the first and second cycle of healing at the same spot. 
Figure

3.1.1 Two parts of initiation: (1) decomposition of benzoyl peroxide into radicals; (2) transfer of radical onto styrene. 55

3.1.2 Modes of termination: coupling and disproportionation. 56

3.1.3 2-isocyanatoethyl methacrylate is unique with both acrylate and isocyanate pieces.

3.3.1 FT-IR spectrum overlay of PMMA-Isocyanate, furfuryl alcohol modified PMMA and PMMA-DA. (\% Transmittance was adjusted for clarity of the graph)

3.3.2 ${ }^{1} \mathrm{H}$ NMR spectrum overlay of PMMA-NCO and PMMA-FA.

3.3.3 FT-IR spectrum zoom overlay of PMMA-Isocyanate, furfuryl alcohol modified PMMA and PMMA-DA with exact location of carbonyl of DA adduct.

3.3.4 ${ }^{1} \mathrm{H}$ NMR spectrum overlay of furfuryl alcohol modified PMMA and PMMA-DA.

3.3.5 DSC thermograms data of pristine PMMA and PMMA-DA.

3.3.6 Thermally reversible PMMA before (a) and after (b) heating at $120^{\circ} \mathrm{C}$ for 15 minutes. 


\section{LIST OF SCHEMES}

$\begin{array}{ll}\text { Schemes } & \text { Page }\end{array}$

2.3.1 Synthesis of phenolic-maleimide. 27

2.3.2 Synthesis of opened succinic anhydride. 27

2.3.3 Synthesis of thermally responsive soybean oil resin. 29

3.3.1 Synthesis of thermally reversible PMMA resin. 62 


\section{Coatings Overview}

\subsection{Introduction}

Coatings have become an important part of our daily lives, both in and outdoors. Coating technology has revolutionized the lifespan, appearance and functionality of objects in everyday use. Electronics, automobiles, wall surfaces, and many everyday objects are layered with coatings. The appearance of the coating can vary from glossy to flat, or pigmented to unpigmented, depending upon the application. The coating's function can include corrosion, weather, and abrasion protection as well as decorative uses. The two common types of coating formulations used today are solventborne and waterborne. Waterborne coatings rely on water as the medium and are more environmentally friendly because less solvent is included in the formulations. Solventborne coatings rely on solvents other than water to solubilize the coating components.

Common solventborne commercial coatings are composed of the following components: volatile solvents, pigments, fillers, additives, and resins. Volatile solvents help to facilitate the application process of the coating. These organic solvents evaporate during and after the application process. Pigments are colored, black, white, or fluorescent particulate organic or inorganic solids typically dispersible in the vehicle (water or solvent). ${ }^{1}$ Fillers are solid materials used to fill the irregularities in a surface. ${ }^{2}$ Fillers must remain suspended after film formation occurs to ensure an optimum film. Additives are used to adjust the coating's properties during its manufacture, storage, transport, or application. The resin is the solid ingredient that holds the pigment particles 
apart from one another and helps to adhere them to the substrate. ${ }^{3}$ The resin can be dissolved into a solution and ready to apply ( 1 component) or can be made in the process of forming the coating (2 components).

\subsection{Resins}

Resins are the foundation of the coating used to form the film. Key properties of the coating such as curing time, adhesion, blocking, and chemical resistance are determined by the resin. ${ }^{4}$ There are two classifications of resins, thermoset and thermoplastic. Thermoset resins are crosslinked via covalent bonds, analogous to silk strands in a spider web (see Figure 1.2.1, left). Due to their high degree of crosslinking, thermosetting resins are not easily processed once formed and therefore very difficult to recycle. Thermoplastics, on the other hand, are large molecules interacting via intermolecular forces similar to cooked spaghetti (see Figure 1.2.1, right). Because of the lack of chemical crosslinks between the molecules, thermoplastics are able to be processed more easily and can therefore often be recycled.
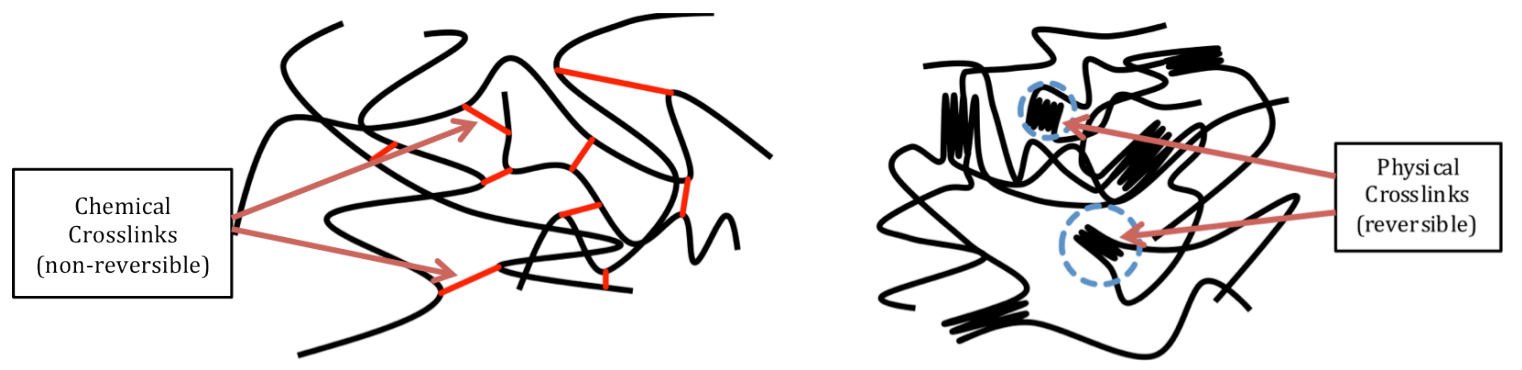

Figure 1.2.1. Thermoset (left) and thermoplastic (right).

Thermoset and thermoplastic resins typically have different applications. If chemical resistance or heat resistance is desired, a thermoset is typically used. Polyimide thermosets are often used for solar sailing spacecraft due to their excellent thermal properties. ${ }^{5}$ Another thermosetting resin, melamine-formaldehyde (MF) is one of the 
hardest and stiffest polymeric materials and is used in laminate flooring and microwave safe dishware, as well as in cabinets. ${ }^{6}$ Common thermoplastics include polyethylene and polycarbonates, both of which are used for recyclable bottles and packaging. A more expanded list of thermosets and thermoplastics is shown in Table 1.2.1.

Table 1.2.1. List of thermoset and thermoplastic resins with applications. ${ }^{7}$

\begin{tabular}{llll}
\hline Thermoset & & Thermoplastic \\
\hline Resin & Application & Resin & Application \\
\hline Epoxy & Adhesives & Nylons & Rope, fabrics \\
Melamine-formaldehyde & Flooring, dishware & Polycarbonates & CDs, football helmets \\
Polyimides & $\begin{array}{l}\text { Spacecraft, computer } \\
\text { chips }\end{array}$ & Polyethylene & $\begin{array}{l}\text { Shopping bags, toy } \\
\text { packaging }\end{array}$ \\
Phenol-formaldehyde & $\begin{array}{l}\text { Circuit boards, } \\
\text { laboratory } \\
\text { countertops }\end{array}$ & Polyurethane & $\begin{array}{l}\text { Surf board, housing } \\
\text { insulation }\end{array}$ \\
Silicones & Implants, lubricants & Polyolefin & Seat cushions, shoes \\
\hline
\end{tabular}

Resins can be made either synthetically from petroleum or from renewable sources. The wide variety of synthetic resins enables the polymer chemist to tailor the resin with different functional groups for various applications in response to market demands. ${ }^{8}$ Synthetic resin are most commonly made via step growth or chain growth polymerization. Step growth polymerization occurs through a stepwise reaction between the functional groups of reactants (dimer to trimer to tetramer), where the size of the polymer molecules increases at a relatively slow rate. In contrast, the chain growth polymerization occurs through monomer reaction with a reactive center with the addition of a large number of molecules in a chain reaction in a short amount of time. ${ }^{9}$ Phenolic, polyester, and epoxy resins are prepared via step growth polymerization while acrylic resins are prepared via chain growth polymerization. ${ }^{9}$

To satisfy the demand for a robust coating with good adhesion and chemical resistance, epoxy resins were developed by reacting bisphenol A and epichlorohydrin to 
form a prepolymer which is then reacted with an amine. The resulting resins contain glycidyl ethers which are responsible for the creation of strong adhesion to the surface. ${ }^{10}$

Recently, there has been a shift towards biodegradable and ecofriendly resins. If petroleum based polymeric resins are incinerated, a large amount of carbon dioxide is released into the atmosphere. If these synthetic resins were to be replaced with an environmentally friendly material then the disposal of the resin would not be as detrimental to our environment. Examples of renewable resins are rosin from pine trees and latex from the tree Hevea brasiliensis. ${ }^{11,12}$ Other renewable resins are produced from the extraction of oils such as tung, fish, soybean, and linseed. ${ }^{13}$ Additionally, plant oils today are the most important renewable raw material for the chemical industry. ${ }^{14}$ Shogren et al. report that vegetable oil derived polymer containing triglycerides degrade rapidly into soil, especially when having chain ends such as alcohol or carboxylic acid. ${ }^{15}$

The differences in properties between renewable and petroleum resins have been studied over the past two decades. Lignin-based resins have been shown to have physical and electrical properties similar to synthetic laminate resins for printed wiring boards. ${ }^{16} \mathrm{~A}$ comparison of canola, soybean, linseed, sunflower, and corn oil showed that the mechanical and thermal properties of the natural based resins did not differ significantly from petroleum resins. Additionally, the use of different oils was able to change the properties of the material (resin). ${ }^{17}$ While it may not currently be as economically viable to completely replace petroleum based resins with renewable resins, the technological advancement will allow for greater use of renewable materials in the future. 


\subsection{Pigments and Fillers}

In addition to relying on the natural properties of the resin, fillers are often added to alter desired properties such as gloss, adhesion, and elasticity. ${ }^{18} \mathrm{~A}$ filler is described as a solid material that is used to fill the irregularities within the material, causing change in the material's mechanical and chemical properties. ${ }^{19}$ The three classes of fillers are prime pigments, extender pigments, and specialty pigments. Prime pigments are responsible for color and hiding; extender pigments are used to lower gloss, affect $\mathrm{pH}$, and modify rheology; and, specialty pigments are added for special properties, such as corrosion protection and film reinforcement. ${ }^{20}$

One well-known white primer pigment is titanium dioxide $\left(\mathrm{TiO}_{2}\right)$. Rutile $\mathrm{TiO}_{2}$ pigment has a higher refractive index and density compared to anatase $\mathrm{TiO}_{2}$, resulting in better light scattering or enhancing hiding properties. ${ }^{21}$ Specialty fillers, such as zinc phosphate, provide anticorrosion properties by reacting with free hydroxyls and metal ions. The proposed mechanism is that the phosphate ions in solution react with metal ions released due to corrosion and precipitates out to form a film. This film prevents further oxygen from reacting with the metal. ${ }^{22}$ Additionally, lamellar zinc phosphate particles also act as barrier pigments for the coating by creating a much more complicated path for water to travel to the substrate (see Figure 1.3.1). ${ }^{23}$

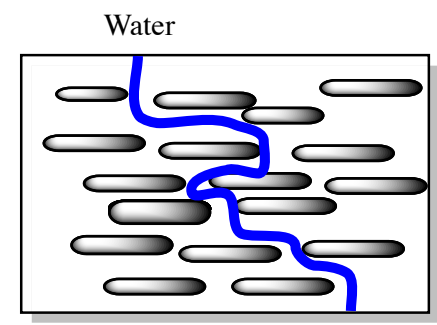

Substrate

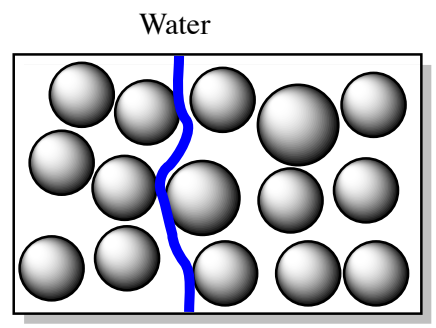

Substrate

Figure 1.3.1. Platy particles create a better barrier by providing a more complex path for the water to reach the substrate. 
With the development of nanotechnology, nanoparticle fillers such as gold, calcium carbonate, silica and alumina are employed in the production of specialty coatings. ${ }^{24}$ Due to their surface area, nanoparticles have different properties than the bulk material. For example, silver nanoparticles added to a coating are proven to produce more effective antimicrobial coatings than free silver ion. ${ }^{25}$

As opposed to adding fillers to a polymer matrix, fillers can be modified to change their properties within the matrix (see Table 1.3.1). Fillers are either synthesized from raw materials or modify the surface of existing particles. Surface modification relies on active sites on the filler, while synthetic fillers utilize a reaction such as grafting using isocyanates or silane modification to change the properties. ${ }^{26}$ For example, carbon whisker can be made via graft polymerization of methyl methacrylate off of carbon black. ${ }^{27} \mathrm{~A}$ filler can also be modified using isocyanates by reacting the hydroxyl group on a surface with an isocyanate. These types of fillers are used to reinforce polyurethane. ${ }^{26}$

Table 1.3.1. Enhanced properties due to modified fillers. ${ }^{26}$

\begin{tabular}{lll}
\hline Filler & Modification & Property change \\
\hline Glass bead & Silane & Reinforcement \\
Carbon black & Oxidation & Increase rubber-filler bonding \\
Carbon whisker & Grafting & Improve dispersion \\
Carbon fiber & Thermal and Epoxy Oxidation & Increase shear strength \\
Calcium carbonate & Stearate & Increase melt flow \\
\hline
\end{tabular}

\subsection{Solvents and Additives}

Solvents are volatile liquids added to dissolve and disperse the resin, filler, or any additional additives. Solvents evaporate during or after application and do not become a part of the dried film. They are typically used to minimize defects, control drying time, and adjust the viscosity for the application of the coating. ${ }^{28}$ Solvents can be divided into three categories: hydrocarbon (aliphatic, napthenic, and aromatic), oxygenated (ketones, 
esters, glycol esters, and alcohols) and water. ${ }^{2}$ Certain solvents will be incompatible with certain resins; therefore, it is important to choose the right solvent for the formulation and the application.

Additives are defined as supplementary substances added to formulations to influence the coating properties in specific and selective ways. Additives are often super efficient and their quantities in the formulation must be scaled perfectly to avoid coating defects. ${ }^{3}$ Examples of additives include leveling or flow agents, dispersant agents, catalysts, UV inhibitors, and anti-flocculation agents.

Leveling and flow agents help to produce defect-free coatings by minimizing or inhibiting the formation of craters or pinholes. Polysiloxanes and polyacrylates are often used for this particular purpose. Anti-flocculant additives are critical to stabilizing particles and allowing them to remain dispersed in the system. Flocculation often results in increased viscosity, decreased gloss and hiding, and reduced mechanical strength of the coating. Anti-flocculant additives consist of one or more anchoring or adhesive groups which provide strong adsorption onto pigment surfaces, creating a space between the particles. ${ }^{29}$

Catalytic additives are often used to minimize reaction time and curing temperature of the coatings. Catalysts provide different reaction mechanisms by lowering the activation energy. Thiocarbamates and dibutyl tin dilaurate are the two common catalysts used in polyurethane coatings. ${ }^{29}$

Providing green additives to meet tighter regulatory requirements for coatings is a challenge for coatings scientists. A primary concern is reducing volatile organic compounds (VOC) in additives. VOC regulation has been highlighted for the last decade 
due to the formation of ground level ozone when it reacts with the oxygen species in the atmosphere in the presence of UV radiation from sunlight. According to a 2010 U.S. Environmental Protection Agency (EPA) report, inhaling ozone caused a variety of problems such as coughing, chest pain, throat irritation, and congestion that can lead to asthma and reduction of lung function.

One method to reduce VOC is to transition from a solventborne to a waterborne coating. However, a waterborne coating is not without its challenges. A major problem of using a waterborne coating is wetting defects, due to the high surface tension of water. ${ }^{30}$ Additives such as surfactants and silicone are often used to resolve this problem. Dimethyl groups in silicones are responsible for low surface tension while the polyether modifications in silicones make it easier to control the surface tension. ${ }^{31}$ Other alternatives utilized to create green additives are naturally derived raw materials and solid additives. $^{30}$

\subsection{Physical properties of coatings}

The physical properties of the coatings such as hardness, gloss, and adhesion are important to evaluate the performance and durability of the coatings. This section will discuss each physical property as well as how each is assessed for the coatings.

\section{Hardness}

In the coatings field, hardness is typically measured through the coatings' resistance against indentations and scratches. Hardness can be affected by the thickness of the film and the composition of the coating. Hardness is often tested through use of the pencil hardness test or the pendulum hardness test. The pencil hardness test rates organic coatings based on their resistance to the scratch made by a pencil point with different 
hardness levels. ${ }^{32}$ A pendulum hardness test such as the Persoz pendulum measures how long it takes to dampen the pendulum amplitude. ${ }^{32}$

Adhesion

The adhesion of a coating is often affected by the affinity of the resin to the substrate as well as the surface roughness of the substrate. Adhesion is defined as interfacial forces between the coating and the substrate and it is measured by determining the force required to remove the coating from the substrate. There are many procedures used to measure this force, including scratching, knife removal, and the peel method. The cross-cut adhesion test is widely used in industry and is determined by the number of coating squares remaining after cross cuts and pull on tape were performed on the substrate (see Figure 1.5.1). ${ }^{33}$

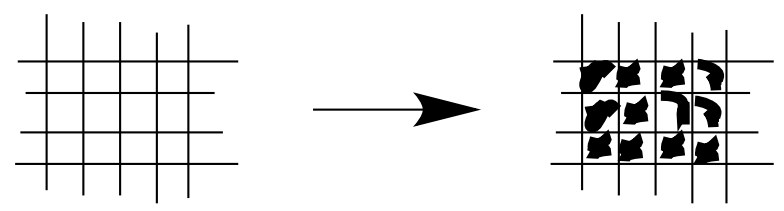

Figure 1.5.1. Cross cut adhesion test.

Gloss

Gloss is a measurement of the fraction of light reflected from the surface off the substrate or coating. It can often be measured using three different angles of incidence: $85^{\circ}, 60^{\circ}$, and $20^{\circ}$. The 60 -degree angle is widely used to assess the entire range of coatings. The 85-degree angle is used to assess the low gloss specimens while the 20degree angle is used to assess high gloss specimens. The smoother the surface, the higher the gloss value while rough surfaces have low gloss values due to diffuse reflection (see Figure 1.5.2). ${ }^{32}$ The filler in the coating and the solubility of the resin in the coating 
system often dictate the gloss. There are many gloss measurement instruments, ranging from goniophotometers to photoelectric gloss meters. ${ }^{32}$
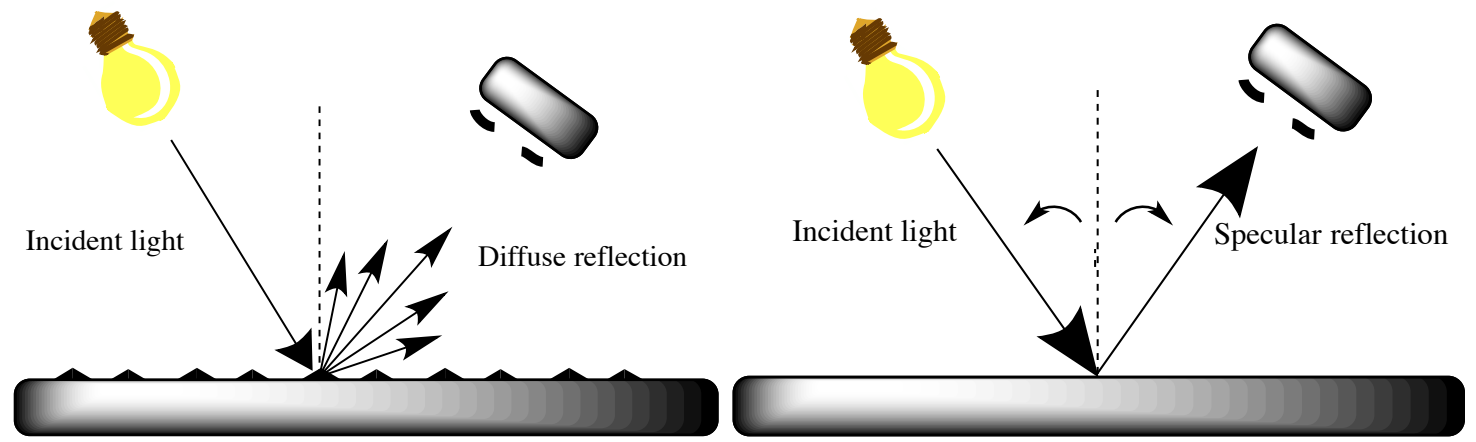

Figure 1.5.2. Gloss measurement for a rough surface (left) and a smooth surface (right).

\subsection{Self-healing materials}

Self-healing is the ability of a material to recover its initial physical properties after a deformation or tear occurs. Autonomic and non-autonomic self-healing materials are categorized as shown in Figure 1.6.1. Autonomic materials begin self-repair immediately after the deformation starts (e.g., releasing a curing agent), while nonautonomic materials require stimulus such as heat or UV radiation to prompt the healing process. $^{34}$

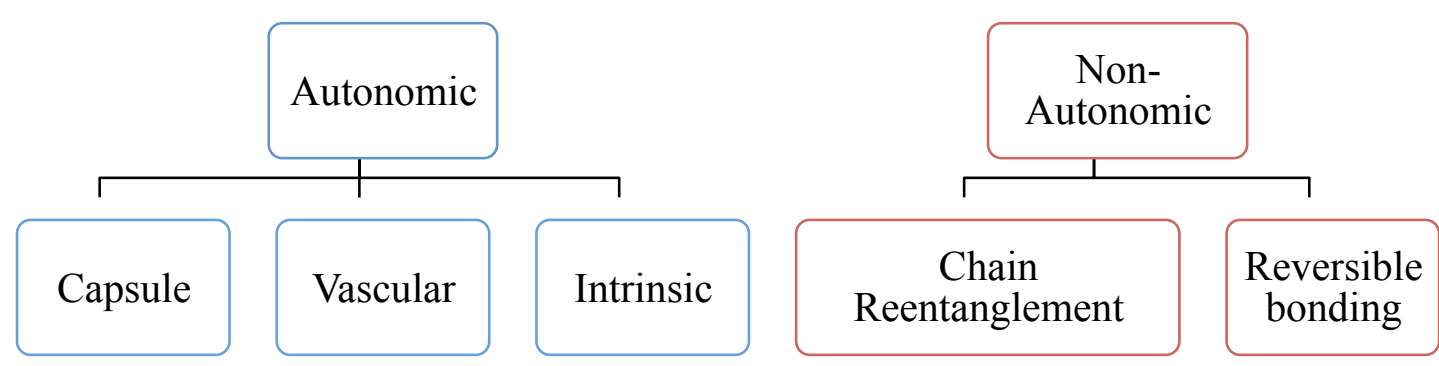

Figure 1.6.1. Categories and subcategories of self-healing materials. ${ }^{34}$

Autonomic self-healing materials have three main branches: capsules, vascular networks, and intrinsic self-healing (see Figure 1.6.2). Capsules are filled with the healing agent which rupture due to the damage and trigger the healing process. The 
vascular method fills the healing agent in a network (1D, 2D, 3D) of capillaries and hollow channels, which can be connected to one another and then are released as soon as the coating is damaged. Intrinsic self-healing results from reversible formation of bonds in the polymer matrix.

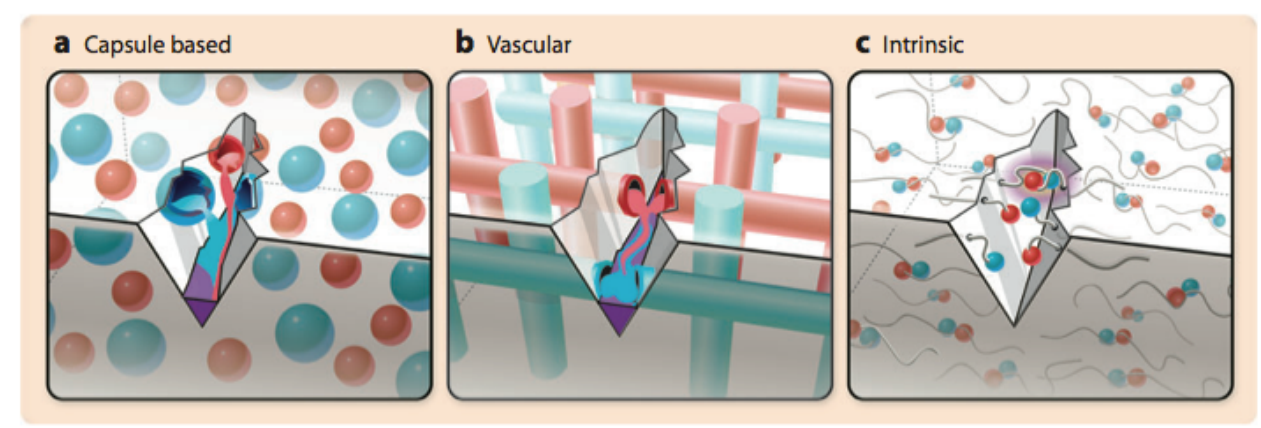

Figure 1.6.2. Three main branches of autonomic self-healing. ${ }^{34}$

There are limitations with each method of self-healing. Capsule materials only work for one time deformation. After the self-healing agent is used, deformation in the same site is difficult, if not impossible, to heal. ${ }^{19}$ Vascular systems require specialized equipment to make, which can be difficult and expensive. 3D vascular networks are often made with the use of robotic deposition software to model a structure and a machine to fabricate it. ${ }^{35}$ Since intrinsic material relies on the bonding reversibility, mechanical properties such as strength and hardness are often sacrificed. ${ }^{19}$

Non-autonomic self-healing can be as simple as reforming hydrogen bonds or returning to more favorable polymer conformations.$^{34}$ Non-autonomic systems provide similar challenges except the chemistry is typically incorporated into the polymer chain. These systems also rely on an external stimulus to break and rebuild the bonds. 


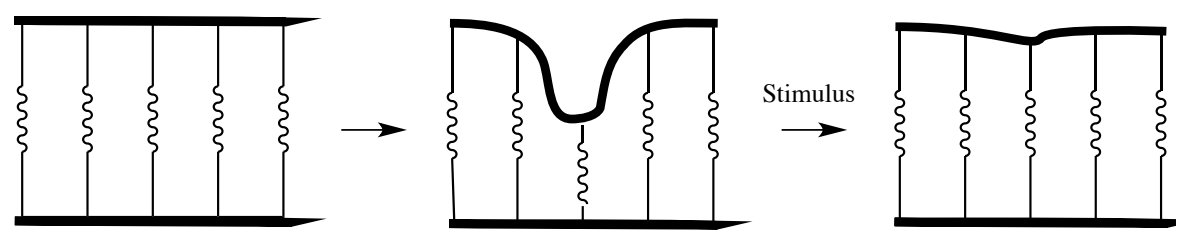

Figure 1.6.3. Non-autonomic self-healing materials need stimuli in order to regain the properties. $^{36}$

As mentioned previously, heat and UV radiation are common non-autonomic stimuli incorporating a metathesis reaction, photo-thermal ring opening, redox, and DielsAlder reactions..$^{37}$ The Diels-Alder reaction is a simple and efficient reaction between a diene and a dienophile. A diene, as the name suggests, has two conjugated double bonds. Dieneophiles typically have an electron-withdrawing group to favor the reaction with conjugated dienes. ${ }^{38}$ The electron-withdrawing group is commonly a carbonyl adjacent to the double bond of the dienophile (example shown in Figure 1.6.4). The efficiency of the Diels-Alder reaction has made it useful in organic synthesis as well as in polymer science.<smiles>[R]N1C(=O)C=CC1=O</smiles><smiles>[R]N1C(=O)C2C3C=CC([R])(O3)C2C1=O</smiles>

Exo product<smiles>[R]N1C(=O)C2C3C=CC([R])(O3)C2C1=O</smiles>

Endo product

Figure 1.6.4. Retro Diels-Alder (rDA) reaction of a furan with a maleimide.

Retro Diels-Alder (rDA) chemistry is one of the most studied thermal reversible reactions. ${ }^{37}$ Similar to Diels-Alder, rDA allows for bonds to be broken at a high temperature and then reformed at a lower temperature. Retro Diels-Alder is favorable to produce cycloaddition because both $\pi$ bonds are replaced by more stable $\sigma$ bonds. To 
reverse the reaction, a higher temperature is needed to overcome the energy barrier to break the molecule into its original components. ${ }^{38}$ In organic synthesis rDA is used to functionalize maleimide derivatives by a Diels-Alder reaction between a furan and a maleimide (see Figure 1.6.4)..$^{39}$

The fact that rDA is thermoreversible makes it ideal for rehealable polymer networks as no additional catalyst is required to be within the system. Additionally, the concerted mechanism of rDA does not involve radicals and is therefore unlikely to form unwanted side products. ${ }^{40}$ Scientific research in the 1990 s produced a sharp increase in the use of Diels-Alder polymers. ${ }^{41}$ Eventually fully crosslinked polymers made of entirely reversible crosslinks were made (see Figure 1.6.5). ${ }^{42}$
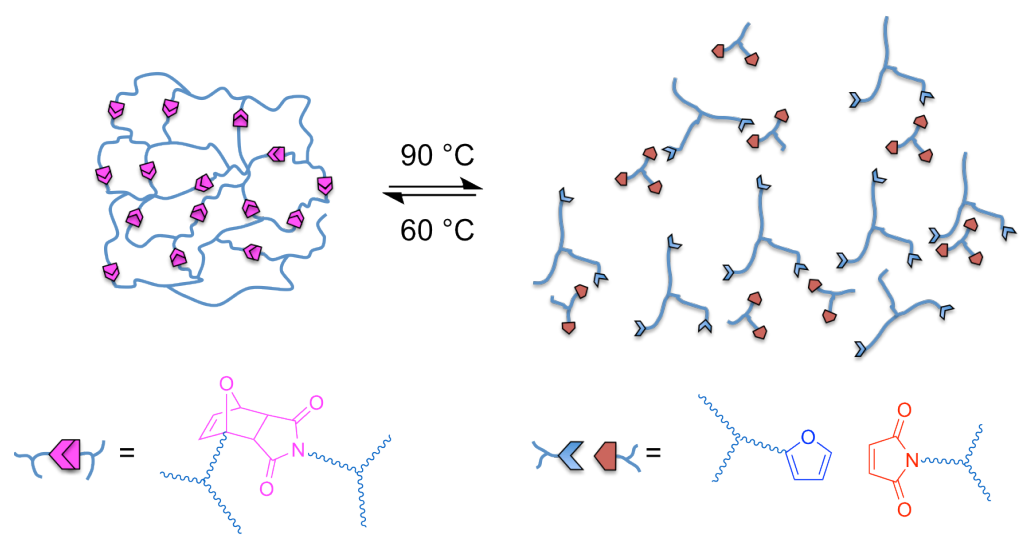

Figure 1.6.5. Polymeric system comprised entirely out of reversible crosslinks.

\subsection{Polyurethanes}

A common resin that is often utilized for its robustness is the polyurethane. Polyurethanes are widely used as adhesives, surface protectors, housing insulation, and automotive coatings. They are used industrially due to their high flexibility, chemical resistance, high reactivity of monomers (due to the presence of the isocyanate) and weathering resistance capabilities. ${ }^{43}$ A urethane contains two oxygen atoms and a 
nitrogen making it able to hydrogen bond with other urethanes (Figure 1.7.1). ${ }^{44}$ These hydrogen bonds are capable of breaking (applied stress up to $25 \mathrm{~kJ} \mathrm{~mol}^{-1}$ ) and reforming after the stress is removed. ${ }^{3}$

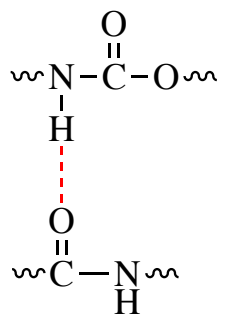

Figure 1.7.1. Intermolecular hydrogen bonding in polyurethanes.

Polyurethanes are made via a step-growth reaction between an alcohol and an isocyanate to form a carbamate (Figure 1.7.2). ${ }^{9}$ Thousands of common products such as foams, plastics, rubber, and adhesives have been made from this reaction. ${ }^{45}$ The isocyanates are often responsible as the hard segment of the material while the polyols act as the soft segments.

$$
\mathrm{R}-\mathrm{N}=\mathrm{C}=\mathrm{O}+\mathrm{R}_{1}-\mathrm{OH} \longrightarrow \mathrm{R}_{\mathrm{N}_{\mathrm{H}}-\mathrm{C}_{-} \mathrm{O}^{-}-\mathrm{R}_{1}}^{\mathrm{O}}
$$

Figure 1.7.2. Reaction of an isocyanate (red) with an alcohol (blue) to form a urethane/carbamate (right). ${ }^{9}$

Polyurethane coatings are often categorized into two types: one component $(1 \mathrm{~K})$ and two component $(2 \mathrm{~K})$ systems. The $1 \mathrm{~K}$ system contains a high molecular weight prepolymer that reacts with moisture in the air as a method of curing. Toluene diisocyanate is the most common isocyanate used to make polyurethane since it is relatively easy to handle and has excellent reaction rates. The application methods for $1 \mathrm{~K}$ polyurethane systems include spray, brush, and roller. ${ }^{46}$

A $2 \mathrm{~K}$ system contains two chemically different parts, part A and part B, typically isocyanates and polyol. The reaction between the two parts will determine the coating 
properties. Aliphatic isocyanates such as hexamethylene diisocyanates (HMDI) and polyisocyanurates such as Desmodur N3300 are often used in these systems. Desmodur N3300 contains multiple isocyanates in which the reaction with an alcohol will take place much faster due to its extra source of branching and crosslinking. ${ }^{9}$ The properties of $2 \mathrm{~K}$ polyurethane systems can easily be tailored using different isocyanates and ratios of isocyanates to alcohol. Additionally, by varying the reactivity of the isocyanates (primary and secondary) the physical properties of the coating can be manipulated (see Table $1.7 .1)^{47}$

Table 1.7.1. Composition and Reactivity of IPDI, HMDI and Desmodur N3300. ${ }^{48}$

\begin{tabular}{llcc}
\hline & IPDI & HMDI & Desmodur N3300 \\
$\begin{array}{c}1^{\circ} \text { isocyanates } \\
2^{\circ} \text { isocyanates } \\
\text { Reactivity }\end{array}$ & Slowest & Fast & Fastest \\
\hline
\end{tabular}




\section{References}

(1) Vernardakis, T. G. Pigment Dispersion. In Coatings Technology Handbook; Taylor \& Francis Group, LLC, 1991; pp. 529-550.

(2) AIi, M. F.; Bassam, M.; Speight, J. G. Handbook of Industrial Chemistry. In; McGraw-Hill, 2004; pp. 201-256.

(3) Wicks, Z. W., Jr; Jones, F. N.; Pappas, S. P.; Wicks, D. A. Organic coatings: science and technology. 2007.

(4) challener, C. Coatings Tech. August 2011, pp. 40-45.

(5) Bell, V. L.; Stump, B. L.; Gager, H. Polyimide structure-property relationships. II. Polymers from isomeric diamines. J. Polym. Sci. Polym. Chem. Ed. 1976, 14, 2275-2291.

(6) Gindl, W.; Zargar-Yaghubi, F.; Wimmer, R. Impregnation of softwood cell walls with melamine-formaldehyde resin. Bioresour. Technol. 2003, 87, 325-330.

(7) Carraher, C. E., Jr Seymour/Carraher's Polymer Chemistry; CRC Press, 2003.

(8) Flick, E. W. Industrial synthetic resins handbook; William Andrew Publishing, 1991.

(9) Odian, G. Principles of Polymerization; Wiley-Interscience, 2004.

(10) Pascault, J.-P.; Williams, R. J. J. Epoxy Polymers; Wiley-VCH, 2009.

(11) Joye, N. M.; Lawrence, R. V. Resin acid composition of pine oleoresins. $J$. Chem. Eng. Data 1967, 12, 279-282.

(12) Imle, E. P. Hevea rubber - past and future. Economic Botany 1978, 32, 264-277.

(13) Sharma, V.; Kundu, P. P. Addition polymers from natural oils - A review. Progress in Polymer Science 2006, 31, 983-1008.

(14) Meier, M. A. R.; Metzger, J. O.; Schubert, U. S. Plant oil renewable resources as green alternatives in polymer science. Chem Soc Rev 2007, 36, 1788-1802.

(15) Shogren, R. L.; Petrovic, Z.; Liu, Z.; Erhan, S. Z. Biodegradation behavior of some vegetable oil-based polymers. J Polym Environ 2004, 12, 173-178.

(16) Kosbar, L. L.; Gelorme, J. D.; Japp, R. M.; Fotorny, W. T. Introducing biobased materials into the electronics industry. Journal of Industrial Ecology 2000, 4, 93 105.

(17) Zlatani, A.; Lava, C.; Zhang, W.; Petrovi, Z. S. Effect of structure on properties of polyols and polyurethanes based on different vegetable oils. J. Polym. Sci. B Polym. Phys. 2004, 42, 809-819.

(18) Chattopadhyay, D. K.; Raju, K. V. S. N. Structural engineering of polyurethane coatings for high performance applications. Progress in Polymer Science 2007, 32, 352-418.

(19) García, S. J.; Fischer, H. R.; van der Zwaag, S. A critical appraisal of the potential of self healing polymeric coatings. Progress in Organic Coatings 2011, 72, 211-221.

(20) Praw, M. Coatings Tech. April 2010, pp. 22-23.

(21) Braun, J. H. Introduction to Pigments; Federation for Societies of Coatings Technology, 1993.

(22) Zin, I. M.; Lyon, S. B.; Pokhmurskii, V. I. Corrosion control of galvanized steel using a phosphate/calcium ion inhibitor mixture. Corrosion Science 2003, 45, 777-788. 
(23) Smith, A. Inorganic Primer Pigments; Federation for Societies of Coatings Technology, 1988.

(24) Fernando, R. H.; Sung, L.-P. Nanotechnology Applications in Coatings; Amer Chemical Society, 2009.

(25) Chaloupka, K.; Malam, Y.; Seifalian, A. M. Nanosilver as a new generation of nanoproduct in biomedical applications. Trends in Biotechnology 2010, 28, 580 588.

(26) Wypych, G. Handbook of fillers; Chemtec Publishing, 1999.

(27) Ueno, H.; Tsubokawa, N. Radical graft polymerization initiated by azo groups introduced onto the surface of carbon whisker. Composite Interfaces 1996, 4, 1120.

(28) Freitag, W.; Stoye, D. Paints, Coatings and Solvents; Wiley-VCH, 2008.

(29) Tracton, A. A. Coatings Technology Handbook, Third Edition; CRC Press, 2010.

(30) Challener, C. Coatings Tech. February 2011, pp. 36-40.

(31) Bieleman, J. Additives for Coatings; Wiley-VCH, 2008.

(32) Konstandt, F. Organic Coatings : Properties and Evaluation; Chemical Pub. Co. Inc.,New York, NY, 1985.

(33) ASTM Committee D-1 on Paint and Related Coatings, M. A. A. Standard Test Methods for Measuring Adhesion by Tape Test; 9 ed. D3359; 2009; p. 16.

(34) Blaiszik, B. J.; Kramer, S. L. B.; Olugebefola, S. C.; Moore, J. S.; Sottos, N. R.; White, S. R. Self-Healing Polymers and Composites. Annu. Rev. Mater. Res. 2010, 40, 179-211.

(35) Therriault, D.; White, S. R.; Lewis, J. A. Chaotic mixing in three-dimensional microvascular networks fabricated by direct-write assembly. Nat Mater 2003, 2 , 265-271.

(36) Zhang, M. Q.; Rong, M. Z. Self-Healing Polymers and Polymer Composites; Wiley, 2011.

(37) Liu, Y.-L.; Chuo, T.-W. Self-healing polymers based on thermally reversible Diels-Alder chemistry. Polymer Chemistry 2013, 4, 2194-2205.

(38) Fringuelli, F.; Taticchi, A.; Wiley, J. The Diels-Alder reaction: selected practical methods. 2002.

(39) Clevenger, R. C.; Turnbull, K. D. Synthesis on N-Alkylated Maleimides. Synthetic Communications 2000, 30, 1379-1388.

(40) Kersey, F. R.; Loveless, D. M.; Craig, S. L. A hybrid polymer gel with controlled rates of cross-link rupture and self-repair. $J R$ Soc Interface 2007, 4, 373-380.

(41) Gandini, A. The application of the Diels-Alder reaction to polymer syntheses based on furan/maleimide reversible couplings. Polimeros 2005, 15, 95-101.

(42) Zhang, Y.; Broekhuis, A. A.; Picchioni, F. Thermally Self-Healing Polymeric Materials: The Next Step to Recycling Thermoset Polymers? Macromolecules 2009, 42, 1906-1912.

(43) Malucelli, G.; Priola, A.; Ferrero, F.; Quaglia, A.; Frigione, M.; Carfagna, C. Polyurethane resin-based adhesives: curing reaction and properties of cured systems. International Journal of Adhesion and Adhesives 2005, 25, 87-91.

(44) Yen, F.-S.; Hong, J.-L. Hydrogen-bond interactions between ester and urethane linkages in small model compounds and polyurethanes. Macromolecules 1997, 30, 7927-7938. 
(45) Li, S.; Vatanparast, R.; Lemmetyinen, H. Cross-linking kinetics and swelling behaviour of aliphatic polyurethane. Polymer 2000, 41, 5571-5576.

(46) Szycher, M. Szycher's Handbook of Polyurethanes; CRC Press Llc, 2012.

(47) Mooibroek, J. Toward a Sustainable Synthesis of Aromatic Isocyanates. Department of Metals in Catalysis, Biomimetics \& Inorganic Materials 2011, 1300.

(48) Thomson, T. Polyurathanes As Specialty Chemicals; CRC PressI Llc, 2005. 


\section{Thermally Responsive Soybean Oil Resin and Coatings}

\subsection{Introduction}

Soybean oil

Along with the rest of the world, the United States has a diminishing reserve of fossil fuels. In fact, about 56 percent of the U.S. demand for oil is now met by depending upon imports supplied by foreign sources, up from 40 percent in 1990. ${ }^{1}$ To combat our dependence on petroleum-based products, the government and many private industries have funded research to derive similar products from alternative sources.

One promising alternative to petroleum is found by extracting oils from plants. The United States government subsidizes the production of certain plants (mainly corn and soybeans) making the cost of certain vegetable oils significantly lower. The use of vegetable oils is favorable because they have been recognized as sustainable and biodegradable materials which could contribute to a reduction in global warming effects.

Vegetable oils are a precursor to many polymeric materials, ${ }^{1,2}$ lubricants, ${ }^{3,4}$ polyols, ${ }^{5}$ and rigid polyurethane foam. ${ }^{6}$ A benefit to using vegetable oil as a raw material is that unsaturated oils like soybean or linseed oil can be easily epoxidized via peracid oxidation as shown below in Figure 2.1.1. ${ }^{7}$ The ring strain created from the threemembered ring epoxides makes them very electrophillic and thus many other compounds can be readily attached to epoxidized oil. In particular, alcohols, amines, thiols, and carboxylic acids can react with an epoxide.

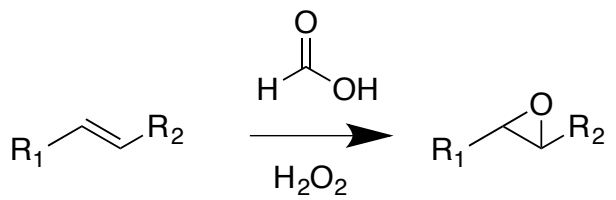

Figure 2.1.1. Example of a typical epoxidation. 
Soybean oil, like other vegetable oils, can be prepared into resin for various coatings such as epoxy and polyurethane. Soybean oil is a triglyceride molecule composed of linoleic, oleic, palmitic and a small amount of linolenic and stearic acid (see Table 2.1.1). With the perfect modification and viscosity, soybean oil resin can provide rigidity and strength comparable to chemical resin. ${ }^{2,8}$ This epoxidation of soybean oil is relatively easy and can obtain $90 \%$ conversion and selectivity. Gerbase has shown that epoxidized soybean oil has impeccable properties with thermal stability up to $300^{\circ} \mathrm{C}$ and also found that $\mathrm{T}_{\mathrm{g}}$ (glass transition temperature) and hardness increase with a higher number of epoxy groups in soybean oil. ${ }^{4,9}$

Table 2.1.1. The composition of soybean oil. ${ }^{3}$

\begin{tabular}{|c|c|c|}
\hline Mixture & Structure & Composition \\
\hline Linoleic & & $56 \%$ \\
\hline Oleic & & $25 \%$ \\
\hline Palmitic & & $11 \%$ \\
\hline Linolenic & & $9 \%$ \\
\hline Stearic & & $4 \%$ \\
\hline
\end{tabular}

Opening epoxidized soybean oil with an acid is the most common way to make a soybean-based polyol. ${ }^{10}$ Other molecules such as organic and inorganic acids, alcohols, water or hydrogenation can be used to open the epoxide. ${ }^{6,11}$ After epoxidation and subsequent opening of the epoxide with an organic acid, a molecule of soybean oil on average has 4.5 hydroxyl group attached to it. Depending on the substituent attached to the organic acid one can also change physical properties such as $\mathrm{T}_{\mathrm{g}}{ }^{7,11}$ 


\section{Project Goal}

The goal of this project is to generate soybean-based resin with thermally responsive Diels-Alder linkages. This resin can be incorporated to polyurethane 2 components automotive formulations to achieve thermally responsive coating.

\subsection{Experimental}

\section{Methods and Materials}

All materials were purchased from commercially available sources.

\section{Synthesis of Phenolic-maleimide}

To a $1000 \mathrm{~mL}$ Erlenmeyer flask equipped with a magnetic stir bar was added 4aminophenol acid $(44.5 \mathrm{~g}, 400 \mathrm{mmol})$ followed by acetone $(500 \mathrm{~mL})$ and the mixture was stirred at room temperature. In a $500 \mathrm{~mL}$ beaker, maleic anhydride (40 g, $400 \mathrm{mmol})$ was dissolved in acetone $(300 \mathrm{~mL})$. This mixture was then slowly added to the Erlenmeyer flask and a yellow precipitate formed which was isolated by vacuum filtration. The product was added to a $300 \mathrm{~mL}$ round bottom flask equipped with a magnetic stir bar followed by $\mathrm{DMF}(50 \mathrm{~mL})$. To a $150 \mathrm{~mL}$ beaker equipped with a stir bar was added DMF (70 mL), followed by phosphorus pentoxide $(21 \mathrm{~g}, 140 \mathrm{mmol})$ and fuming sulfuric acid $(9 \mathrm{~g}, 91.8 \mathrm{mmol})$ (weighed out in a $10 \mathrm{~mL}$ graduated cylinder), and additional DMF (20 mL) which was used to rinse the sulfuric acid from the graduated cylinder into the beaker; this mixture was then added to the $300 \mathrm{~mL}$ round bottom flask which was sealed with a rubber septa and allowed to stir at $70^{\circ} \mathrm{C}$ for $24 \mathrm{~h}$. The resulting viscous black liquid was then poured into a $4 \mathrm{~L}$ beaker containing ice water $(3 \mathrm{~L})$, precipitating a fine yellow powder that was isolated by vacuum filtration. The structure of the resulting 
orange crystals (55 g, 65\% yield) was then confirmed via ${ }^{1} \mathrm{H}$ NMR: $\delta(\mathrm{ppm}) 7.15(2 \mathrm{H}, \mathrm{d})$, $7.0(2 \mathrm{H}, \mathrm{s}), 6.9(2 \mathrm{H}, \mathrm{d})$.

Synthesis of opened succinic anhydride (OSA)

To a $500 \mathrm{ml}$ round bottom flask equipped with stir bar, succinic anhydride (16.5 $\mathrm{g}, 163 \mathrm{mmol}$ ) was added followed with furfuryl alcohol (16 g, $163 \mathrm{mmol})$, toluene (200 $\mathrm{mL})$, and DMAP $(0.5 \mathrm{~g}, 4 \mathrm{mmol})$. This mixture was refluxed at $120^{\circ} \mathrm{C}$ for 24 hours. The mixture was cooled, rotovapped, and then dissolved with diethyl ether ( $\sim 100 \mathrm{~mL})$ before washing it with $2.5 \% \mathrm{HCl}$. The organic layer was then dried with anhydrous magnesium sulfate, filtered, and rotovapped. The solvent was further removed under reduced pressure. The structure was then confirmed via ${ }^{1} \mathrm{HNMR}: \delta(\mathrm{ppm}) 7.45(1 \mathrm{H}, \mathrm{s}), 6.4(1 \mathrm{H}$, d), $6.35(1 \mathrm{H}, \mathrm{t}), 5.5(2 \mathrm{H}, \mathrm{s}), 2.15(4 \mathrm{H}, \mathrm{m})$. Synthesis of epoxidized soybean oil (ESBO)

Soybean oil (76.8 $\mathrm{g}, 84 \mathrm{mmol})$ was added to a $500 \mathrm{ml}$ round bottom flask equipped with a stir bar followed by the slow addition of formic acid (25.6 g, $556 \mathrm{mmol})$ and cooled to $0{ }^{\circ} \mathrm{C}$. To the mixture $\mathrm{H}_{2} \mathrm{O}_{2}(80 \mathrm{~g}, 2.2 \mathrm{~mol})$ was slowly added and stirred for 24 hours at room temperature. The mixture was stirred with diethyl ether and transferred to a $500 \mathrm{~mL}$ Erlenmeyer flask equipped with a stir bar before adding $\mathrm{NaHCO}_{3}$ until the mixture reached $\mathrm{pH} 8$. The mixture was washed with brine to separate the aqueous layer. The organic layer was then dried with anhydrous magnesium sulfate, filtered, and rotovapped. Solvent was further removed under reduced pressure. The structure was then confirmed via ${ }^{1} \mathrm{H}$ NMR: $\delta(\mathrm{ppm})$ epoxide peaks at 2.85, 2.95 and 3.1. 
Synthesis of furan soybean oil (FSBO)

Epoxidized soybean oil $(14.8 \mathrm{~g}, 15 \mathrm{mmol})$ was added to a 250 round bottom flask equipped with a stir bar, followed with open succinic anhydride $(23.7 \mathrm{~g}, 120 \mathrm{mmol})$. The mixture was refluxed at $100^{\circ} \mathrm{C}$ for 24 hours. The mixture was cooled and dissolved with diethyl ether before washing with saturated $\mathrm{NaHCO}_{3}$. The organic layer was then dried with anhydrous magnesium sulfate, filtered, and rotovapped. Solvent was further removed under reduced pressure. The structure was then confirmed via ${ }^{1} \mathrm{H}$ NMR: $\delta$ (ppm) furan peaks at $\delta(\mathrm{ppm}) 6.35,6.4$, and 7.4. Acetylation of furan soybean oil (AcFSBO)

To a $500 \mathrm{~mL}$ round bottom flask equipped with stir bar, FSBO (17.8 g, $10 \mathrm{mmol})$ was added followed with acetic anhydride $(4.2 \mathrm{~g}, 41 \mathrm{mmol})$, triethylamine $(4.4 \mathrm{~g}, 43$ $\mathrm{mmol})$, and THF ( 25 mL). The mixture was then refluxed at $70^{\circ} \mathrm{C}$ for 24 hours. The mixture was cooled, rotovapped, dissolved in $\sim 100 \mathrm{~mL}$ diethyl ether, and washed with brine. The organic layer was then dried with anhydrous magnesium sulfate, filtered, and rotovapped. Solvent was further removed under reduced pressure. The structure was then confirmed via ${ }^{1} \mathrm{H}$ NMR: $\delta(\mathrm{ppm})$ by a new peak at $\delta(\mathrm{ppm}) 2.05$.

Synthesis of thermally responsive soybean oil (TR-SBO) with 100\% Diels Alder linkages Acetylated furan soybean oil (18 g, $9.3 \mathrm{mmol})$ was added to a $500 \mathrm{~mL}$ round bottom flask equipped with a stir bar, and followed by phenolic-maleimide ( $7 \mathrm{~g}, 37$ mmol). The reaction was run utilizing $\mathrm{THF}$ as a solvent and was run at $50^{\circ} \mathrm{C}$ for two days. The mixture was rotovaped and extra solvents were removed under pressure. The structure was then confirmed via ${ }^{1} \mathrm{H}$ NMR: $\delta$ (ppm) 6.55, 6.4, 5.35, 3.05 and 2.95. The 
$66 \%$ and $33 \%$ Diels-Alders soybean polyol was prepared by varying the amount of phenolic maleimide.

\section{Coating Formulation}

Soybean oil polyols, both acetylated and unacetylated with $100 \%, 66 \%$, and $33 \%$ DA linkages, were incorporated into a $2 \mathrm{~K}$ automotive coating polyurethane coating system. Three isocyanates, Desmodur N3300, isophorone diisocyanate (IPDI) and hexamethylene diisocyanate (HMDI), were used to formulate three different coatings.

Table 2.2.1. Acetylated resin coating preparation.

\begin{tabular}{ccccc}
\hline \multicolumn{2}{c}{ Acetylated Resin } & \# crosslink site/ molecule \\
\hline Isocyanates & \% Diels Alder & NCO:OH & Permanent & Reversible \\
\hline IPDI & 100 & $1: 1,3: 1,5: 1$ & 0 & 4.4 \\
& 54 & $1: 1,3: 1,5: 1$ & 0 & 2.4 \\
& 30 & $1: 1,3: 1,5: 1$ & 0 & 1.3 \\
\hline HMDI & 100 & $1: 1,3: 1,5: 1$ & 0 & 4.4 \\
\hline Desmodur & 100 & $1: 1,0.33: 1,0.2: 1$ & 0 & 4.4 \\
\hline
\end{tabular}

Table 2.2.2. Unacetylated resin coating preparation.

\begin{tabular}{ccccc}
\hline \multicolumn{2}{c}{ Unacetylated Resin } & \multicolumn{3}{c}{ \# crosslink site/ molecule } \\
\hline Isocyanates & \% Diels Alder & NCO:OH & Permanent & Reversible \\
\hline IPDI & 100 & $1: 1$ & 4.4 & 4.4 \\
IPDI & 54 & $1: 1$ & 4.4 & 2.4 \\
IPDI & 30 & $1: 1$ & 4.4 & 1.3 \\
\hline
\end{tabular}

All coatings were formulated without catalyst with variety $1: 1,3: 1,5: 1$ ratio between isocyanates and polyol. Each coating was drawn down on a $4 \times 6$ inch stainless steel panel with a 10 millimeter BYK draw down bar. For each coating at least three panels were prepared. The coating was placed in a $35^{\circ} \mathrm{C}$ oven for 30 minutes after letting it sit for approximately 15 minutes at room temperature. 
Table 2.2.3. Typical polyurethane formulation.

\begin{tabular}{lll}
\hline Part A & Mass $(\mathbf{g})$ & Volume $(\mathbf{m L})$ \\
\hline Soybean polyol & 10 & \\
Methyl amyl ketone & 4.705 & 5.77 \\
Xylene & 0.195 & 0.226 \\
n-Pentyl propionate & 0.141 & 0.162 \\
Total & 15.04 & \\
\hline Part B & Mass $(\mathbf{g})$ & Volume $(\mathbf{m L})$ \\
\hline Desmodur N3300 A & 3.11 & \\
n-Butyl acetate & 0.271 & 0.307 \\
Total & 3.382 & \\
\hline
\end{tabular}

Hardness

The pendulum hardness test was used to compare the effect of retained solvents on the hardness of the film. A Byk Gardner pendulum hardness tester was used in the Konig mode. This mode measures the time taken for the pendulum amplitude to decrease from $6^{\circ}$ to $3^{\circ}$. Each coating's hardness was measured every two days over a 20 -day period. Three data points were obtained for each panel.

\section{Gloss measurement}

Gloss measurements were taken as an average of three data points across the panel using a BYK Gardener Micro-TRI-Gloss gloss meter at a $60^{\circ}$ angle. ASTM D523-08 was followed for gloss measurements. The first measurement was taken after the coating had dried for four days. Then, the same panel was damaged using a mallet. A piece of sand paper was attached to the mallet to act as an abrasive component. A $3 \mathrm{~kg}$ weight on top of the mallet was added to maintain the amount of force applied to the panel. The mallet, sand paper, and weight combination were run across the panel three times. The second measurement of gloss was then recorded. The same panel was then heated for 30 seconds using the heat gun and cooled for 30 seconds. A third measurement of the panel was taken to measure the gloss after heating. The same process was done 
every four days up to a 20-day period. The best coating panels were also chosen to damage at the same site a second time to determine how the gloss changed with a second heating.

\section{Crosscut adhesion test}

The adhesion testing followed ASTM D3359 and used a BYK crosscut test kit to make the crosscut. Scotch 3M No. 897 strapping tape was used for the pull-off portion of the test. The test was done on day six after the coating had cured.

\section{ImageJ analysis}

The panel was horizontally cut with the Byk crosscut blade. The cut area was then scanned and the picture analyzed using ImageJ software. The cut area of the same panel was heated with the heat gun for 30 seconds and cooled for 30 seconds. The panel was again scanned and analyzed with ImageJ software. ImageJ was able to measure the intensity and the distance between each cut before and after heating.

\section{Differential Scanning Calorimetry (DSC) analysis}

To ensure DA linkages were successfully incorporated, samples of polyol with different DA percentage were analyzed via DSC. Each sample went through a total of three cycles with heating rate of $10{ }^{\circ} \mathrm{C} / \mathrm{min}$ from $50{ }^{\circ} \mathrm{C}$ to $180{ }^{\circ} \mathrm{C}$. The coating of choice thermal properties was analyzed using DSC. The sample went through a total of three cycles with a heating rate of $20{ }^{\circ} \mathrm{C} / \mathrm{min}$ from $50{ }^{\circ} \mathrm{C}$ to $250{ }^{\circ} \mathrm{C}$.

\section{Thermogravimetric (TGA) analysis}

The coating of choice was analyzed for solvent retention after oven heating, and room temperature curing for six days using TGA. Each sample was analyzed under the ramp mode with a heating rate of $20^{\circ} \mathrm{C} / \mathrm{min}$ and heated to $500{ }^{\circ} \mathrm{C}$. 


\section{Controls Panel Preparation}

A control coating without reversible crosslinks was made using FSBO as a polyol and using IPDI as an isocyanate to compare properties. Formulation of the coatings followed the previous procedure. Five different panels were prepared and the properties of the coating were also analyzed the same way.

\subsection{Results and Discussion}

Small molecule components

Scheme 2.3.1. Synthesis of phenolic-maleimide.

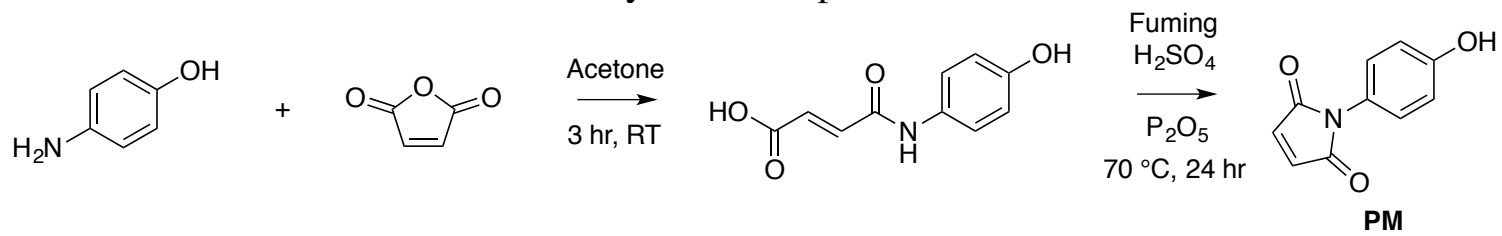

Phenolic maleimide was successfully synthesized according to Scheme 2.3.1.

Doublets appear in ${ }^{1} \mathrm{H}$ NMR at 7.15, 7.0, and $6.9 \mathrm{ppm}$. The first doublet appeared at 7.15 ppm corresponding to two hydrogens of vinyl maleimeide. The other doublet at $7.0 \mathrm{ppm}$ corresponds to the other two hydrogens in the benzene closer to the nitrogen. The last doublet at 6.9 ppm corresponds to the two hydrogens in the benzene adjacent to the alcohol.

Scheme 2.3.2. Synthesis of opened succinic anhydride.

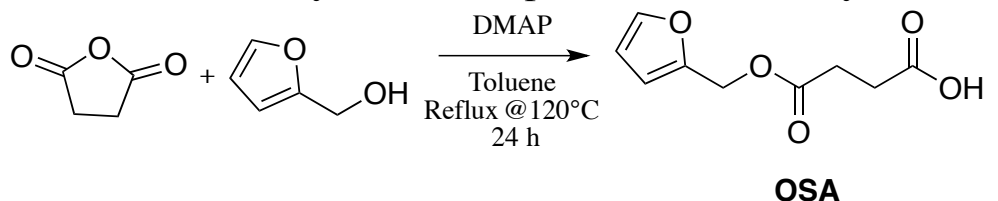

Open succinic anhydride successfully synthesized according to scheme 2.3.2.

The structure was confirmed via ${ }^{1} \mathrm{HNMR}: \delta(\mathrm{ppm}) 7.45(1 \mathrm{H}, \mathrm{s}), 6.4(1 \mathrm{H}, \mathrm{d}), 6.35(1 \mathrm{H}, \mathrm{t})$, $5.5(2 \mathrm{H}, \mathrm{s}), 2.15(4 \mathrm{H}, \mathrm{m})$. The first singlet at $7.45 \mathrm{ppm}$ corresponded to one hydrogen 
from carbon connected to the oxygen. The peak at 6.4 and 6.35 corresponds to two furan's hydrogens. The singlet at $5.5 \mathrm{ppm}$ corresponds to two hydrogens from the carbon connected to furan and oxygen. The last peak at $2.15 \mathrm{ppm}$ corresponds to the last four hydrogens in between the carbonyl peak.

Thermally responsive soybean oil resin

Thermally responsive soybean oil was successfully synthesized according to Scheme 2.3.3.

The analysis of the structure will be broken down into four parts, A through D.

- Part A: Epoxidized soybean oil (ESBO)

${ }^{1} \mathrm{H}$ NMR of ESO: $\delta(\mathrm{ppm})$ confirmed by the appearance of epoxide peaks at $\delta(\mathrm{ppm})$ 2.85, 2.95 and 3.1 and the disappearance of alkene peaks at $\delta(\mathrm{ppm}) 5.3$.

- Part B: Furan soybean oil (FSBO)

The structure was then confirmed via ${ }^{1} \mathrm{H}$ NMR: $\delta$ (ppm) product by the disappearance of the epoxide peaks at $\delta(\mathrm{ppm}) 2.85,2.95$, and 3.1 and the appearance of furan peaks at $\delta(\mathrm{ppm}) 6.35,6.4$, and 7.4 in the proper ratio.

- Part C: Acetylation of furan soybean oil (AcFSBO)

The new peak present at $2.05 \mathrm{ppm}$ corresponds to the acetylation of the alcohols along the fatty acids.

- Part D: Thermally responsive soybean oil (TR-SBO)

${ }^{1} \mathrm{H}$ NMR: $\delta$ (ppm) confirmed by the disappearance of the furan peaks at $\delta$ ppm 6.35 , 6.4 and 7.4 and the appearance of the appropriate Diels-Alder adduct peaks: 6.55, 6.4, $5.35,3.05$ and 2.95 . 
Scheme 2.3.3. Synthesis of thermally responsive soybean oil resin.

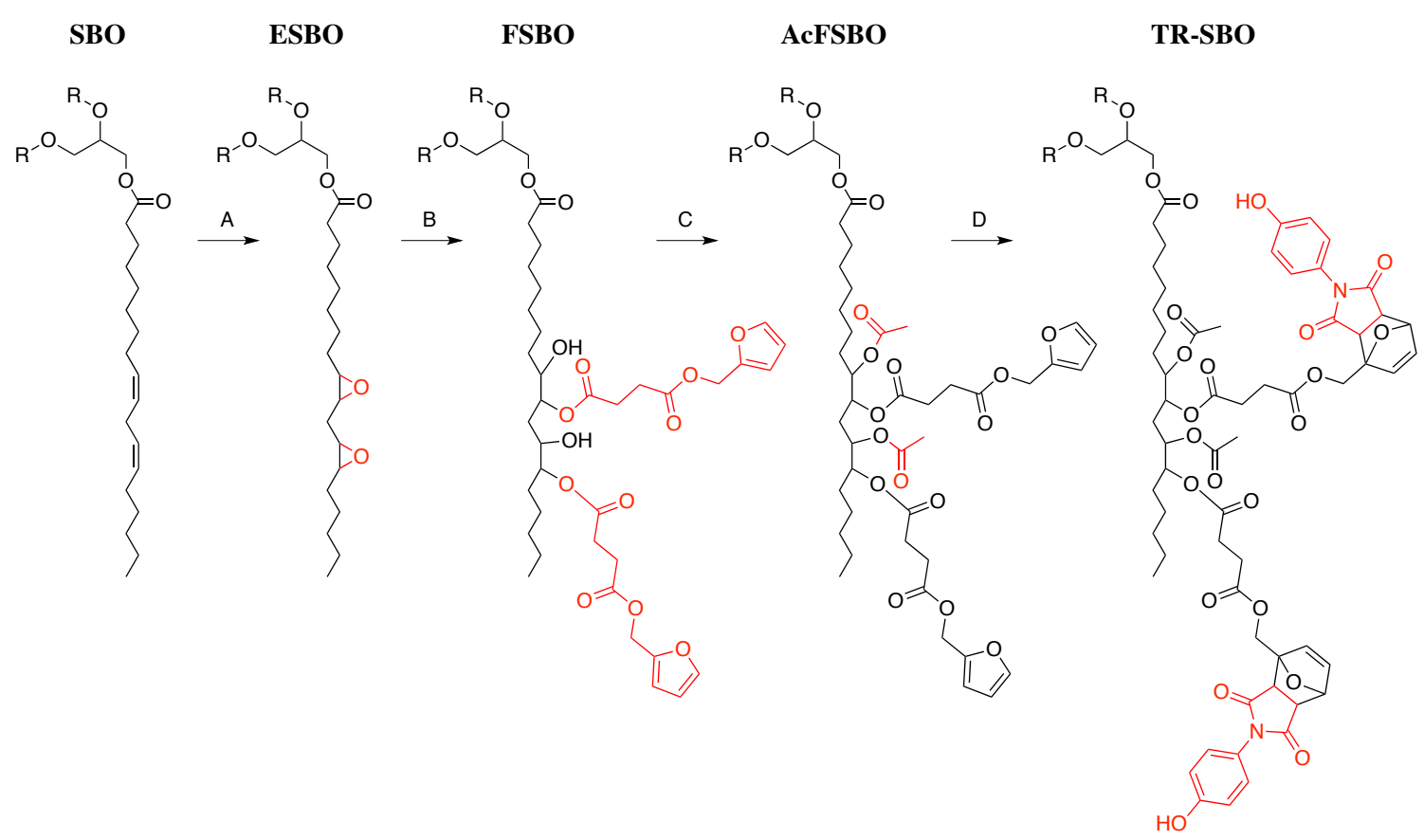

A) Formic acid, $\mathrm{H}_{2} \mathrm{O}_{2}$ at $\mathrm{RT} ; B$ ) $\mathrm{OSA}$ at $100{ }^{\circ} \mathrm{C}$; C) $\mathrm{Et}_{3} \mathrm{~N}$, acetic anhydride, $\mathrm{THF}$ at $70^{\circ} \mathrm{C}$; and $D$ ) Phenolic maleimide, $\mathrm{THF}$ at $50{ }^{\circ} \mathrm{C}$.

\section{DSC Result}

Initially soybean oil was analyzed as a baseline to show that no endotherm was present (Figure 2.3.1). Sample 1 (TR-SBO with 100\% Diels-Alder) showed a significant endotherm from $100-170{ }^{\circ} \mathrm{C}$ was present, indicative of Diels-Alder. With smaller percentage of DA incorporated into soybean oil the trend of endotherm peak also smaller. Endotherm peak occur due to the breaking of the bond in DA bonds. The presence of endotherm peak ensure Diels-Alder linkages were successfully attached to the soybean oil. 


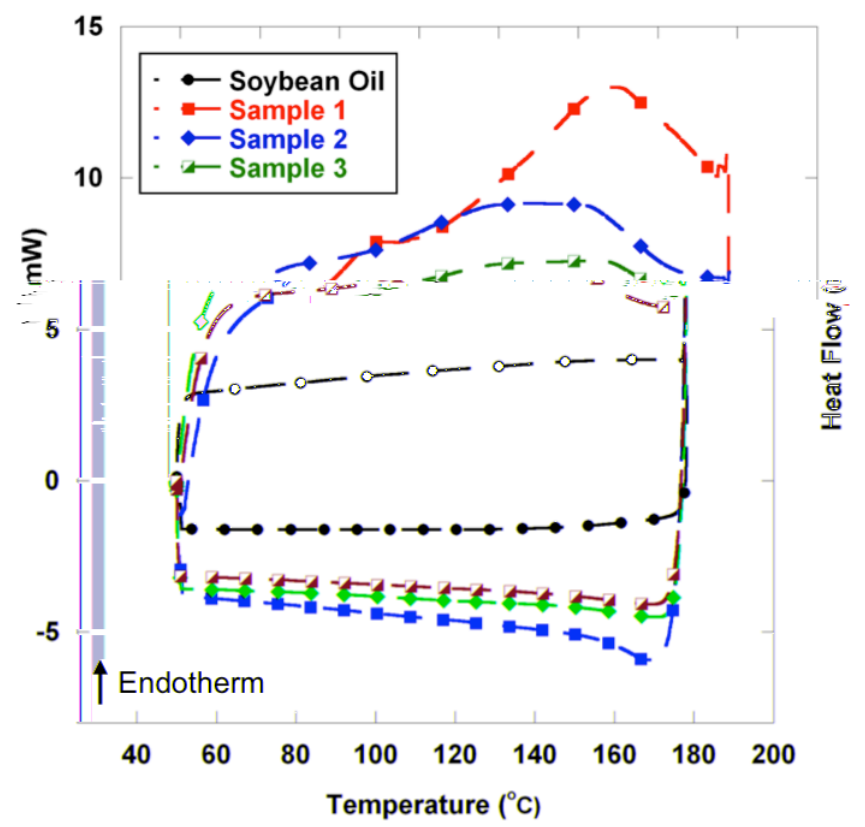

Figure 2.3.1. DSC data of polyol with various percentages of Diels-Alder $(100,54,30)$ acetylated TR-SBO.

\section{Hardness Results}

In the reaction between acetylated furan soybean oil (AcFSBO) and phenolic maleimide (PM), by varying the amount of phenolic maleimide the amount of alcohols per soybean molecule changes. Table 2.3.1 shows the calculated maximum number of alcohols (crosslink sites) per soybean molecule.

Table 2.3.1. Calculated crosslink sites for coatings.*

\begin{tabular}{ccc}
\hline Acetylated Resin & \multicolumn{2}{c}{ \# crosslink site/ molecule } \\
\hline \% Diels Alder & Permanent & Reversible \\
\hline 100 & 0 & 4.4 \\
54 & 0 & 2.4 \\
30 & 0 & 1.3 \\
\hline
\end{tabular}

*IPDI was used with all resins.

The effect seen by varying the amount of PM in the system is shown below in Figure 2.3.2. By increasing the amount of phenolic maleimide and keeping the ratio of isocyanate to alcohol 1:1, there was an apparent increase in hardness. Next, by changing the ratio of isocyanate to alcohol to 3:1 and 5:1, there was an additional increase in 
hardness. The data indicates that more alcohol (i.e., higher crosslinking sites) per soybean results in a harder coating. Additionally as excess isocyanate is added, there is an even greater increase in hardness due to higher number of crosslinker (isocyanates).
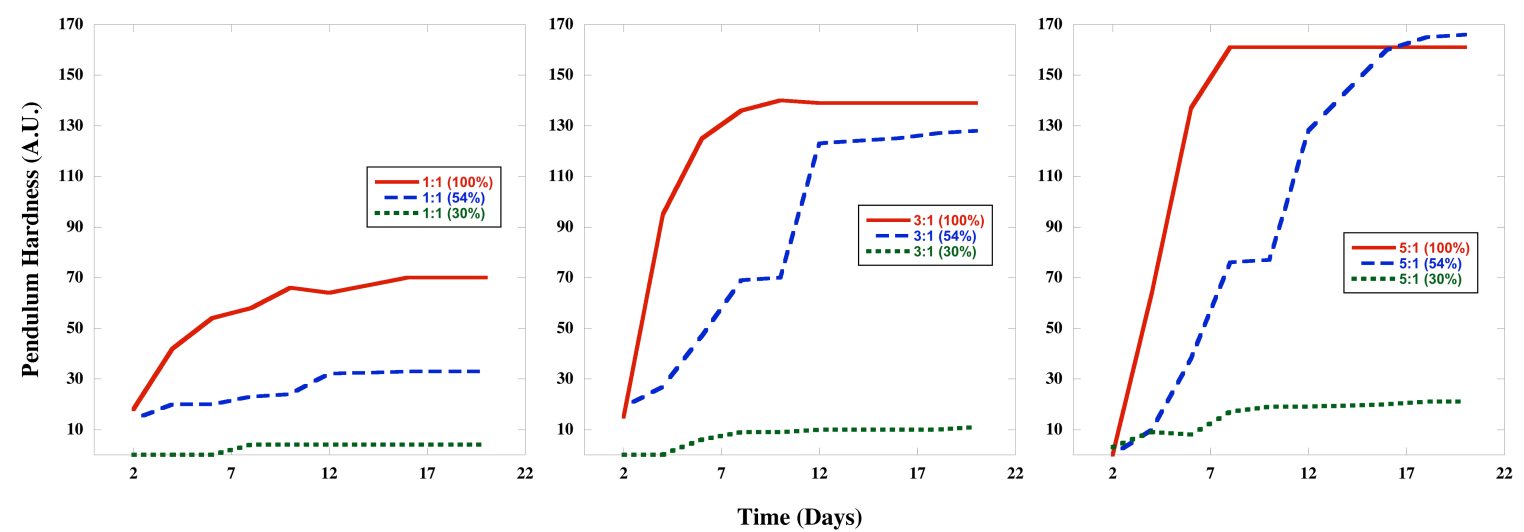

Figure 2.3.2. Hardness data of coating using IPDI as an isocyanate in various ratios $(1,3,5)$ with percentages of Diels-Alder $(100,54,30)$ acetylated TR-SBO.

The data consistently shows that $30 \%$ Diels-Alder (DA) is the softest coating while $100 \%$ DA is the hardest regardless of the isocyanates ratio. It is possible that the polyol with $100 \%$ DA is the hardest due to its higher number of hydroxyls present in the system. 54\% DA TR-SBO has excess dangling chains that are furan terminated. These dangling chains are without alcohols and therefore cannot participate in the crosslinking of the coating. If the amount of DA present is increased then the number of alcohols per molecule of TR-SBO is increased as well. With a higher number of crosslink sites available per molecule, $100 \%$ DA TR-SBO can create a coating with a greater crosslink density than 54\% TR-SBO. Higher crosslink densities create harder coatings. This result is consistent with another study that measured tensile strength. Desai et al. found that by replacing a polyol with a new polyol containing a higher number of alcohols, the tensile strength of their materials increased. ${ }^{12}$ 
Incorporating different isocyanates into a coating is important to see the compatibility of the soybean resin. Three different isocyanates, (Desmodur N3300, HMDI, IPDI), were used with 100\% DA TR-SBO resin. The ratios of isocyanate (HMDI and IPDI) to alcohol were between 1,3, and 5. On the other hand, the ratio of Desmodur to alcohol was decreased from 1:1, to $0.33: 1$, and $0.2: 1$. The ratio for Desmodur was decreased as a previous trial had showed that coatings with a ratio greater than 1:1 did not have desirable properties.

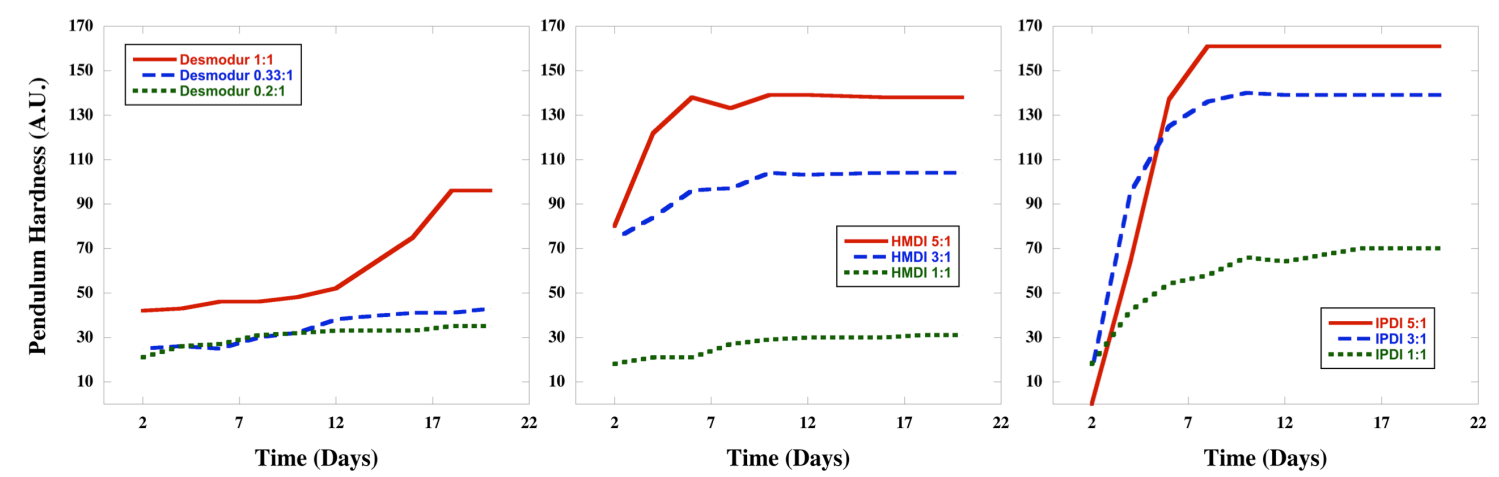

Figure 2.3.3. Hardness data of coating using Desmodur N3300 (right) HMDI (middle) and IPDI (left) as isocyanate in various ratios with 100\% DA TR-SBO (acetylated).

Desmodur N3300, HMDI, and IPDI followed a trend of an increase in hardness with an increase in isocyanate due to an increase in crosslink density. The difference in structure between the isocyanates can lead to the macroscopic differences in hardness. Desmodur 1:1 is much harder than HMDI 1:1, due to the increase in crosslink density (>3) for Desmodur. The hardness also depends on the cure speed of the isocyanate themselves. For example, HMDI 1:1 and IPDI 1:1 both contain the same number of isocyanates per molecule (2), however IPDI is much harder than HMDI. This is due to HMDI curing a lot faster causing the solvent to be trapped within the coating, decreasing its hardness. As there is an increase in the $\mathrm{NCO}: \mathrm{OH}$ ratio, the hardness increases because adding more NCO increases the hard segment. The hardest coating by day 20 for the 1:1 
NCO:OH, was Desmodur. As previously described, Desmodur is made up of trimers that form rings that contribute to the hardness of the material. ${ }^{13}$ IPDI also contains six membered rings and is the second hardest coating among the 1:1 ratios. HMDI is aliphatic and is not trimerized and is therefore the softest coating (see Figure 2.3.4).
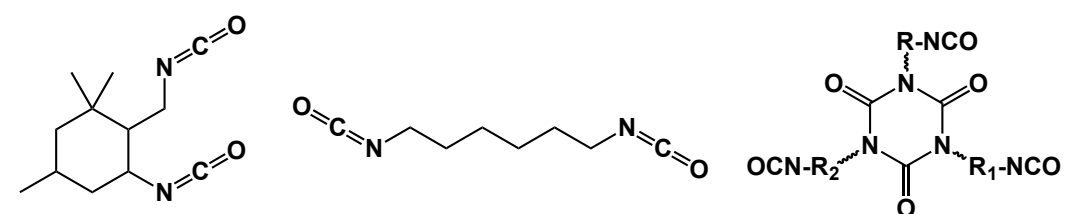

Figure 2.3.4. Three different isocyanates (from the left to right) (IPDI, HMDI and Desmodur N3300).

After observing the hardness between isocyanates, we were also interested to see the difference in hardness between the coating with acetylated and unacetylated TR-SBO resin. The unacetylated TR-SBO has twice the crosslink sites than acetylated TR-SBO per molecule (both permanent $[4.4 \mathrm{OH}]$ and reversible $[4.4 \mathrm{OH}]$ linkages) while the acetylated TR-SBO contained only the reversible crosslink site (see Table 2.3.2). The difference in number of available alcohols is reflected in the hardness of the coatings.

Table 2.3.2. Calculated crosslink sites both permanent and reversible for IPDI coatings.

\begin{tabular}{c|cc|cc}
\hline TR-SBO & \multicolumn{2}{|c|}{$\begin{array}{c}\text { Acetylated Resin } \\
\text { \# Crosslink site/ molecule }\end{array}$} & \multicolumn{2}{c}{$\begin{array}{c}\text { Unacetylated Resin } \\
\text { \# Crosslink site/ molecule }\end{array}$} \\
\hline \% Diels Alder & Permanent & Reversible & Permanent & Reversible \\
100 & 0 & 4.4 & 4.4 & 4.4 \\
54 & 0 & 2.4 & 4.4 & 2.4 \\
30 & 0 & 1.3 & 4.4 & 1.3 \\
\hline
\end{tabular}

As shown in Figure 2.3.5, unacetylated coatings are much harder than acetylated coatings. As the crosslink density of the polyol is increased, the coating becomes denser and therefore harder. Regardless of whether TR-SBO is acetylated or not, 100\% DA TRSBO still displayed the hardest coatings. As mentioned previously in the acetylated TR- 
SBO discussion, increasing the amount of phenolic maleimide increases the crosslink density as it provided additional phenols. Here is the same trend: the maximum amount of DA present (100\%) confers the highest crosslink density and therefore hardness.

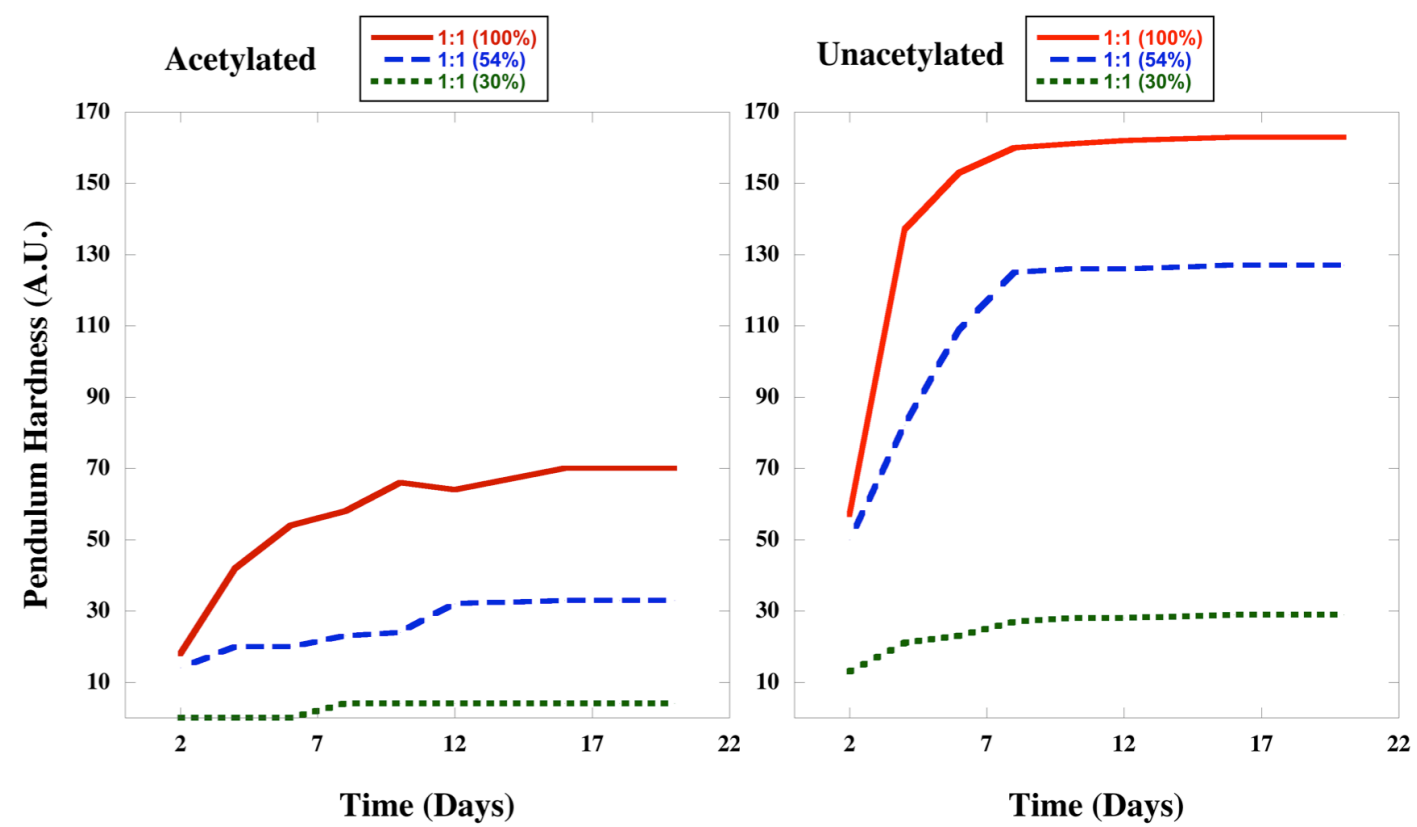

Figure 2.3.5. Hardness data of coating using IPDI as isocyanate using both acetylated (left) and unacetylated (right) with 100\% DA TR-SBO.

\section{Crosscut Result}

The adhesion of a coating to a substrate dictates how durable the coating is against scratches and aging. The first formulation with Desmodur showed that as the $\mathrm{NCO}: \mathrm{OH}$ ratio goes down, the adhesion of the coating to the substrate worsens.

Desmodur at a 1:1 ratio was the most viscous upon adding the TR-SBO. It has been shown previously that as the viscosity increases there is an increase in wettability on the substrate which strengthens the mechanical interlocking and anchorage of the coating into pores and irregularities of the substrate. ${ }^{14}$ The difference in trend between Desmodur and the other two isocyanates, HMDI and IPDI, is their viscosity. Adhesion in coating often relies on the viscosity of the coating and also high crosslink density that creates 
stronger cohesion within the coating. ${ }^{14,15}$ In the case of Desmodur N3300 coatings, the viscosity and the greater number of isocyanates per molecule within Desmodur (i.e., crosslink density) may help to create better adhesion to the substrate.

HMDI showed that as the ratio of $\mathrm{NCO}: \mathrm{OH}$ increases the adhesion worsens. The poor adhesion can be attributed to the difference in chemical structure between HMDI and the other isocyanates. HMDI consist of entirely primary isocyanates which means that it will cure faster than IPDI (has both primary and secondary). This faster cure time can result on poor adhesion. IPDI showed a vast improvement of adhesion as the $\mathrm{NCO}: \mathrm{OH}$ ratio was increased. There is a balance between the ratio of $\mathrm{NCO}: \mathrm{OH}$ that is necessary in order to get a coating that when scratched did not flake off (like IPDI 5:1 and Desmodur 1:1).

Next, for HMDI and IPDI (low viscosity isocyanates), with the increased ratio of isocyanates the coating viscosity decreases. The low viscosity tends to create a qualitatively thinner film due to easier leveling. Again with different ratios, IPDI coatings seem to be able to achieve the balance between hardness and adhesion. The increased ratio of isocyanates hardly makes the difference in the coatings. Because of the good adhesion results, the change in \%DA for the coating was used with IPDI.

Coatings prepared with less DA $(54 \%, 30 \%)$ tended to be more tacky than those with $100 \%$ DA. The more tacky coatings created more adhesion to the substrate, therefore, with the decrease of DA in TR-SBO, the coating cross cut is improved. The same tacky coating was also found in the control panel, which showed good adhesion. However, as discussed previously, the tacky material tends to have low hardness. The balance between the hardness and adhesion is needed for a desirable topcoat coating. 


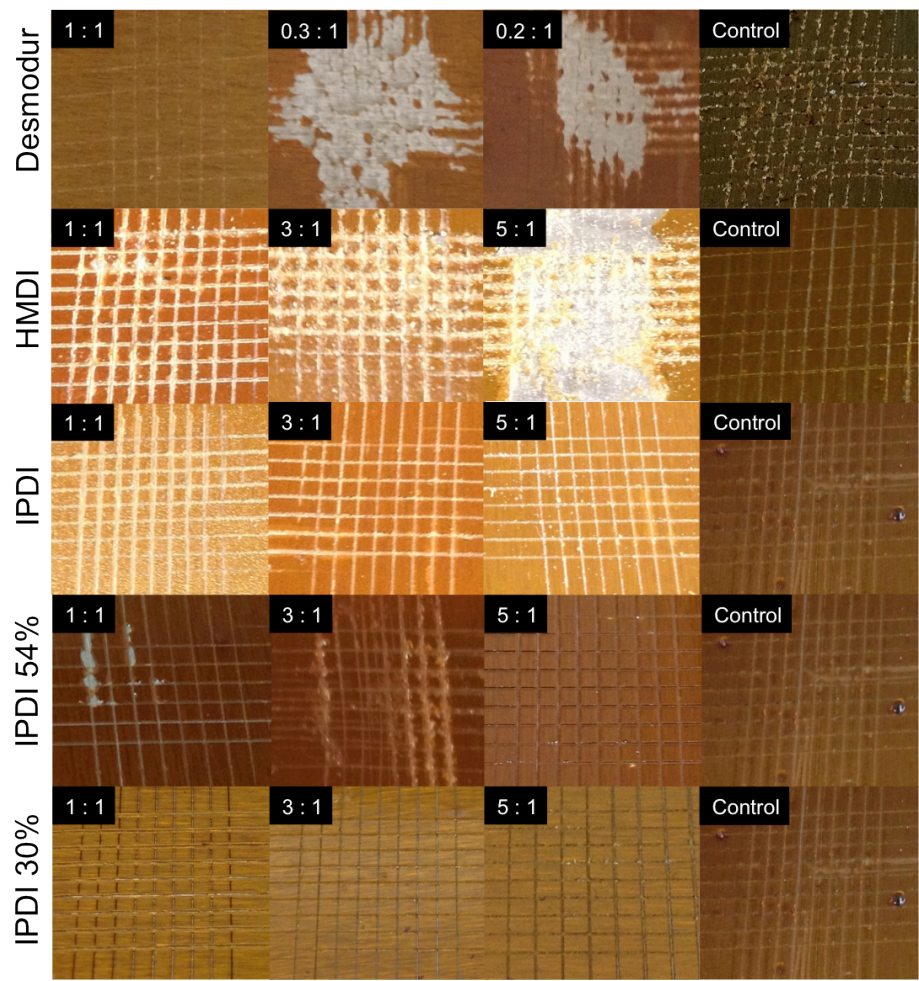

Figure 2.3.6. Crosscut of coating using three different isocyanates (Desmodur N3300, IPDI and HMDI) with various percentage Diels-Alder of TR-SBO.

Besides observing the trend in changing the percentage of DA TR-SBO, the observation for acetylated and unacetylated TR-SBO was also made using IPDI as consistently good coating with the ratio 1:1 (see Figure 2.3.7). As seen previously, the decreased percentages of DA in TR-SBO increased the adhesion of the coating to the panel. However, the adhesion of the unacetylated coatings to the substrate generally is poor. The high functionality of unacetylated TR-SBO with reversible and permanent crosslink sites might be the cause of this poor adhesion. A similar study of cellulose based resin also showed the same poor adhesion when the functionality is too high. ${ }^{16}$ 


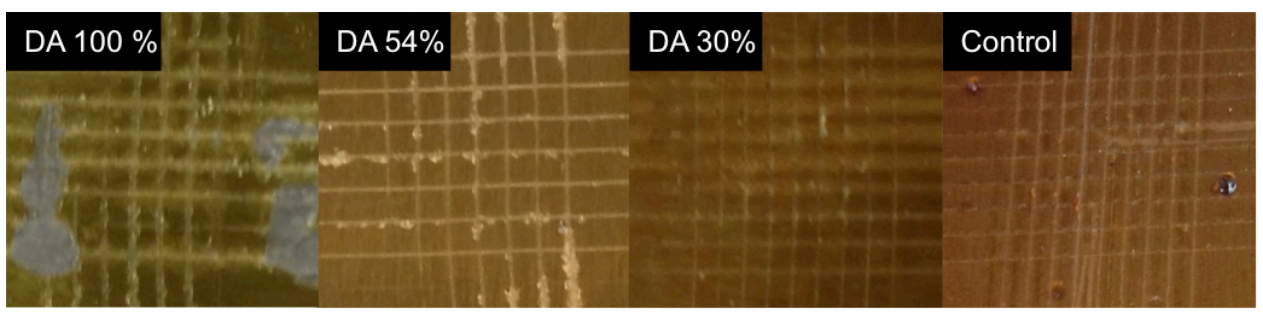

Figure 2.3.7. Crosscut of coating using IPDI as isocyanates with various percentages Diels-Alder of unacetylated TR-SBO.

\section{Gloss Results}

To quantify the re-healability of the coating could be a challenging task since there is not exactly a unit that defines re-healability. For TR-SBO coating, the rehealability can be triggered using heat and relies on the retro Diels-Alder reaction. Rehealable property was observed with some coatings such as IPDI re-healing better than the Desmodur coating (see Figure 2.3.8).

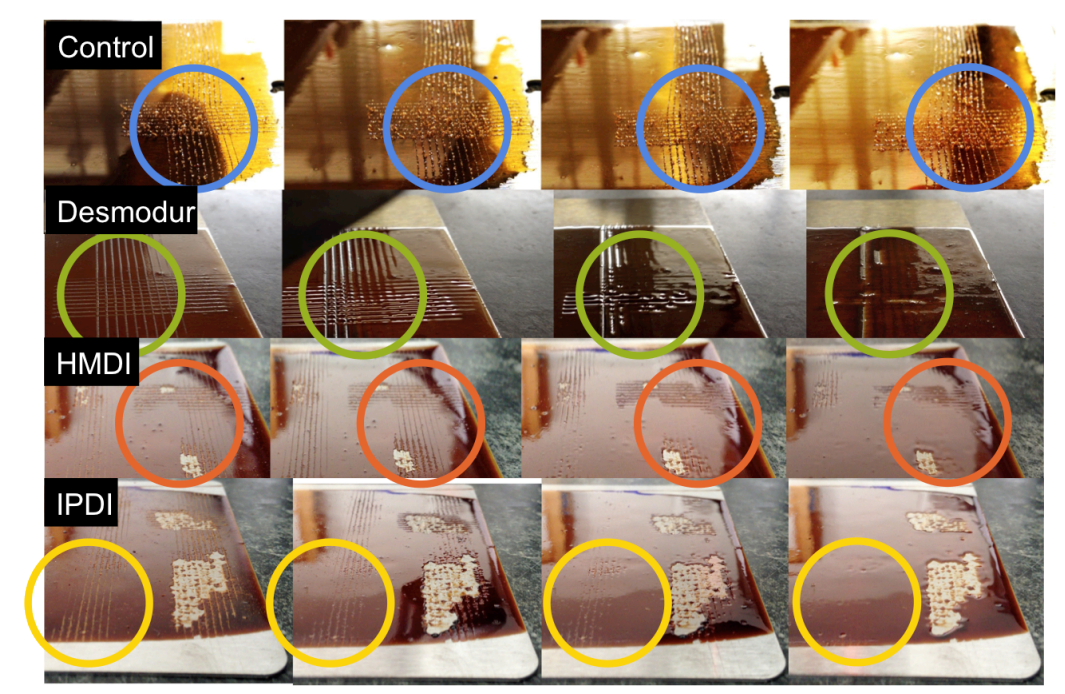

Figure 2.3.8. Re-healability of the coating employing three different isocyanates (Desmodur N3300, IPDI and HMDI) with 100\% Diels-Alder of TR-SBO.

However, observing the re-healability alone did not provide a way to quantify the re-healability of the coating. To be able to solve this issue, the re-healability was quantify using the concept of gloss. A damaged coating will have a rougher surface than 
the regular non-damaged coating, which causes the gloss value to goes down. Using this, we can roughly quantify the re-healability of the coating by measuring original gloss (virgin), gloss after damage (scratched), and gloss after heating (healed). After damage has occurred on the coating the gloss goes down due to diffuse reflection. Then, heating the coating should trigger the coating to flow and create a new smooth surface, which will improve the gloss.

In the first part of the study we analyzed the difference in gloss (re-healability) of coatings (IPDI, HMDI, and Desmodur) containing DA to a control coating that did not contain any DA. It is observed that the control did not re-heal like coatings containing DA (true in all three different isocyanates). The DA coatings undergo the retro DielsAlder reactions when heated, causing the scratched gloss value to improve tremendously after heat treatment (see Figure 2.3.9). It is important to note that not all coatings have the same initial gloss. This could be due to differences in the isocyanates, or differences in the resin from batch to batch.

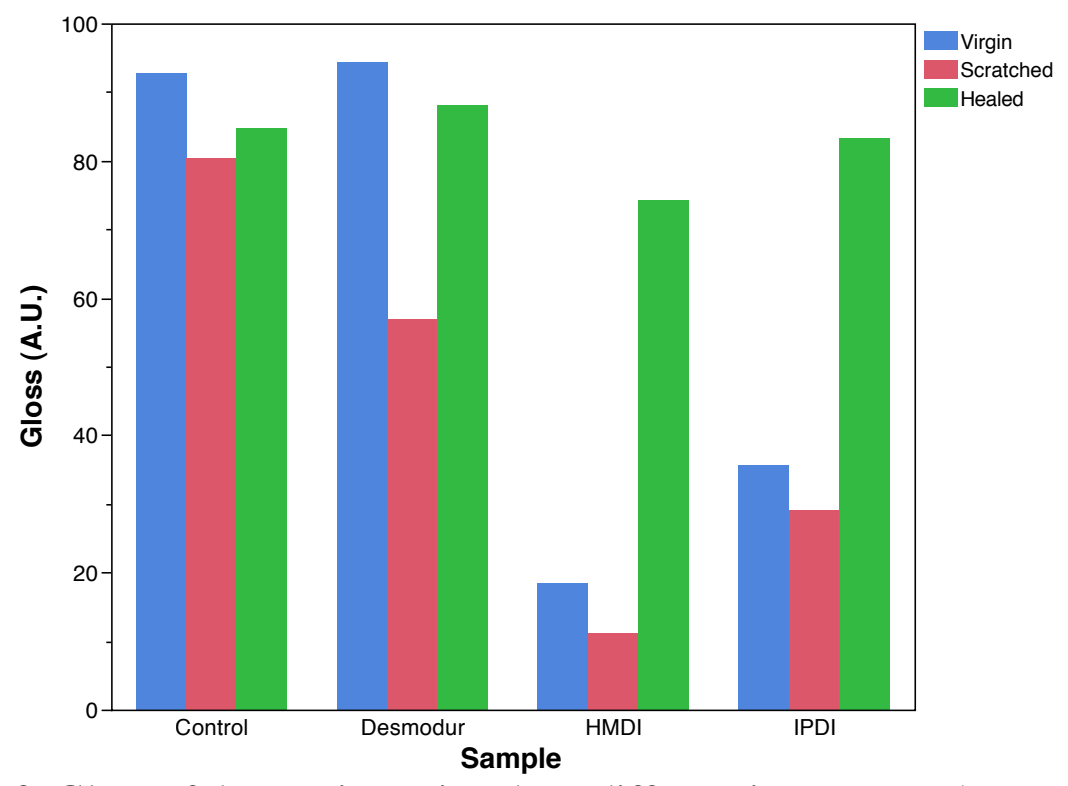

Figure 2.3.9. Gloss of the coating using three different isocyanates (Desmodur N3300, IPDI and HMDI) 1:1 ratio isocyanate to alcohol. 
Next the NCO:OH ratio was changed while using the $100 \%$ DA TR-SBO resin. In general, as the ratio of $\mathrm{NCO}: \mathrm{OH}$ increases the improvement in gloss decreases for all three different isocyanates (see Figure 2.3.8). A tabulated value for gloss improvement was calculated using Equation 1.

$$
\text { Gloss Improvement } \%=\frac{(\text { Healed-Scratched })}{\text { Scratched }} \times 100
$$

This equation allowed for a single number to compare the re-healability of coatings prepared with different $\mathrm{NCO}: \mathrm{OH}$ ratios and isocyanates. As shown in Figure 2.3.10, the gloss improvement values for each isocyanate included the control (IPDI) with different ratios of $\mathrm{NCO}: \mathrm{OH}$. The gloss improvement percentage for the control was $5 \%$. This improvement could be due to the removal of residual plasticizer retained within the coating, altering the gloss. Increasing the $\mathrm{NCO}: \mathrm{OH}$ ratio could cause the decrease in gloss improvement by increasing the cure time and the lack of as many reversible crosslinks. If for every available $\mathrm{OH}$ there are five $\mathrm{NCO}$, then the coating will cure fast and the residual isocyanates will eventually react and form non-reversible crosslinks. From this, the re-healability of the 5:1 coatings for IPDI and HMDI should have the lowest improvement in gloss. Interestingly, IPDI 3:1 showed a significant increase in gloss improvement relative to the 3:1 for HMDI. The fact that all samples do not have the same initial gloss could be the cause for this. As evidenced by more samples, those that re-heal tend to have a gloss improvement greater than five percent. Samples that re-heal but have a lower initial gloss tend to show the largest improvement in gloss. 


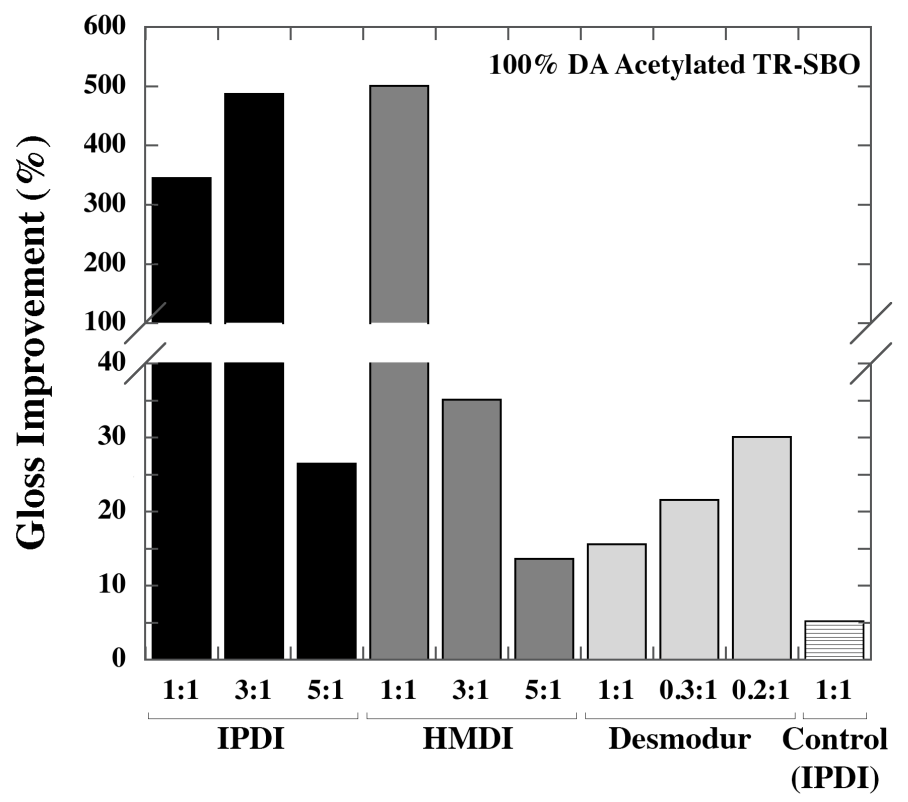

Isocyanate/Ratio

Figure 2.3.10. Improvement in gloss for three different isocyanates at three different ratios including the control (FSBO).

Coatings also did not surpass their virgin gloss states. This can be observed in 5:1 IPDI or HMDI that showed a higher virgin gloss value than after being healed. The same observation is also found in 1:1. This might be explained by the increase in hard blocks in the coating due to increase of isocyanates. ${ }^{17}$ The hard blocks that formed in the coating tend to lock with each other, which increases the resistance to flow. Because the coating cannot reflow fully it cannot always obtain the same initial gloss as the virgin coating.

\section{Virgin Coating}

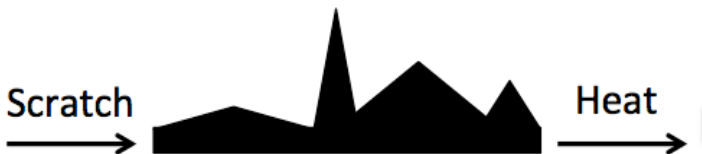

Figure 2.3.11. Mechanism for decreased gloss values for different treatments of panels.

Desmodur (1:1) showed the lowest gloss improvement when compared to the 0.2:1 ratio (see Figure 2.3.10). Due to the decreased amount of Desmodur, the properties of the coating at the $0.2: 1$ ratio are dictated by the TR-SBO rather than isocyanates. Some isocyanates also showed different trends of re-healability. IPDI 1:1 and HMDI 1:1 
showed better gloss improvement than Desmodur 1:1. This can be explained by the difference in viscosity of the isocyanates. More viscous isocyanates have less flow than non-viscous isocyanates. ${ }^{18}$ Desmodur has a very high viscosity (honey like) and is much more difficult to flow than IPDI or HMDI. The high viscosity as a precursor is likely due to Desmodur's ability to trimerize and form a network of isocyanurates. This preexisting network is further crosslinked with the TR-SBO. The existence of the isocyanurates may inhibit re-healability as they themselves are not thermally reversible crosslinks. Even if all reversible linkages in the coating (Desmodur with TR-SBO) broke, the remaining viscous network of Desmodur would not allow for as much flow as HMDI and IPDI. Additionally, Desmodur coatings with NCO:OH ratios greater than 1:1 did not show any re-healability.

IPDI showed the best re-healability among all three isocyanates since the gloss value after healing was either better or the same as the virgin gloss value. Due to consistent results with IPDI, IPDI was chosen to be the isocyanate used in further studies.

The time dependence of the gloss studies was also done in increments of every four days. Each day, a different panel made from the same batch was subjected to a scratch and a re-heal. The data of the gloss measurements is presented in Figure 2.3.12. 

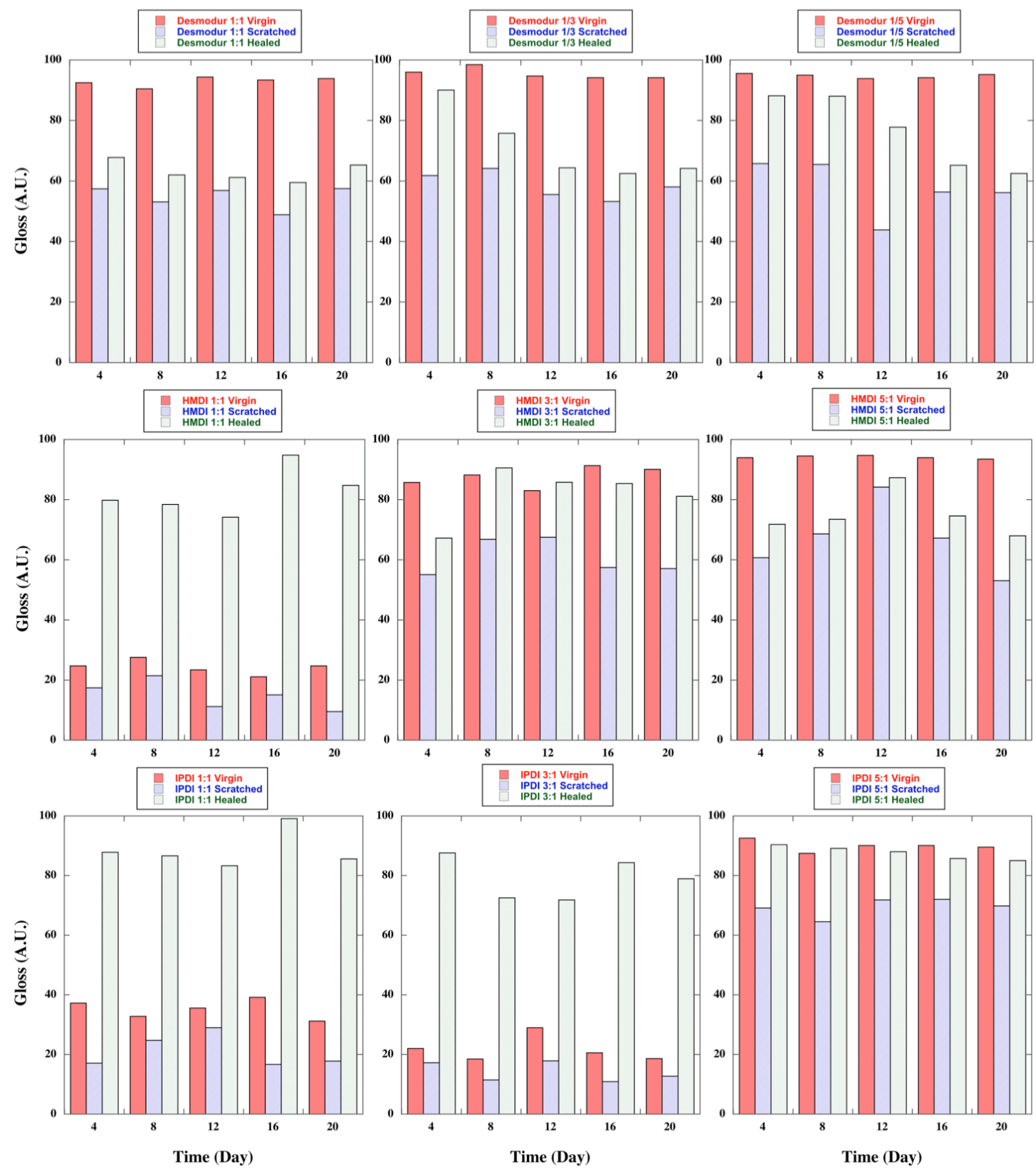

Figure 2.3.12. Gloss of the coating using three different isocyanates (Desmodur N3300, IPDI and HMDI) in various ratio $(1,3,5)$ with $100 \%$ Diels-Alder of acetylated TR-SBO.

Desmodur in the time dependent study showed a decrease in the ability to re-heal over time for the 0.3:1 and 0.2:1 ratios. IPDI and HMDI showed a time independent rehealability. From this, Desmodur was excluded from further analysis as a potential isocyanate, due to its lack of consistent gloss improvement. Additionally, from the 
crosscut adhesion tests and the hardness data, HMDI was excluded from time dependent studies. IPDI showed the optimal balance of adhesion, re-healability, gloss improvement, and hardness.

Unlike the hardness and crosscut data, changing the percentage of DA in TR-SBO while keeping the isocyanate constant (IPDI) hardly had an impact on the re-healability of the coatings. Coatings made with 54\% and 30\% TR-SBO using IPDI almost have the same exact trend over 20 days (see Figure 2.3.13 and 2.3.14).

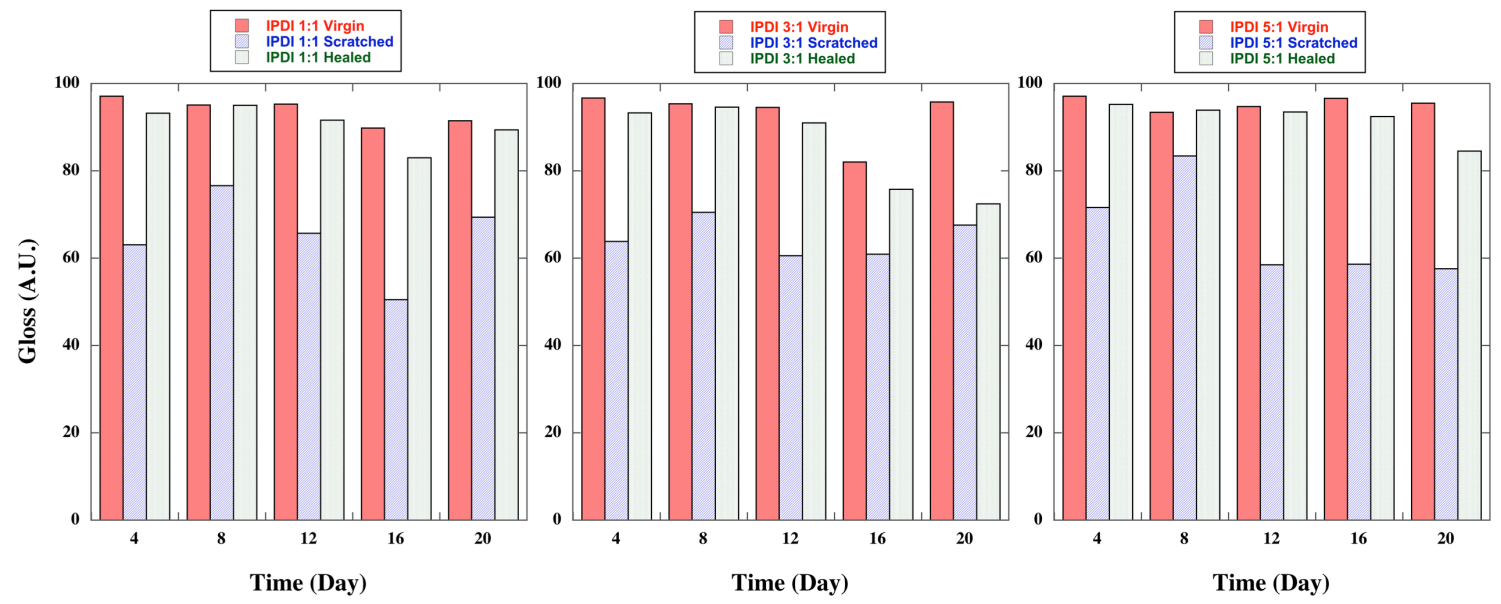

Figure 2.3.13. Gloss measurements of IPDI under various ratios $(1,3,5)$ using a $54 \%$ Diels-Alder acetylated TR-SBO.
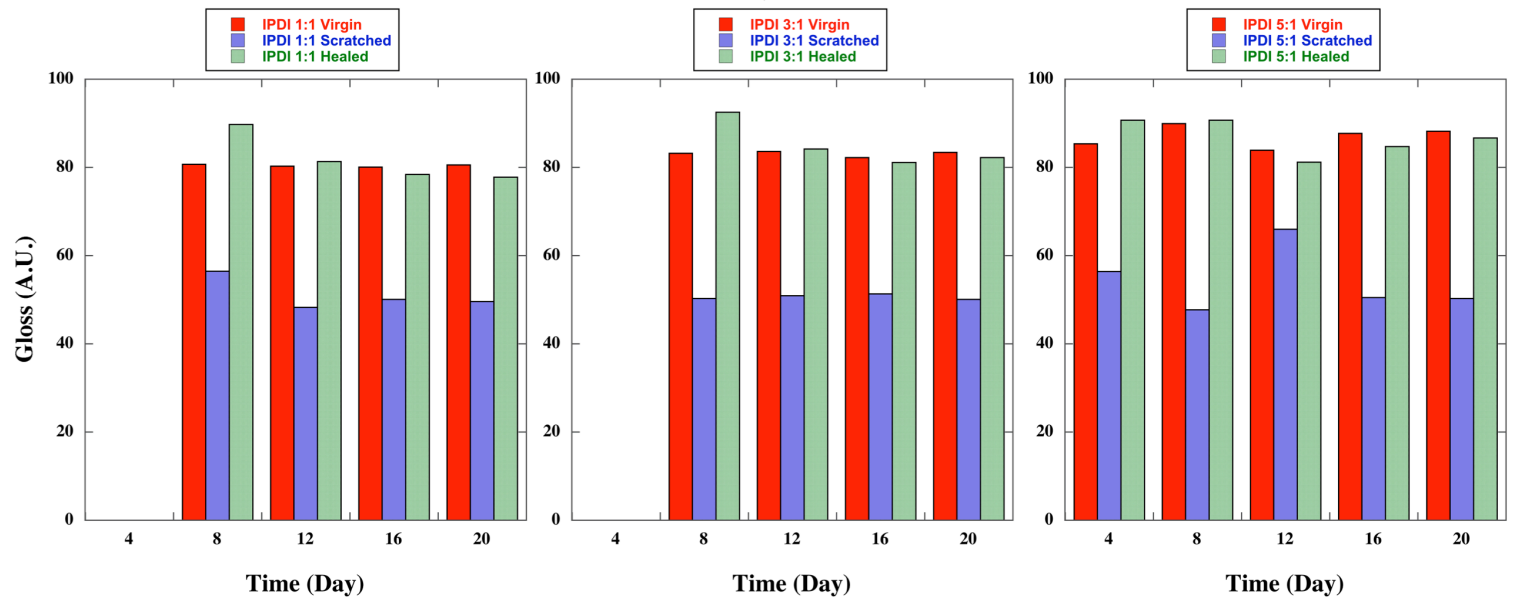

Figure 2.3.14. Gloss of the coating using IPDI in various ratios $(1,3,5)$ with $30 \%$ DielsAlder acetylated TR-SBO. 
The same gloss study was also done using unacetylated 100\% DA TR-SBO employing IPDI as the isocyanate. Interestingly, unacetylated TR-SBO made high gloss coatings that showed great gloss improvement (Figure 2.3.15). Even though the coating contains a mixture of both reversible and nonreversible linkages, the coating is able to achieve a similar gloss to virgin gloss value.

The gloss improvement percentage of IPDI 1:1 coatings made with different percentages of DA was studied (Figure 2.3.15). As the percent of DA in the unacetylated coatings went down, the gloss improvement went down as well. The time dependent data also showed that the unacetylated coatings produced high gloss and very reproducible gloss improvement (Figure 2.3.16).

Acetylated coatings showed that as there was an increase in $\mathrm{NCO}: \mathrm{OH}$ from 3:1 to 5:1 and a decrease in \%DA, the gloss improvement increases (Figure 2.3.17). As there is an increase in isocyanate and a decrease in the amount of crosslink sites, the gloss improves more. This means that the less crosslinks formed the easier it is for the coating to improve in gloss. 


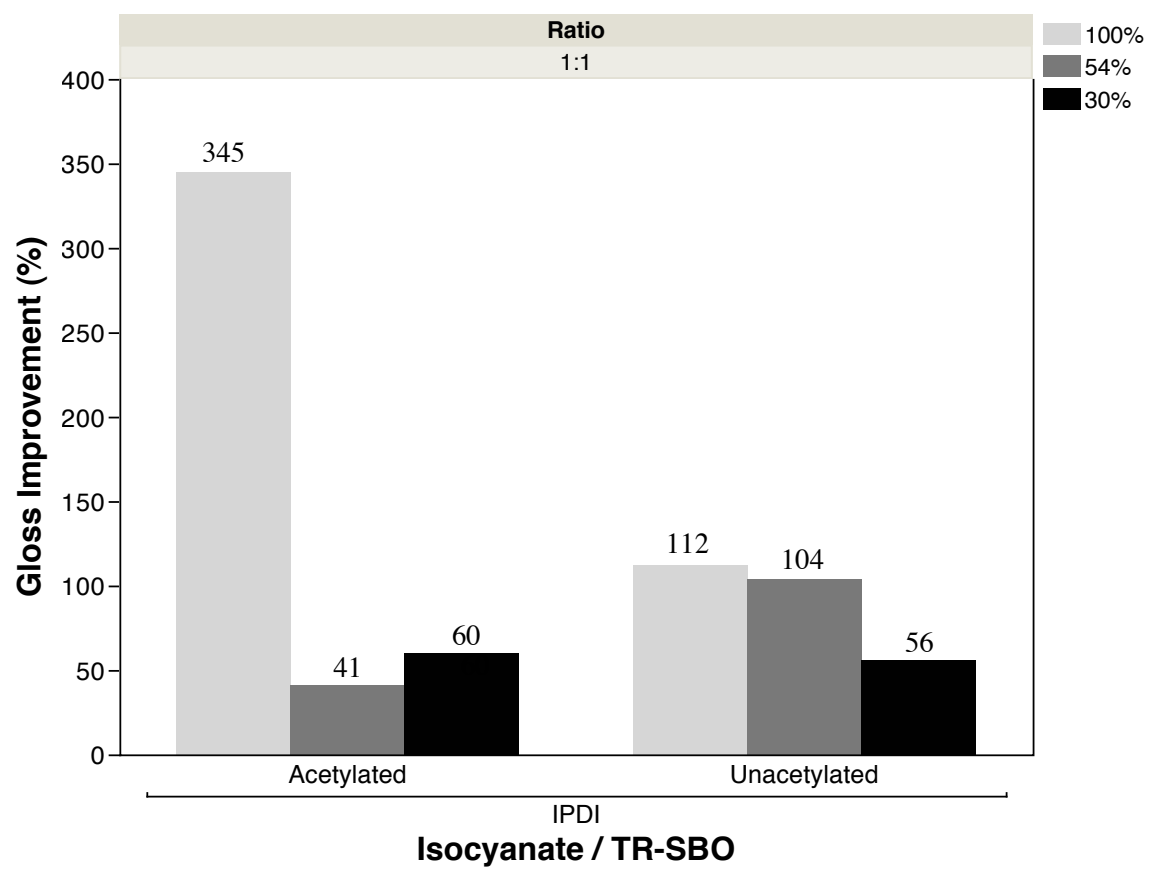

Figure 2.3.15. Comparison between acetylated (left) and unacetylated (right) coatings with different percentages of Diels Alder.

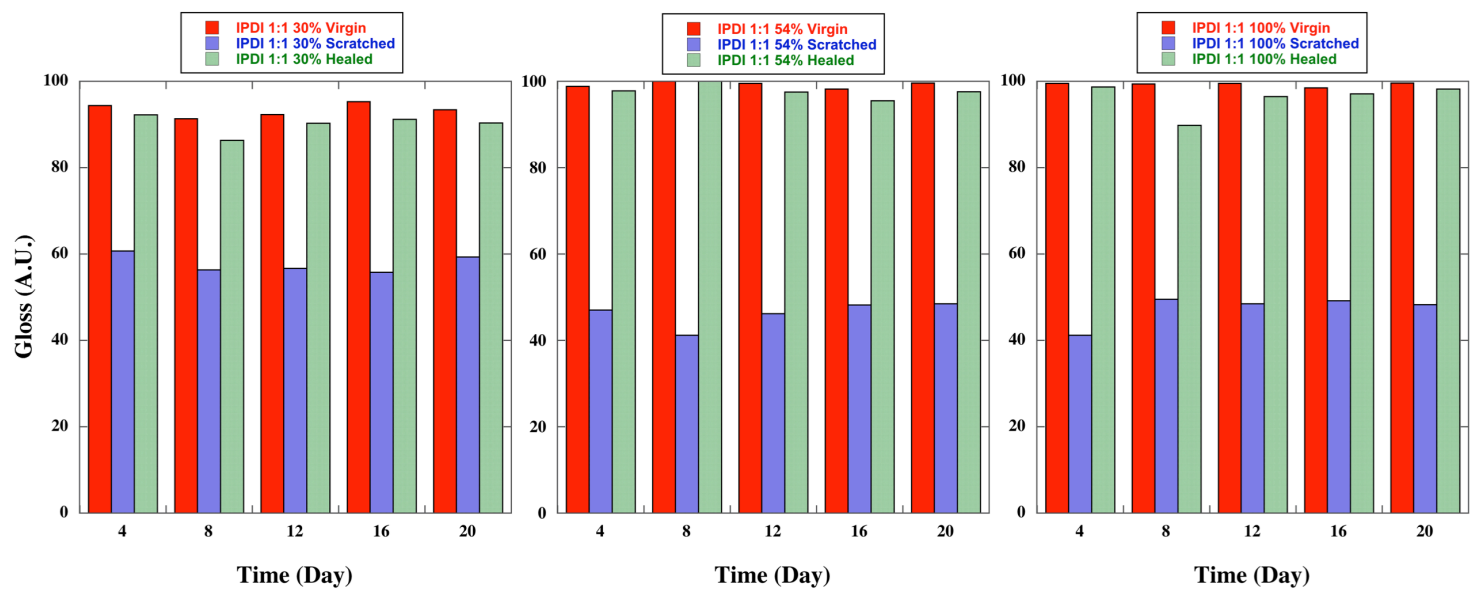

Figure 2.3.16. Gloss of the coating using IPDI 1:1 ratio with 30\%, 54\%, and 100\% Diels-Alder unacetylated TR-SBO. 


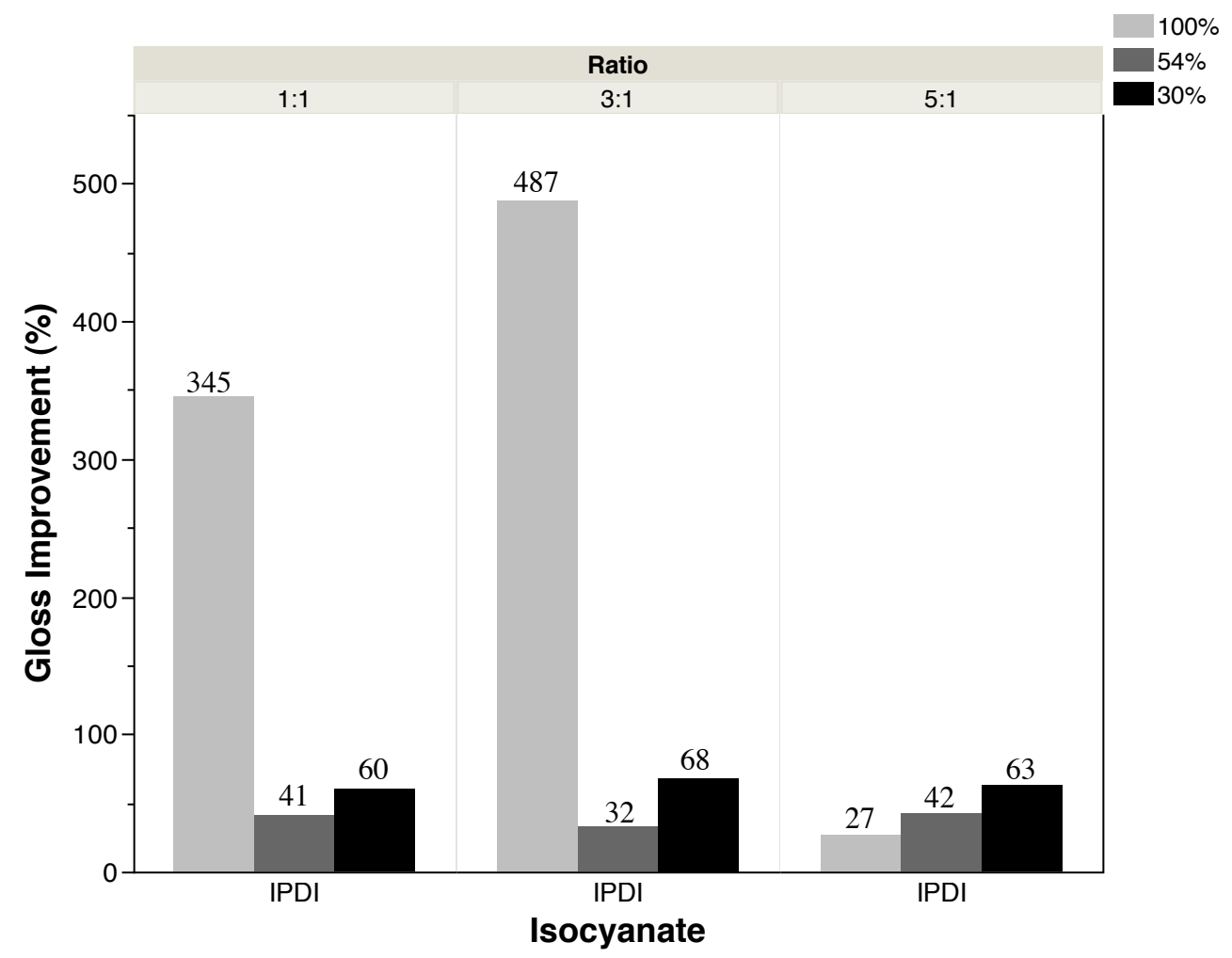

Figure 2.3.17. NCO:OH ratio effect on acetylated TR-SBO with varying amounts of DA.

While the optical properties of the coating are promising, the poor adhesion and hardness prevent the unacetylated coatings from industrial use as an automotive topcoat.

\section{Coating of choice}

After observing the coating properties, it is found that the best coating with balance in hardness, crosscut and gloss is 5:1 IPDI with 54\% DA acetylated TR-SBO. One of reasons that $54 \% \mathrm{DA}$ is give the best coating in re-healability is due to excess of dangling furan chains. The extra furan that does not react with the phenolic maleimide, becomes available to react with the maleimide once the Diels Alder linkages have broken (see Figure 2.3.18). This makes it easier for the rDA reaction to occur, therefore the rehealability is significant improved compared to $100 \%$ DA TR-SBO. In the 100\% DA TRSBO when all of the DA linkages break when heated, the likely hood of all the 
maleimides finding a furan is low, therefore decreasing its re-healability. Using IPDI in a 5:1 ratio with the 54\% DA TR-SBO resin also had good adhesion since it contains a lot of isocyanates that help to create an anchor to the substrate. Further studies of this coating, including TGA analysis, DSC, ImageJ analysis, and multiple re-heal experiments, were performed.
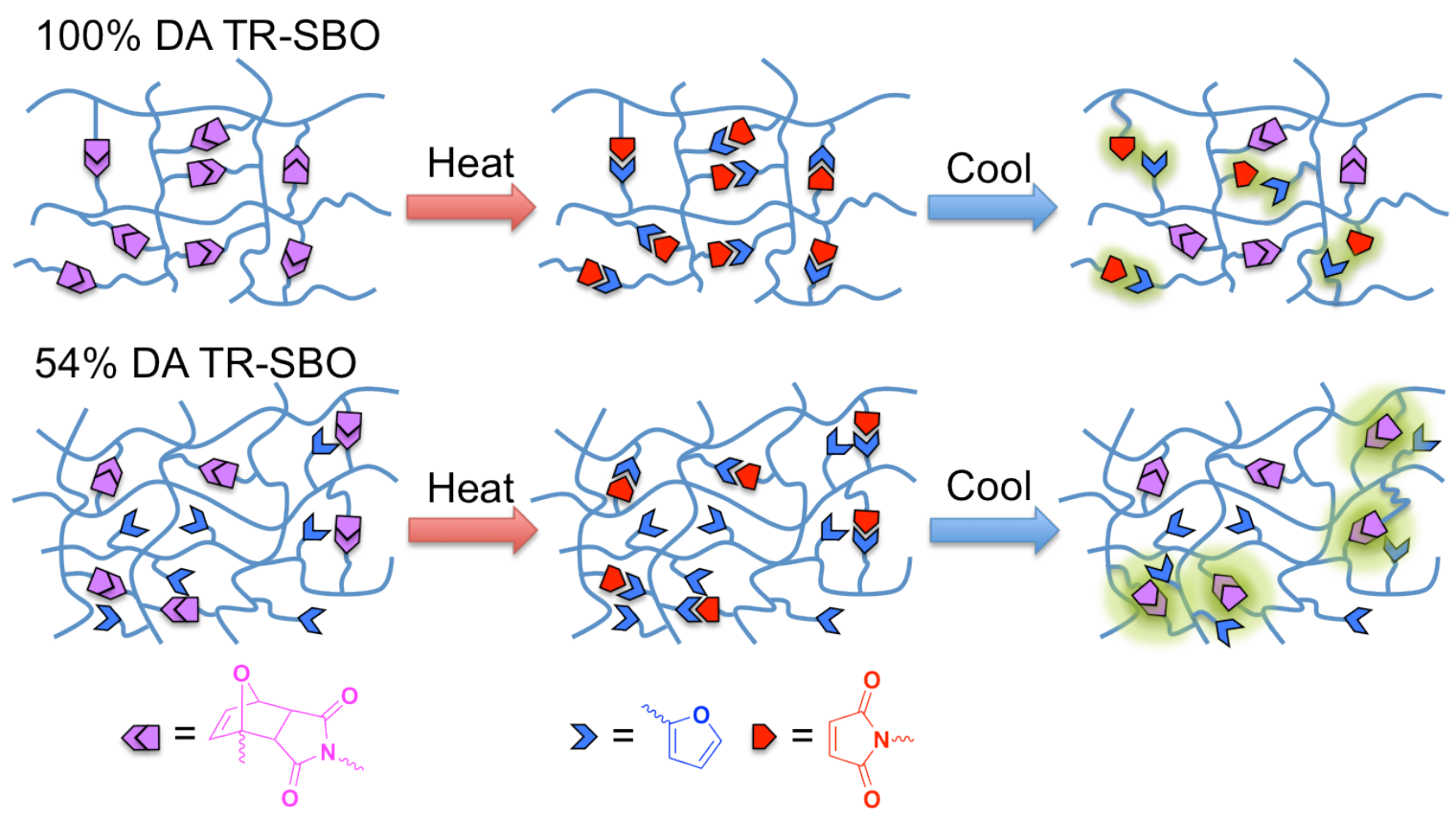

Figure 2.3.18. The effect of excess furans on re-healabilty of TR-SBO.

TGA analysis of 5:1 IPDI with 54\% DA acetylated TR-SBO showed a consistent loss of a small amount of solvent over time (see Figure 2.3.19). After 0.5 hour of heating in the oven at $35^{\circ} \mathrm{C}$, there is approximately $\sim 2 \%$ solvent loss at $140^{\circ} \mathrm{C}$. The gradual shift toward the right as the coating ages shows that the coating is losing more solvent into Day 6. 


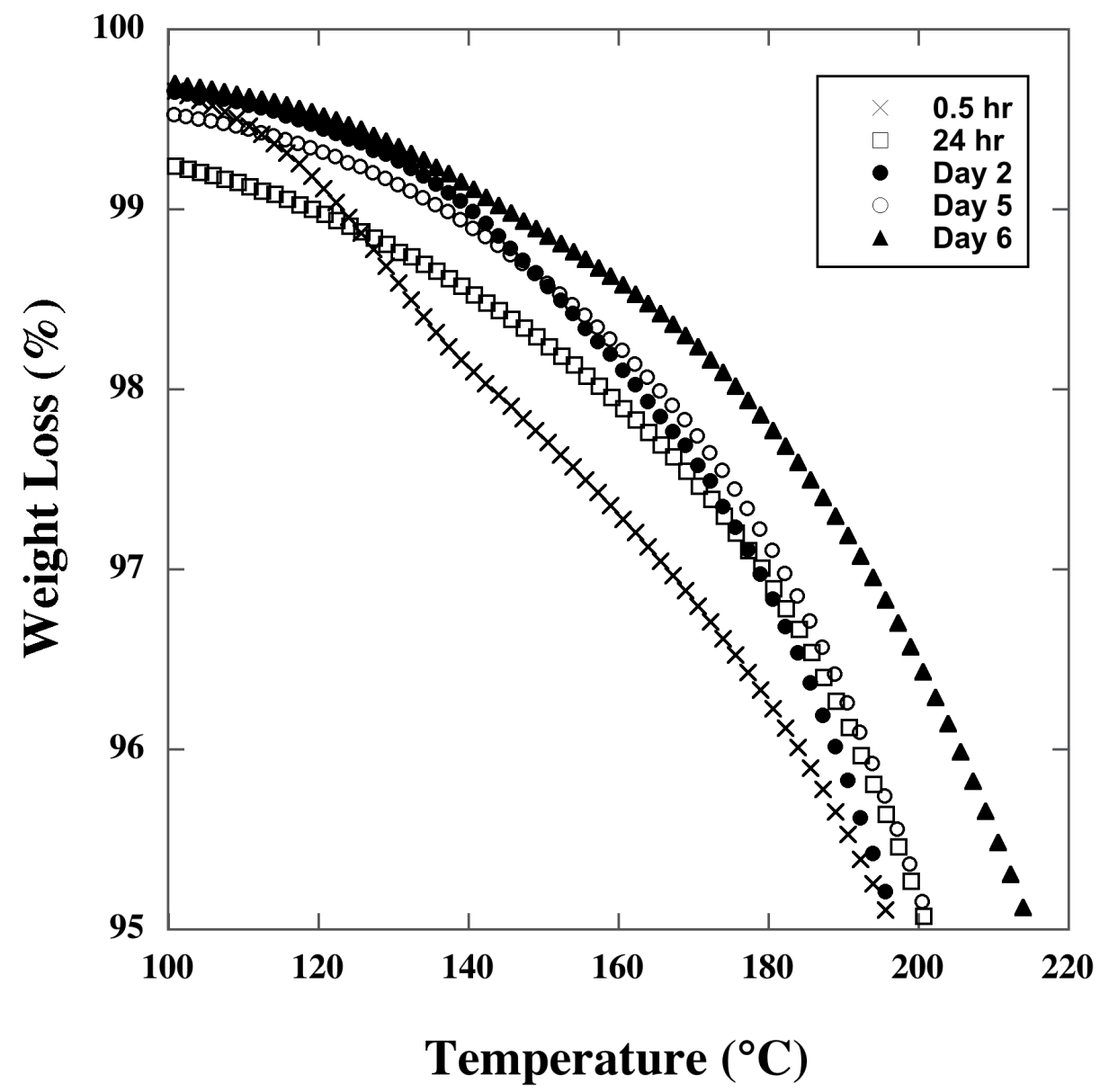

Figure 2.3.19. TGA analysis of IPDI 5:1 ratio with 54\% DA unacetylated TR-SBO.

A DSC study of 54\% DA unacetylated TR-SBO showed a large endotherm peak due to breaking of the Diels-Alder adduct starting at $100^{\circ} \mathrm{C}$ (see Figure 2.3.20). This type of endotherm peak has been observed before in another retro Diels-Alder study with range temperature start at $95^{\circ} \mathrm{C}$ to $150^{\circ} \mathrm{C} .{ }^{19}$ 


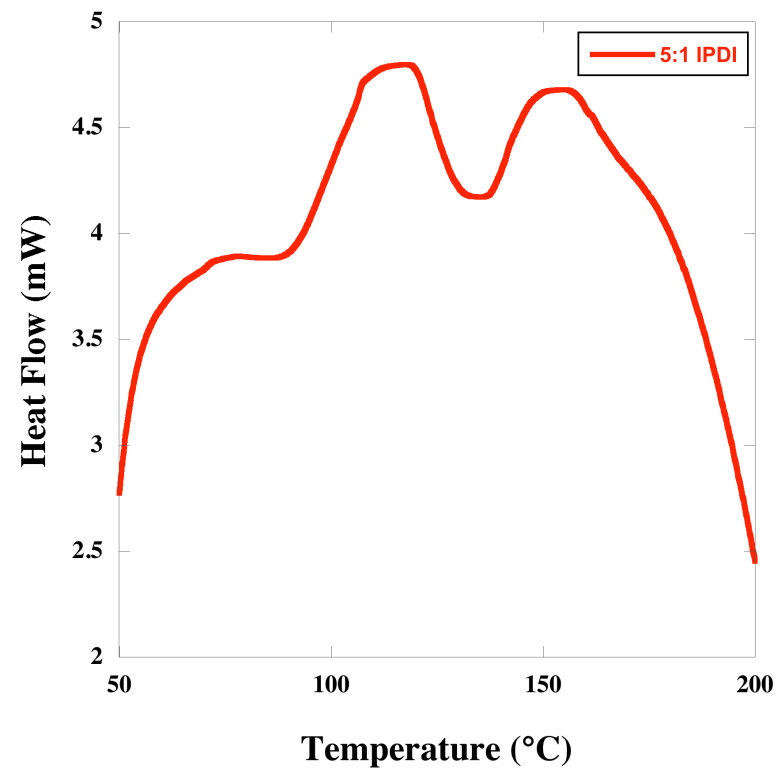

Figure 2.3.20. DSC analysis of IPDI 5:1 ratio with 54\% DA unacetylated TR-SBO.

Aside from using gloss as a way to quantify data, ImageJ software analysis was taken to see the extent of re-healing. The data shown in Figure 2.3.20 shows the clear difference between a coating that contains DA (right) and the control (no DA, left). The control data intensity is relatively the same before and after healing, while the coating with DA showed tremendous improvement after crosscut. The slight decrease in intensity from the control is consistent with the gloss data in showing that there is, to a small extent, some (but negligible in comparison) re-healability within the control coating. The 54\% DA acetylated TR-SBO, however, shows how the intensity of the line created from the cut is absent after heat treatment (see Figure 2.3.21). 

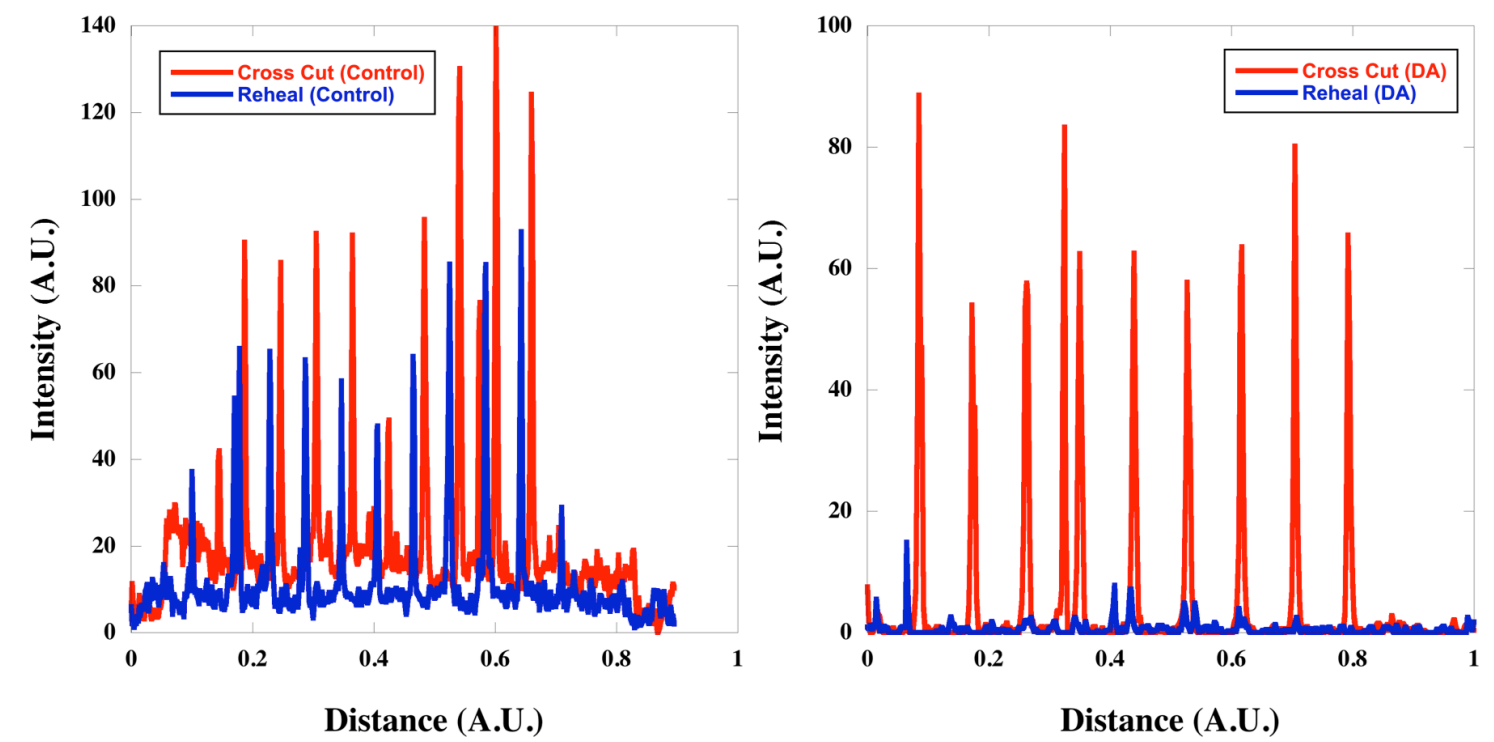

Figure 2.3.21. ImageJ analysis of control coating (IPDI 1:1 FSBO) and IPDI 5:1 ratio with 54\% DA unacetylated TR-SBO (Day 12).

The last study examined the ability of the coating to re-heal in the same spot that had been re-healed before. The ability of the coating to re-heal at the same spot that has been damaged before is certainly a desirable property. The measurement of gloss after the first healing and second healing was done on both control (IPDI 1:1 FSBO) and IPDI 5:1 54\% DA unacetylated TR-SBO (see Figure 2.3.22). The control panel showed that the gloss decreased from one scratch after another without showing any improvement upon heating. IPDI 5:1 54\% DA unacetylated TR-SBO showed good re-healability after the first scratch and then a slight decrease in re-healability was observed for the second reheal. This often happens with rDA chemistry since not all the Diels-Alder adducts were reformed after the first healing cycle. 

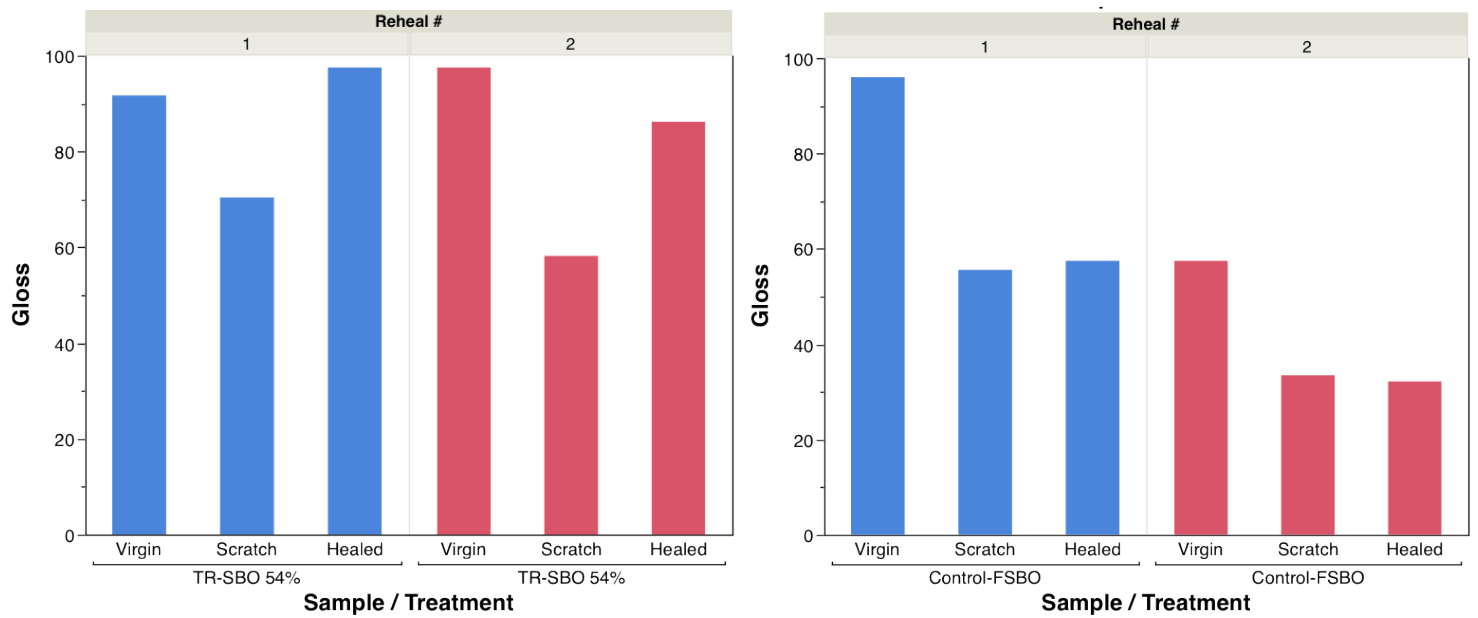

Figure 2.3.22. Left: IPDI 5:1 ratio with $54 \%$ Diels-Alder of TR-SBO Right: gloss of control coating (IPDI 1:1 FSBO) for the first and second cycle of healing at the same spot.

\subsection{Conclusion}

Common properties for an automotive topcoat with re-healable properties were analyzed. An ideal re-healable automotive topcoat should be hard, have high gloss, strong adhesion, and good re-healability. After making several panels with various ratios of different isocyanates to TR-SBO, an obvious balance was needed to maintain all of the desirable coatings. It was found that Desmodur at a 1:1 ratio had a great adhesion yet failed to show much improvement in gloss after being damaged. Lower ratios $\mathrm{NCO}: \mathrm{OH}$ using Desmodur resulted in improved re-healability at the cost of adhesion as the bulk properties of the TR-SBO dominated the coating.

HMDI showed that as the $\mathrm{NCO}: \mathrm{OH}$ ratio was increased the adhesion resistance decreased as the coating became more crystalline. The gloss improvement for HMDI 1:1 did exceed the control, yet not as drastically as IPDI. IPDI showed an increase in adhesion with an increase in isocyanate along with the best gloss improvement percentage after being damaged. A comparison of acetylated and unacetylated TR-SBO with IPDI showed that unacetylated TR-SBO at 54\% and 30\% DA was tackier even up to 
day 20. Among the various ratios of acetylated TR-SBO, only the IPDI 5:1 54\% DA unacetylated TR-SBO coatings showed a clear balance of hardness, good re-healability, gloss, and adhesion. ImageJ analysis further vetted the ability of the coating to re-heal. DSC analysis showed the coating contains the rDA chemistry that is incorporated within the coating allowing it to re-heal. TGA analysis shows a small amount of plasticizer remains within the coating over time. The ability for the coating to re-heal more than once was shown to a lesser extent by gloss measurements.

Future studies include analyzing the surface topology of the coating from scratched to re-healed. Additionally titrations of the hydroxyl count for the various percentages of DA in the TR-SBO will provide further evidence for the increase in crosslink density provided by an increase in phenols. Finally, the incorporation of a different rDA adduct, one that is UV responsive, will be developed and incorporated into the same system. 


\section{References:}

(1) Future, C. O. A. E.; National Academy of Sciences; National Academy of Engineering; National Research Council America's Energy Future; National Academies Press, 2009.

(2) Li, F.; Hanson, M. V .; Larock, R. C. Soybean oil-divinylbenzene thermosetting polymers: synthesis, structure, properties and their relationships. Polymer 2001, 42, 1567-1579.

(3) Meyer, P. P.; Techaphattana, N.; Manundawee, S.; Sangkeaw, S.; Junlakan, W.; Tongurai, C. Epoxidation of soybean oil and jatropha oil. Thammasat International Journal of Science Technology 2008, 13, 1-5.

(4) Sharma, B. K.; Perez, J. M.; Erhan, S. Z. Soybean Oil-Based Lubricants: A Search for Synergistic Antioxidants †. Energy Fuels 2007, 21, 2408-2414.

(5) Ionescu, M.; Petrović, Z. S.; Wan, X. Ethoxylated Soybean Polyols for Polyurethanes. J Polym Environ 2007, 15, 237-243.

(6) Guo, A.; Javni, I.; Petrovic, Z. Rigid polyurethane foams based on soybean oil. J Appl Polym Sci 2000, 77, 467-467.

(7) Bähr, M.; Mülhaupt, R. Linseed and soybean oil-based polyurethanes prepared via the non-isocyanate route and catalytic carbon dioxide conversion. Green Chem. 2012, 14, 483.

(8) Hong, C. K.; Wool, R. P. Development of a bio-based composite material from soybean oil and keratin fibers. J Appl Polym Sci 2005, 95, 1524-1538.

(9) Gerbase, A. E.; Petzhold, C. L.; Costa, A. P. O. Dynamic mechanical and thermal behavior of epoxy resins based on soybean oil. Journal of the American Oil Chemists' Society 2002, 79, 797-802.

(10) Clemente, T. E.; Cahoon, E. B. Soybean Oil: Genetic Approaches for Modification of Functionality and Total Content. PLANT PHYSIOLOGY 2009, 151, 1030-1040.

(11) Petrović, Z. S. Polymers from biological oils. CM 2010, 1, 39-50.

(12) Desai, S.; Thakore, I. M.; Sarawade, B. D.; Devi, S. Structure-property relationship in polyurethane elastomers containing starch as a crosslinker. Polym. Eng. Sci. 2004, 40, 1200-1210.

(13) Malavašič, T.; Černilec, N.; Mirčeva, A.; Osredkar, U. Synthesis and adhesive properties of some polyurethane dispersions. International Journal of Adhesion and Adhesives 1992, 12, 38-42.

(14) Khan, I.; Poh, B. T.; Badriah, C. M. Effect of sodium sulfate on the viscosity, tack, and adhesion properties of SMR 10-based pressure-sensitive adhesive. Journal of Elastomers and Plastics 2011, 43, 85-95.

(15) Srivastava, A.; Agarwal, D.; Mistry, S.; Singh, J. UV curable polyurethane acrylate coatings for metal surfaces. Pigment \& Resin Technology 2008, 37, 217223.

(16) Patel, M. M.; Patel, K. I.; Patel, H. B.; Parmar, J. S. UV-curable polyurethane coatings derived from cellulose. Iranian Polymer Journal 2009, 18, 903-915.

(17) Kim, B. K.; Lee, Y. M. Structure-property relationship of polyurethane ionomer. Colloid and Polymer Science 1992, 270, 956-961.

(18) McMillen, E. L. Relation between Thixotropy and Leveling Characteristics of 
Paint. Ind. Eng. Chem. 1931, 23, 676-679.

(19) Canary, S. A.; Stevens, M. P. Thermally reversible crosslinking of polystyrene via the furan-maleimide Diels-Alder reaction. J. Polym. Sci. A Polym. Chem. 1992, 30, 1755-1760. 


\section{Preparation of Polymeric Resin via Post Polymerization Modification}

\subsection{Introduction}

Free radical polymerization

Free radical polymerization is a process to synthesize polymers separated into three different phases: initiation, propagation, and termination (disproportionation and combination). ${ }^{1}$ Initiation occurs when a molecule creates a radical that attacks double or triple bond. The process is divided into two steps: the generation of the free radical and the transfer of the radical to a monomer (see Figure 3.1.1). Free radical initiation can be generated by various stimuli, such as heat, UV, visible light and electricity, depending on the type of initiator. ${ }^{2}$ The temperatures where the initiator is used depend upon the decomposition rate of the initiator. ${ }^{3}$

(1)

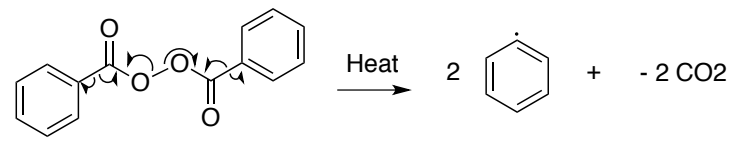

(2)

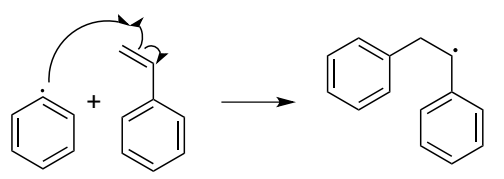

Figure 3.1.1. Two parts of initiation: (1) decomposition of benzoyl peroxide into radicals; (2) transfer of radical onto styrene. ${ }^{2}$

Propagation is the transfer of the radical from the growing polymer chain to a monomer. The addition of the monomer can occur in the same manner (head to head) or as an alternate to carbon atom (head to tail). The addition via the head to tail arrangement is more likely to occur than head to head due to both steric and resonance ground. ${ }^{3}$ The polymers that propagate exclusively via the head to tail addition are known as isoregic while polymers added alternatively head to head and head to tail are known as 
syndioregic. ${ }^{3}$ Further, the rate of propagation in free radical polymerization is very fast, which gives the polymer a high molecular weight. ${ }^{4}$

Termination can take place with two different modes, disproportionation and coupling (see Figure 3.1.2). Disproportionation occurs when the hydrogen radical in beta position to radical center is transferred to another radical center. This mode is often preferred when molecules are sterically hindered or polymerization temperature increases. For example, the disproportionation mode for methyl methacrylate increases from $67 \%$ in a $25^{\circ} \mathrm{C}$ oil bath to $80 \%$ in an $80^{\circ} \mathrm{C}$ oil bath..$^{5}$ Alternatively, coupling occurs when two radicals react together and stop the propagation. Some monomers, including styrene, acrylonitrile, and methyl acrylate, terminate via coupling only while methyl methacrylate can terminate via both disproportionation and coupling. ${ }^{3}$ Viscosity plays a big role in the termination process. The higher the viscosity, the lower the termination rate, while the rate of propagation is increasing. When this happens the polymers often turn into gel and exhibit the well known Trommdorft effect. ${ }^{3}$

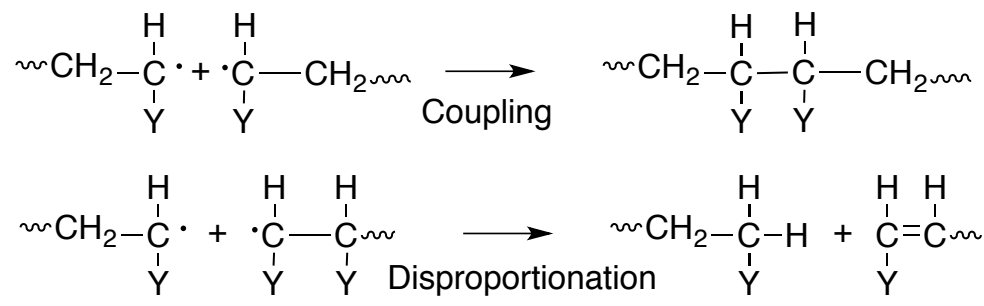

Figure 3.1.2. Modes of termination: coupling and disproportionation. ${ }^{3}$

\section{Free radical copolymerization}

Copolymerization is polymerization of two or more monomers at the same time where the reactivity and concentration of each monomer plays a significant role in determining the copolymer's properties. ${ }^{3}$ Radical copolymerization is classified into two categories in terms of reactivity ratios: $\mathrm{r}_{\mathrm{A}}<1, \mathrm{r}_{\mathrm{B}}>1$ (vice versa) and both $\mathrm{r}_{\mathrm{A}}$ and $\mathrm{r}_{\mathrm{B}}<1$. 
These reactivity ratios heavily depend on the substituents group to stabilize the polymeric radical by delocalization of unpaired electron. ${ }^{6}$

Table 3.1.1. Reactivity ratios at $60^{\circ} \mathrm{C}$ for free radical copolymerization. ${ }^{6}$

\begin{tabular}{llll}
\hline Monomer A & Monomer B & $\mathbf{r}_{\mathbf{A}}$ & $\mathbf{r}_{\mathbf{B}}$ \\
\hline Styrene & Methyl methacrylate & 0.52 & 0.46 \\
Methyl methacrylate & n-Butyl acrylate & 1.8 & 0.37 \\
Vinyl acetate & Acrylonitrile & 0.06 & 4.05 \\
\hline
\end{tabular}

The reactivity ratio of the monomers is often affected by the reaction medium such as solvent and $\mathrm{pH}$. For example, the reactivity ratio of $\mathrm{N}$-vinylcarbazole is 0.06 in benzene and 0.75 in methanol. ${ }^{7}$ This increase of reactivity ratio is due to the formation of microphase of copolymer which, in methanol, is more likely to absorb n-vinylcarbazole. ${ }^{7}$ Other solvent effects are also observed in copolymerization of methyl methacryalate and styrene in benzene. The combination of the two monomers in bulk creates the gel effect which creates a copolymer with less styrene, whereas in benzene the amounts are more even. ${ }^{8}$ Beside solvent, $\mathrm{pH}$ also plays an important part in copolymerization. Some monomers like arylamide are more reactive in basic condition ( $\mathrm{pH} 9)$ with a reactivity ratio of 0.95 and drastically change to a reactivity ratio of 0.25 at $\mathrm{pH} 2 .{ }^{9}$ Unlike initiation, temperature slightly affects copolymerization since the difference in the activation energies is relatively small for most monomers at $<10 \mathrm{~kJ} / \mathrm{mol}^{3}$

2-isocyanatoethyl methacrylate

2-isocyanatoethyl methacrylate is an interesting monomer since it contains both an isocyanate and a radically polymerizable acrylate group (see Figure 3.1.3). Both isocyanates and acrylate can react independently without affecting each other. ${ }^{10}$ The combination of both groups enables this monomer to have high abrasion and tear 
resistance (from the urethane) as well as good optical property and weather resistance (from the acrylate). ${ }^{11}$ This monomer has been used in the past to make UV curable polyurethane resin, ${ }^{11}$ bioadhesives ${ }^{12}$ dental adhesives, ${ }^{13}$ and macromonomers. ${ }^{14}$<smiles>C=C(C)C(=O)OCCN=C=O</smiles>

Figure 3.1.3. 2-isocyanatoethyl methacrylate is unique with both acrylate and isocyanate pieces.

Though the isocyanate group in the molecule has the potential for good properties, the isocyanate unfortunately reacts easily with moisture with a rate like any other aliphatic isocyanates. ${ }^{15}$ The reaction of an isocyanate with moisture often creates bubbles (from $\mathrm{CO}_{2}$ generation), which can lead to a decline in hardness and abrasion resistance. ${ }^{12}$ To resolve this issue, the isocyanate group is often blocked with alcohol, phenol, lactam, or oximes by reacting the isocyanate with active hydrogen compound. Thermal treatment is used to regenerate the reactive isocyanate, in which the temperature often depends on the blocking group structure..$^{10}$

The copolymerization of 2-isocyanatoethyl methacrylate (IEM) and other monomers such as methyl methacryalate (MMA) has been studied. The reactivity ratio of isocyanate methacrylate with MMA is reported to be $0.80 .{ }^{13}$ The combination of MMA and IEM also have been used for periodontics adhesives due to their excellent tensile strength. ${ }^{16}$

Incorporation of Diels-Alder into polymer

The reversibility of Diels-Alder linkages via heat stimulus has received much attention and has proven to be effective for various applications. The incorporation of Diels-Alder in polymers is an active field with the goal of thermally responsive or 
thermally reversible polymers. Many types of polymers with Diels-Alder incorporation have been made from star, ${ }^{17}$ dendritic, hyperbranched, ${ }^{18}$ and crosslink elastomers. ${ }^{19}$ In early 1990, furan and maleimide group was successfully incorporated to create network hydrogel and thermoset that could be recycled..$^{20}$ In 2002 , epoxy materials with $57 \%$ healing ability upon heating from $120-150^{\circ} \mathrm{C}$ was made..$^{21}$ Presently, some Diels-Alder polymers have shown healing efficiency close to $100 \%$ after a few cycles of damage and healing. ${ }^{20}$

\section{Project Goal}

The goal of this project is to make thermally reversible gel out of a poly(methyl methacrylate) resin. In order to achieve this, copolymerization of methyl methacrylate and 2-isocyanatoethyl methacrylate via free radical polymerization was done to synthesize a polymer with pendant isocyanates. The isocyanates allowed for postpolymerization modification for the attachment of a retro Diels Alder (rDA) adduct to the polymer. The resin was then reacted with both hexamethylene diisocyanate (HMDI) and isophorone diisocyanate (IPDI) to create a gel.

\subsection{Experimental}

Method and Materials

All materials were purchased from commercially available sources. Synthesis of Poly(methyl methacryalate-co-Isocyanatoethyl methacrylate (PMMA-NCO)

Methyl methacrylate $(2.1 \mathrm{~mL}, 20 \mathrm{mmol})$ was added to a $50 \mathrm{~mL}$ round bottom flask along with 2-isocyanatoethyl methacryalate $(0.7 \mathrm{~mL}, 5 \mathrm{mmol})$, azobisisobutyronitrile ( $80 \mathrm{mg}, 0.5 \mathrm{mmol})$ and stir bar. Toluene $(10 \mathrm{~mL})$ was added to the mixture to use as a solvent. The round bottom was sealed quickly with rubber septa and 
purged under nitrogen for 25 minutes. The round bottom was then stirred in a $65^{\circ} \mathrm{C}$ oil bath for three hours. A small amount of solvent was then rotovapped before precipitating the mixture in hexane. A white powder was obtained and was quickly placed inside the vacuum desiccator to remove any moisture that might react with isocyanate. The structure was confirmed using Fourier Transform Infrared Spectroscopy (FT-IR) and ${ }^{1} \mathrm{H}$ NMR: $\delta(\mathrm{ppm})$ by the appearance of peaks at $\delta(\mathrm{ppm}) 3.5$ and 4.2. The percentage of IEM in polymer was calculated using the integration of the NMR and found to be $19 \%$. IR (powder) $\left(\mathrm{cm}^{-1}\right): 1150,1245,1440,1800,2271$, and 3010. Synthesis of furfuryl alcohol modified PMMA (PMMA-FA)

PMMA-ISO (0.5 g) was added to a $25 \mathrm{~mL}$ round bottom flask along with a stir bar sealed with a rubber septa. Furfuryl alcohol $(3.4 \mathrm{~g}, 34 \mathrm{mmol})$ and THF (10 mL) were added to a separate $25 \mathrm{~mL}$ round bottom flask and purged under the nitrogen for 25 minutes. A Furfuryl alcohol mixture was added to the copolymer and stirred for 48 hours at room temperature. Some of THF was then rotovapped, and the mixture was precipitated in deionized water. Light yellow powder was obtained and dried for one day before analysis. The structure was confirmed using ${ }^{1} \mathrm{H}$ NMR: $\delta(\mathrm{ppm})$ by the appearance of furan peaks at $\delta(\mathrm{ppm}) 6.35,6.4$ and 7.4. IR (powder) $\left(\mathrm{cm}^{-1}\right): 1150,1245,1440,1800$, 3010, and disappearance of 2271 .

Synthesis of PMMA-Diels-Alder (PMMA-DA)

Modified copolymer ( $1.4 \mathrm{~g}$ ) was added to a $25 \mathrm{~mL}$ round bottom flask along with phenolic maleimide $(0.6 \mathrm{~g}, 3.2 \mathrm{mmol})$ and a stir bar. THF $(10 \mathrm{~mL})$, used as a solvent, was then added to the mixture. The round bottom was refluxed and placed in a $50^{\circ} \mathrm{C}$ oil bath for two days. The mixture was rotovapped to remove excess solvent and then precipitated 
in methanol. A light brown powder was obtained and dried for one day before analysis. The structure was then confirmed via ${ }^{1} \mathrm{H}$ NMR: $\delta(\mathrm{ppm})$ by the disappearance of the furan peaks at $\delta$ ppm 6.35, 6.4 and 7.4 and the appearance of the appropriate Diels-Alder adduct peaks: $6.55,6.4,5.35,3.05$ and 2.95. IR (powder) $\left(\mathrm{cm}^{-1}\right): 1150,1245,1440,1800$ and 3010 , appearance of peak at 1520 .

\section{Differential Scanning Calorimetry (DSC) Study}

To ensure DA linkages were successfully incorporated, PMMA Diels-Alder resin was analyzed and compared to commercially available PMMA via DSC. Each sample went through a total of three cycles with a heating rate of $10^{\circ} \mathrm{C} / \mathrm{min}$ from $30^{\circ} \mathrm{C}$ to $300{ }^{\circ} \mathrm{C}$.

\section{Swelling Experiment}

PMMA resin was added into two $50 \mathrm{~mL}$ glass vials $(1 \mathrm{~g}$ each) and labeled 1 and 2 with addition of $10 \mathrm{~mL}$ of THF to each vial. To the glass vial labeled "1" isophorone diisocyanate (IPDI, $0.095 \mathrm{~g}$ ) was added. To the glass vial labeled "2" hexamethylene diisocyanate (HMDI, $0.124 \mathrm{~g}$ ) was added. Both IPDI and HMDI were added, maintaining a 1:1 ratio between isocyanate and alcohol. Then to each vial one drop of dibutyl tin dilaurate was added. The vials were then placed in a $60^{\circ} \mathrm{C}$ oven for three hours. Upon heating, a solid material was found in both. The solid pellets were then broken up and transferred into two vials and approximately $10 \mathrm{~mL}$ of DMF was added to each vial. The vials were allowed to rest for an hour to swell the solids in DMF and pictures of the vial were taken at this time. Afterwards the vials were submerged in a $120^{\circ} \mathrm{C}$ oil bath for 15 minutes. The vials were removed from the oil bath and pictures were taken of them. 


\subsection{Result and discussion}

Structure analysis

Scheme 3.3.1. Synthesis of thermally reversible PMMA resin.

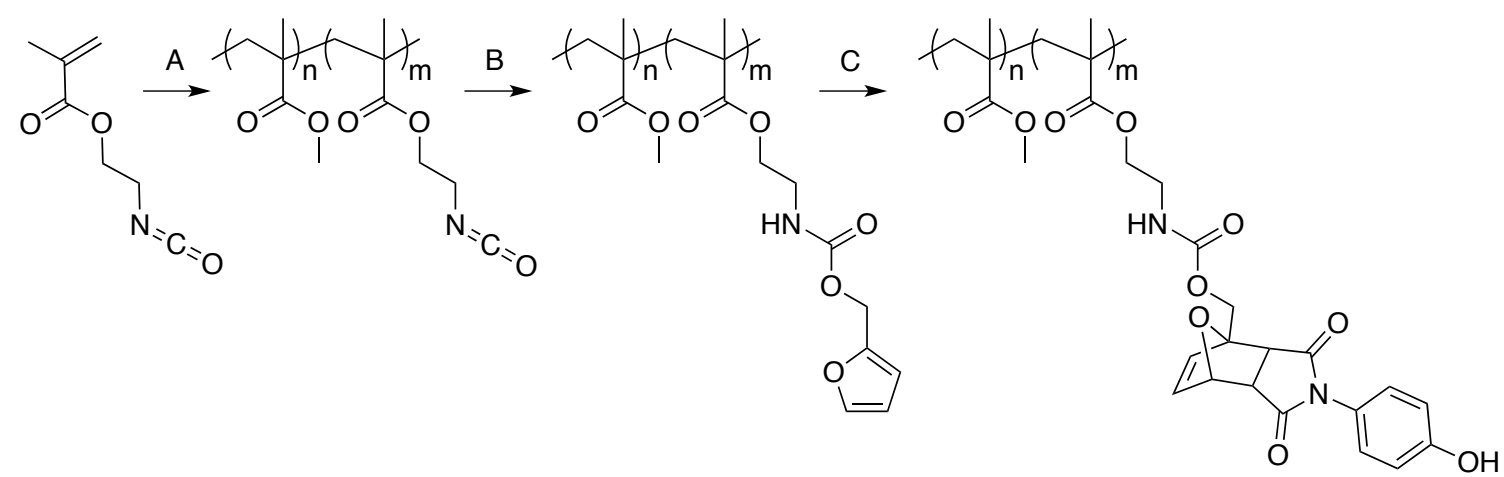

A) MMA, AIBN, toluene at $65^{\circ} \mathrm{C}, 3 \mathrm{hr}$. B) THF, furfuryl alcohol, $48 \mathrm{hr}$ at room temperature C) THF, Phenolic Maleimide, $48 \mathrm{hr}$ at $50^{\circ} \mathrm{C}$.

PMMA-NCO copolymer structure is determined by FT-IR the appearance of isocyanate peak at $2271 \mathrm{~cm}^{-1}$ (black circle Fig. 3.3.1). PMMA-FA was confirmed by the disappearance of the isocyanate peak at $2271 \mathrm{~cm}^{-1}$ (black circle Fig. 3.3.1). The structure was further validated by ${ }^{1} \mathrm{H}$ NMR spectra (Fig. 3.3.2) by the appearance of furan peaks at $\delta(\mathrm{ppm}) 6.35,6.4$ and 7.4. 


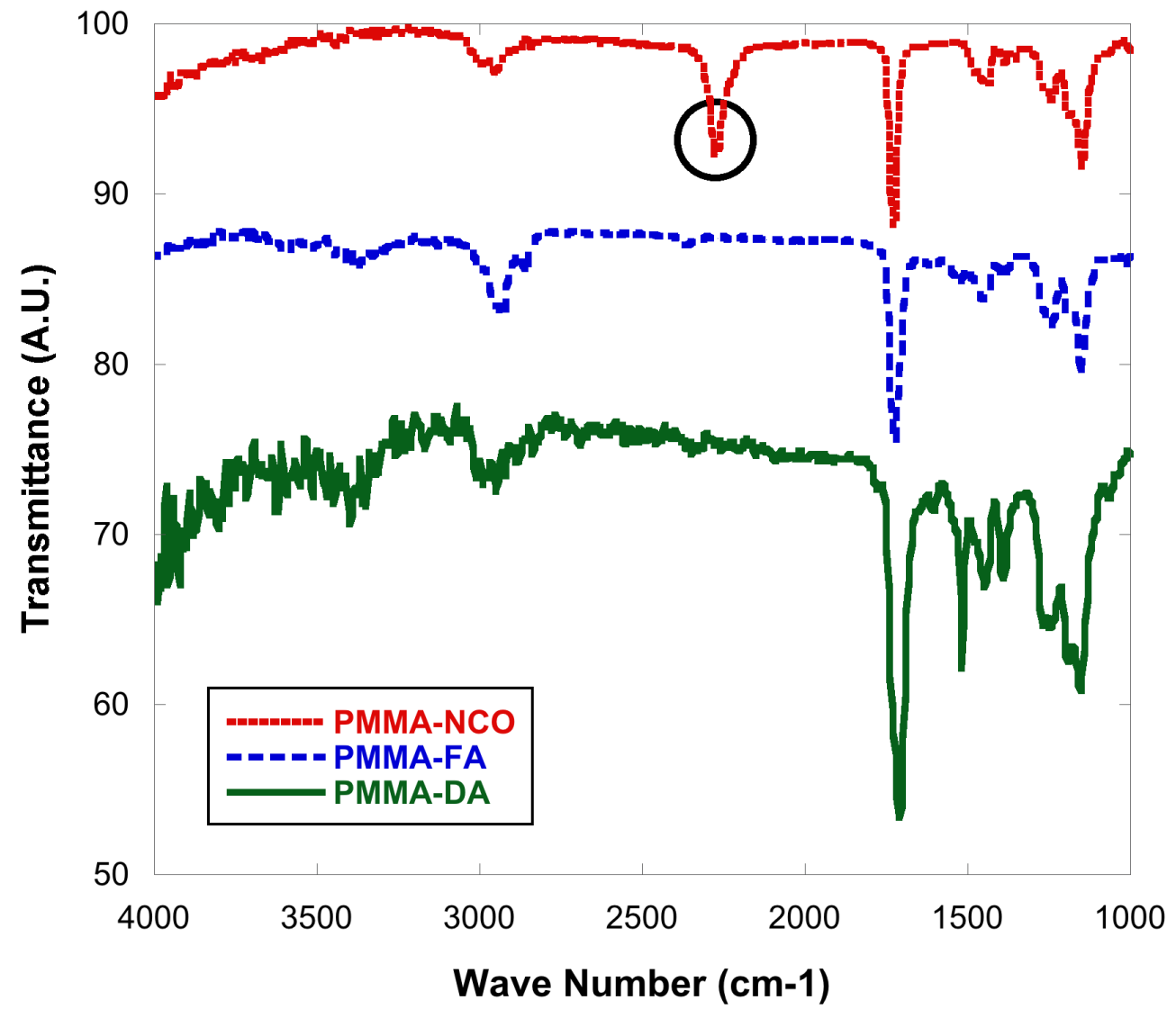

Figure 3.3.1. FT-IR spectrum overlay of PMMA-Isocyanate, furfuryl alcohol modified PMMA and PMMA-DA. (\% Transmittance was adjusted for clarity of the graph)

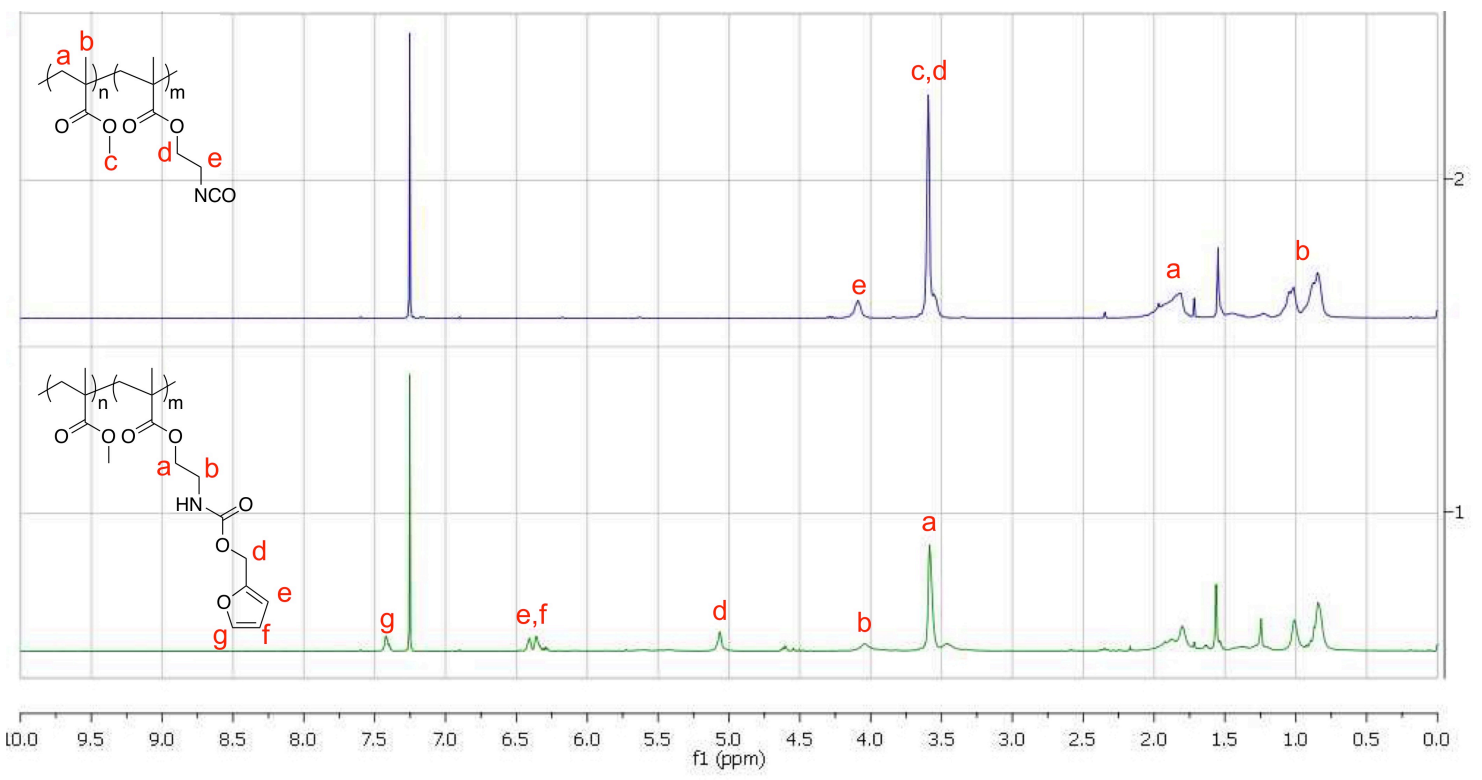

Figure 3.3.2. ${ }^{1} \mathrm{H}$ NMR spectrum overlay of PMMA-NCO and PMMA-FA. 
As previously studied, carbonyl of Diels-Alder adduct appeared as a narrow peak at $1710 \mathrm{~cm}^{-1} \cdot{ }^{22}$ PMMA-DA was confirmed by the appearance the same carbonyl of DA adduct at $1710 \mathrm{~cm}^{-1}$ and further proved via ${ }^{1} \mathrm{H}$ NMR by the disappearance of the furan peaks at $\delta$ ppm $6.35,6.4$ and 7.4 and the appearance of the appropriate Diels-Alder adduct peaks: $6.55,6.4,5.35,3.05$, and 2.95 .

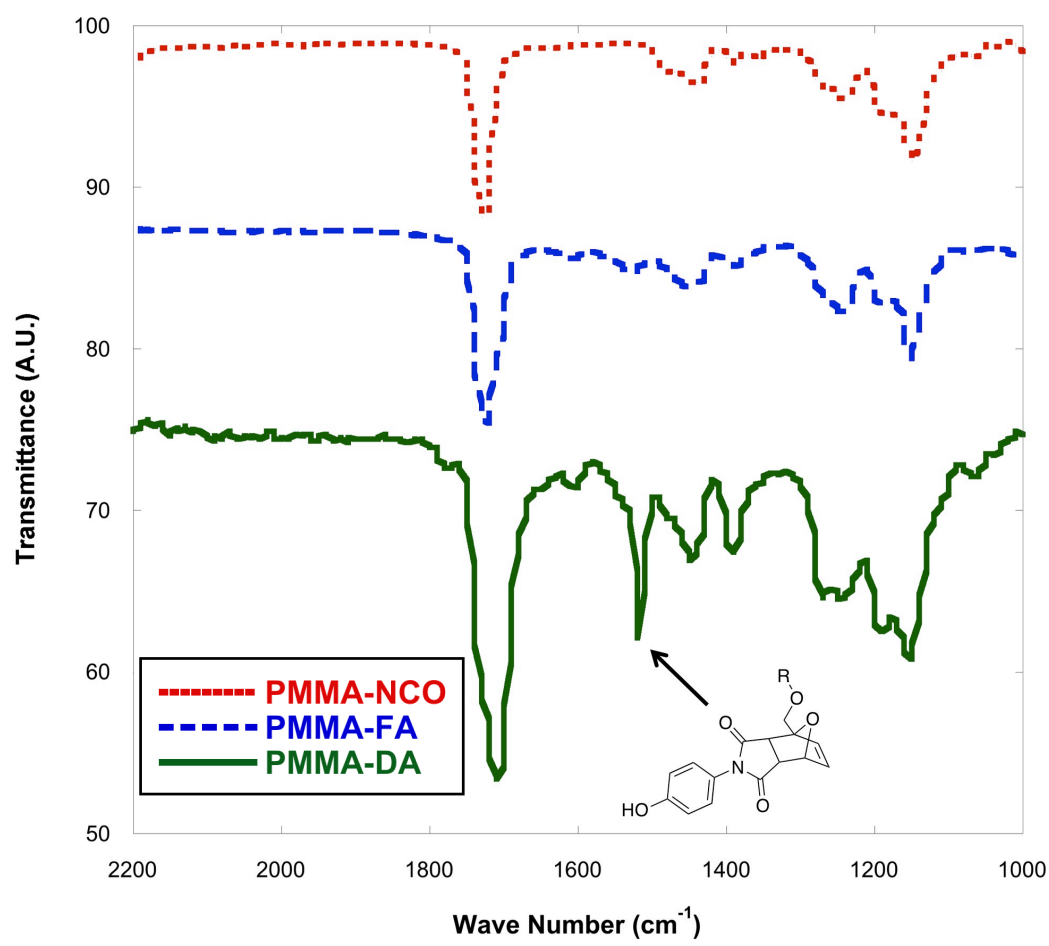

Figure 3.3.3. FT-IR spectrum zoom overlay of PMMA-Isocyanate, furfuryl alcohol modified PMMA and PMMA-DA with exact location of carbonyl of DA adduct. 


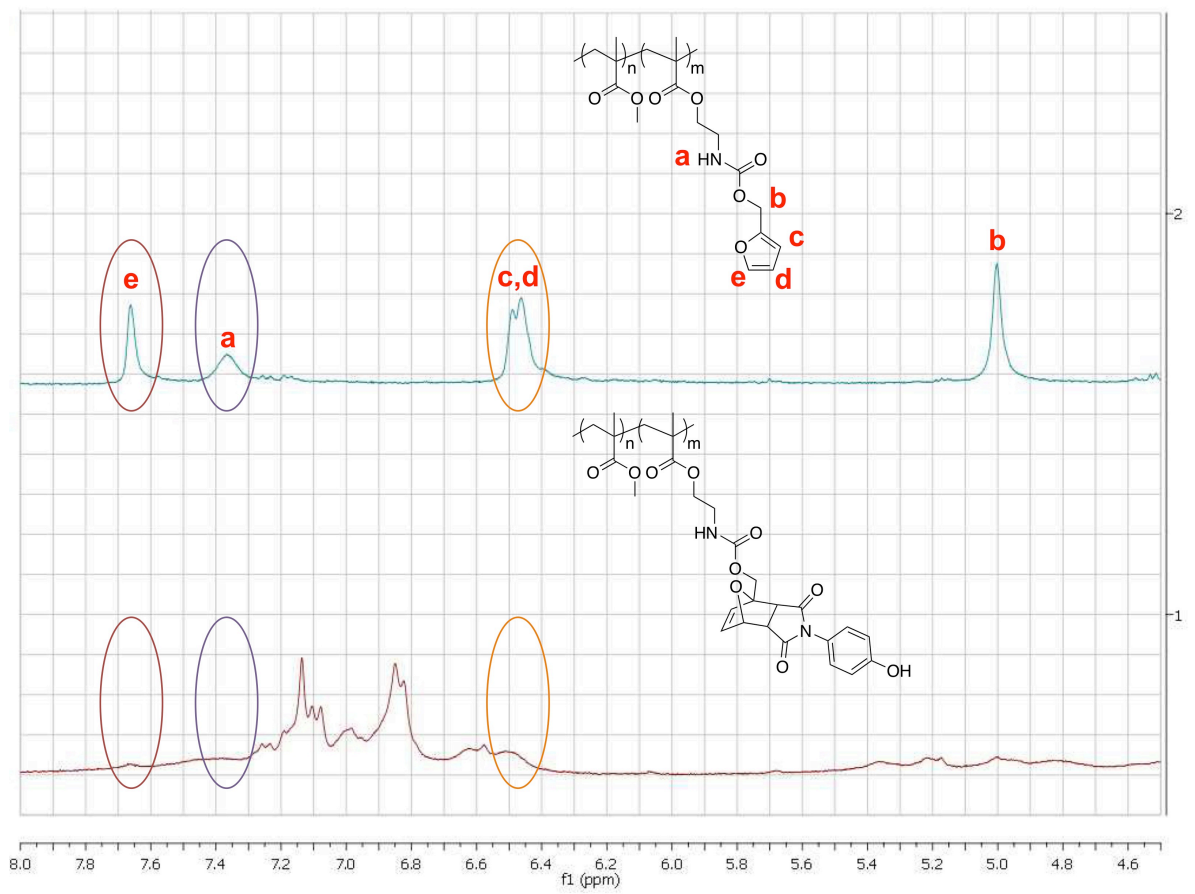

Figure 3.3.4. ${ }^{1} \mathrm{H}$ NMR spectrum overlay of furfuryl alcohol modified PMMA and PMMA-DA.

DSC result

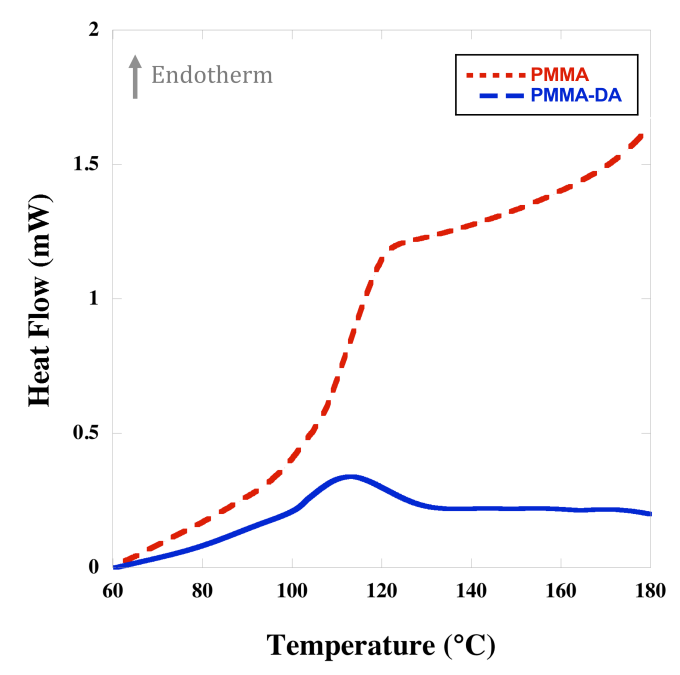

Figure 3.3.5. DSC thermograms data of pristine PMMA and PMMA-DA.

Both PMMA and PMMA-DA demonstrated glass transition temperatures close to $120^{\circ} \mathrm{C}$. However, the PMMA Diels-Alder showed an endotherm peak. As previously reported, the retro Diels-Alder reaction between maleimide and furan shows an 
endotherm starting around $95^{\circ} \mathrm{C}^{22}$ This result of PMMA-DA also showed a similar trend of retro Diels-Alder reaction starting around $100^{\circ} \mathrm{C}$ confirming the presence of the DielsAlder linkage. Several heating and cooling cycles of PMMA-DA samples showed the same reproducible data.

\section{Swelling Experiment}

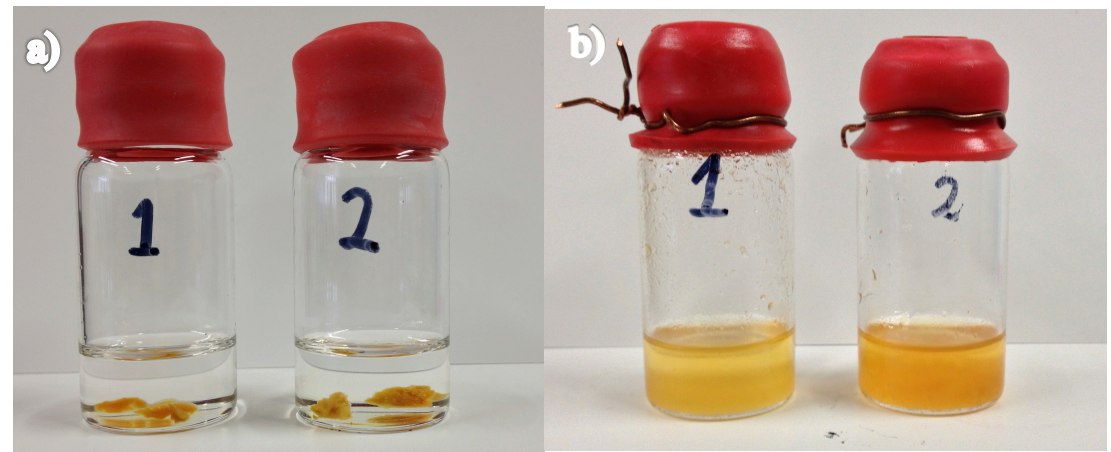

Figure 3.3.6. Thermally reversible PMMA before (a) and after (b) heating at $120^{\circ} \mathrm{C}$ for 15 minutes.

The retro Diels-Alder reaction between the maleimide and furan adduct sites caused thermally responsive polyurethane to clear solution after heating for 15 minutes at $120^{\circ} \mathrm{C}$ (Fig. 3.3.6 (b)). As studied previously rDA occurs above $100^{\circ} \mathrm{C} .{ }^{19}$ During the rDA reaction, PMMA-DA was changed back to PMMA-FA with phenolic maleimide attached to its urethane component. PMMA-FA is soluable in dimethyl formaldehyde, creating the clear solution. Liu et al. noted the significantly faster transformation of rDA with higher temperatures and lower crosslink density.$^{19}$ The use of different isocyanates in the system hardly impacted the thermal reversibility of the two systems since both systems dissolve in about the same heating time. However, it is noted that the properties of the gel for the two systems are different. The polyurethane made out of IPDI was found to be more brittle than the HMDI. As previously studied, polyurethane that uses IPDI is often found to be hard due to aliphatic structure and limited chain mobility. ${ }^{23}$ 


\subsection{Conclusion}

PMMA with Diels-Alder linkages was successfully synthesized and incorporated into a polyurethane gel as proven via ${ }^{1} \mathrm{H}$ NMR and IR. The gel showed thermal reversibility at $120^{\circ} \mathrm{C}$ due to retro-DA reaction via DSC as well as thermally reversible bulk properties.

\subsection{Future Work}

The synthesis in large scale for PMMA-DA resin will be the necessary before incorporating the resin for thermally reversible coating. Future collaboration with the Army Research Lab (ARL) will be done to incorporate pigments into a thermally responsive coating for optical devices. 


\section{References:}

(1) Matyjaszewski, K.; Davis, T. P. Handbook of Radical Polymerization; WileyInterscience, 2003.

(2) Carraher, C. E., Jr Seymour/Carraher's Polymer Chemistry; CRC Press, 2003.

(3) Odian, G. Principles of Polymerization; Wiley-Interscience, 2004.

(4) Chanda, M. Introduction to Polymer Science and Chemistry; CRC PressI Llc, 2006.

(5) Bamford, C. H.; Dyson, R. W.; Eastmond, G. C. Network formation IV. The nature of the termination reaction in free-radical polymerization. Polymer 1969, $10,885-899$.

(6) Young, R. J.; Lovell, P. P. A. Introduction to Polymers; CRC PressI Llc, 2011.

(7) Ledwith, A.; Galli, G.; Chiellini, E.; Solaro, R. Solvent effect in radical copolymerisation of N-vinylcarbazole and methylmethacrylate. Polymer Bulletin 1979, 1, 491-499.

(8) Johnson, M. High conversion copolymerization of styrene with methylmethacrylate. European Polymer Journal 1978, 14, 409-414.

(9) Ponratnam, S.; Kapur, S. L. Reactivity ratios of ionizing monomers in aqueous solution. Copolymerization of acrylic and methacrylic acids with acrylamide Ponratnam - 2003 - Die Makromolekulare Chemie - Wiley Online Library. Makromol. Chem. 1977, 178, 1029-1038.

(10) Fravel, H. G.; Regulski, T. W.; Thomas, M. R. Preparation, polymerization, and evaluation of blocked isocyanatoethyl methacrylate. Ind. Eng. Chem. Prod. Res. Dev. 1984, 23, 586-590.

(11) Levesque, G.; Moitié, V.; Bacle, B.; Depraétère, P. Polyoxyethylenic macromers from polyoxyethylene monomethyl ethers and isocyanatoethyl methacrylate. Synthesis and characterization of copolymers with styrene and methyl methacrylate, obtained through bulk, solution and soap-free emulsion polymerizations. Polymer 1988, 29, 2271-2276.

(12) Kao, F.-J.; Manivannan, G.; Sawan, S. P. UV curable bioadhesives: Copolymers ofN-vinyl pyrrolidone. J. Biomed. Mater. Res. 1997, 38, 191-196.

(13) Lam, O. A.; Hervaud, Y.; Boutevin, B. Homopolymerization and copolymerization of isocyanatoethyl methacrylate. J. Polym. Sci. A Polym. Chem. 2006, 44, 4762-4768.

(14) Gnanou, Y.; Rempp, P. Macromonomer synthesis. New functionalization methods - Gnanou - 2003 - Die Makromolekulare Chemie - Wiley Online Library. Makromol. Chem. 1987, 188, 2111-2119.

(15) Cranley, P. E. Isocyanatoethyl Methacrylate: A Latent Crosslinker for Coating Adhesive Resins. In scholar.google.com; Springer US: Boston, MA, 1985; pp. 765-784.

(16) Taira, Y.; Matsumura, H.; Atsuta, M. Use of 2-isocyanatoethyl methacrylate and iron (II) perchlorate for bonding tri- n-butylborane-initiated luting agents to dentin. Eur J Oral Sci 1998, 106, 887-891.

(17) Dag, A.; Durmaz, H.; Hizal, G.; Tunca, U. Preparation of 3-arm star polymers (A3) via Diels-Alder click reaction. J. Polym. Sci. A Polym. Chem. 2007, 46, 302-313. 
(18) Morgenroth, F.; Müllen, K. Dendritic and hyperbranched polyphenylenes via a simple Diels-Alder route. Tetrahedron 1997, 53, 15349-15366.

(19) Liu, Y.-L.; Hsieh, C.-Y.; Chen, Y.-W. Thermally reversible cross-linked polyamides and thermo-responsive gels by means of Diels-Alder reaction. Polymer 2006, 47, 2581-2586.

(20) Murphy, E. B.; Wudl, F. The world of smart healable materials. Progress in Polymer Science 2010, 35, 223-251.

(21) Chen, J.; Rebek, J. Selectivity in an Encapsulated Cycloaddition Reaction. Org. Lett. 2002, 4, 327-329.

(22) Canary, S. A.; Stevens, M. P. Thermally reversible crosslinking of polystyrene via the furan-maleimide Diels-Alder reaction. J. Polym. Sci. A Polym. Chem. 1992, 30, 1755-1760.

(23) McConnell, J. A.; Willard, F. K. Structure-Performance Relationships of Urethane Acrylates. In scholar.google.com; ACS Symposium Series; American Chemical Society: Washington, DC, 2009; Vol. 417, pp. 272-283. 


\section{Conclusion}

The goal of this thesis was to design thermally responsive polyol resins that would be compatible within an isocyanate formulation. Two approaches were made to reach this goal, the first involved functionalizing soybean oil and the second involved post-polymerization modification of an acrylate based resin. The synthesis, incorporation, and analysis of the TR-SBO resin into a two-component polyurethane formulation were successful.

Various thermally responsive soybean oil resins were successfully synthesized. Synthetically, the number of reversible and non-reversible linkages were adjusted through the control over the amount of Diels-Alder (DA) adduct into the resin as well as acetylating the alcohols produced as a product of the opening of an epoxide. The ratios of thermally responsive DA linkages were proven in nuclear magnetic resonance spectroscopy. Additional confirmation showed that there was a significant decrease in the endotherm as the amount of DA was decreased indicating that there are fewer thermally reversible crosslinks within the system.

After the synthesis of the resin was confirmed, various ratios of isocyanate to alcohol were formulated to find a coating with optimal adhesion, re-healability, hardness, and gloss. The primary property of the coating is the ability to re-heal. Ratios of NCO:OH of 1:1, 3:1, and 5:1 were used for HMDI and IPDI. Desmodur N3300 used ratios of $0.2: 1,0.3: 1$ and $1: 1$ were used as ratios $>1$ did not show evidence of re-healing. Crosscut analysis was then performed on all coatings to analyze adhesion and rehealability (ability to heal scratched incurred by the cross-cut test). It was apparent that 
Desmodur did not have the desired adhesion while IPDI and HMDI showed similarly strong adhesion to the coating.

Other coating properties were scrutinized to find the optimal coating. The hardness of the coating over time showed that both acetylated and nonacetylated IPDI at any ratio became significantly harder than HMDI. Higher hardness is desired on a top-coat as it will prevent objects from easily damaging the coating. Gloss measurements were done as a way to quantify the re-healability of the coating. A scratch on the surface of the coating was made with sandpaper, causing the surface roughness of the coating to increase and the gloss value to decrease. Upon application of heat the coating should reheal and repair the scratches causing an improvement in the coating's surface and increasing gloss. 54\% DA acetylated TR-SBO with IPDI (5:1 isocyanate ratio to alcohol) was able to show the greatest and most consistent improvement in gloss measurements when compared to the other coatings. Further analysis of 54\% DA acetylated TR-SBO with 5:1 IPDI was performed using ImageJ analysis, TGA, and DSC to elucidate additional properties of the coating.

The other TR-acrylic resin was made through the free radical copolymerization of methylmethacrylate (PMMA) with an isocyanate bearing methylacrylate. The isocyanate was used as a chemical handle to incorporate Diels-Alder linkages into the PMMA resin. The PMMA resin with Diels-Alder linkages was successfully synthesized and incorporated into a polyurethane gel as proven via ${ }^{1} \mathrm{H}$ NMR and IR. The gel showed thermal reversibility at $120^{\circ} \mathrm{C}$ due to retro-DA reaction via DSC as well as thermally reversible bulk properties. 